\title{
An in-vitro investigation of frictional resistance of self-ligating and ceramic brackets when subjected to different ligation methods and tipping angles
}

Todd S. Bovenizer

West Virginia University

Follow this and additional works at: https://researchrepository.wvu.edu/etd

\section{Recommended Citation}

Bovenizer, Todd S., "An in-vitro investigation of frictional resistance of self-ligating and ceramic brackets when subjected to different ligation methods and tipping angles" (2006). Graduate Theses, Dissertations, and Problem Reports. 4216.

https://researchrepository.wvu.edu/etd/4216

This Thesis is protected by copyright and/or related rights. It has been brought to you by the The Research Repository @ WVU with permission from the rights-holder(s). You are free to use this Thesis in any way that is permitted by the copyright and related rights legislation that applies to your use. For other uses you must obtain permission from the rights-holder(s) directly, unless additional rights are indicated by a Creative Commons license in the record and/ or on the work itself. This Thesis has been accepted for inclusion in WVU Graduate Theses, Dissertations, and Problem Reports collection by an authorized administrator of The Research Repository @ WVU. For more information, please contact researchrepository@mail.wvu.edu. 


\section{AN IN-VITRO INVESTIGATION OF FRICTIONAL RESISTANCE OF SELF-LIGATING AND CERAMIC BRACKETS WHEN SUBJECTED TO DIFFERENT LIGATION METHODS AND TIPPING ANGLES}

By

Todd S. Bovenizer, D.D.S.

A THESIS

Submitted to

The School of Dentistry

At

West Virginia University

In partial fulfillment of the requirements for

The degree of

Master of Science

In

Orthodontics

Michael Bagby, D.D.S., Chair

Peter Ngan, D.M.D.

Chris Martin, D.D.S., M.S.

Department of Orthodontics

Morgantown, West Virginia

2006 


\title{
ABSTRACT \\ AN IN-VITRO INVESTIGATION OF FRICTIONAL RESISTANCE OF SELF-LIGATING AND CERAMIC BRACKETS WHEN SUBJECTEDTODIFFERENT LIGATION METHODS AND TIPPING ANGLES
}

\author{
Todd S. Bovenizer, D.D.S.
}

Objectives: To investigate the frictional resistance of two new ceramic brackets, two selfligating bracket, and one standard stainless steel bracket with several methods of ligation. The size and composition of the archwires will also be varied. The wires used are all stainless steel and the sizes are .018, 19X25, and 21X25. The frictional forces obtained in this study will be more useful when compared in a relative manner to one another, as opposed to the actual forces that will be measured. Methods: Each bracket and wire was placed in an Instron machine and tested for 120 seconds. During this time period the archwire was pulled superiorly both with and without variable tipping angles introduced to the wire. The bracket and wire combination also had variable methods of ligation, stainless steel, alastic, and self ligation. The data was then analyzed to see the friction averages for each test. Results: The data was separated into two groups, Experiment 1 and 2. This was done to compare the non-self ligating brackets to the self ligating brackets since they already have ligation built in. Therefore Experiment 1 included all brackets and Experiment 2 only included the non-self ligating brackets. ANOVA found significant differences in Experiments 1 and 2. Experiment 1 was significant at the wire, bracket ligature system (BLS), wire-bracket ligature system, stage, and wire-stage. Experiment 2 was significant with the bracket and ligation. 


\section{DEDICATIONS}

To my wife and best friend Megan McDermott Bovenizer, who has stood by me. Thank you for everything you have done and continue to do for me. Without you, I know that I could not accomplish what I set out to do each day. Your love and sacrifice has been beyond comprehension, and I love you for supporting me. I cannot thank you enough for being my partner in the foundation that we are creating together and I can't wait for the rest to unfold. I love you so much.

To my daughter, Caroline Grace, you are our gift from God. My life changed the instant you were born and you make everyday more fulfilling. To see your smiling face and to know how much I love you makes my journey more satisfying.

To my parents, Jerry and Suzanne Bovenizer, thank you for believing in me and giving me the will to persevere. Your guidance and support have been immeasurable. I am blessed to have such giving and loving parents as you have been to me. You have set an example on how to be not only parents but friends with your children. I know I would not be here today without you. I love each of you.

To my sisters, Michelle and Kimberly, thank you for your support and prayers. You all have been great examples to me throughout my life and I know you will continue to be. I have enjoyed being able to talk freely with you and obtain your guidance.

To the rest of my family and friends, the power of prayer is evident in you all. It has been a long journey and I still need you everyday. 


\section{ACKNOWLEDGEMENTS}

I would like to take this opportunity to thank the following individuals who have contributed and assisted me throughout my specialty training:

Dr. Peter Ngan, for you countless hours of dedication to this program and to me. You have been a mentor and friend. I hold you in the highest respect and I thank you for giving me the opportunity to be a part of this wonderful program.

Dr. Chris Martin, for your guidance in the clinic and on my thesis. I have learned so much from you. You continue to impress me everyday in the clinic and I thank you for your dedication to this specialty.

Dr. Mike Bagby, for being the chairman of my thesis. You have been great to work with and your patience and hard work mean a lot to me. Without you I would never have gotten this project done. You went above and beyond your call of duty to be a mentor and friend to me.

Dr. Gerry Hobbs, for your time and effort in understanding and preparing the statistical analysis.

Vincent Kish, for your guidance in helping me with the testing machine. I know I could not have done this project without you. Your availability and willingness to help after hours were greatly appreciated.

Drs. Anissa Anderson, Joe Bonello, Rick Crout, John Dempsey, Jeff Gilmore, Kerry Kirsch, Edward McFarland, Tim Tremont, and J.B.Wilfong for your time and dedication to this program. You are a great example to the young orthodontic profession. You have shaped me and proven to be invaluable resources. I know that what you have taught in this program is cutting edge and applicable to everyday orthodontics. You contribute the backbone of this program. Thank you for everything.

Charlotte and Pam, for your support and for running the clinic efficiently. Your laughter and help made it an enjoyable experience.

Joyce, Katie, and Tammy, for your help and support in everything. You are an asset to this program and we are lucky to have you.

Dr. Michael Hazey, my classmate, for your unwavering friendship. Your dedication and hard work in making this a better program are truly appreciated by all. I had so much fun during all of our travels and good times in the clinic. 
Dr. Meredith Parks, my classmate, for your friendship. Thank you for being like a sister to me and keeping me in line. You were a lot of fun to be with on our trips around the country and your help in the clinic was appreciated.

To my fellow residents; Brett, Matt, Russ, Jackie, Joe, and Thomas for being great examples and leaders. Thank you for your friendship.

To my fellow residents; Glenn, Jennifer, Spencer, Lindsay, Nikia, and Tim for all the good times and laughs on our traveling and in the clinic. Thank you for your support. 


\section{TABLE OF CONTENTS}

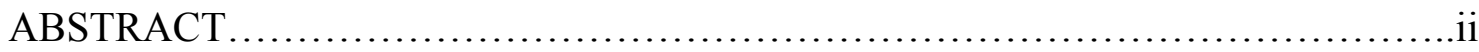

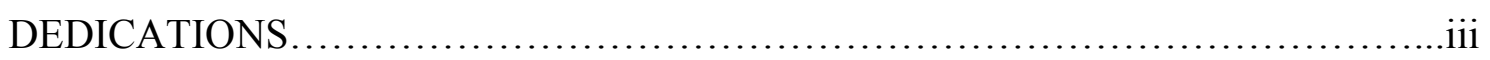

ACKNOWLEDGEMENTS .................................................

TABLE OF CONTENTS...................................................vi

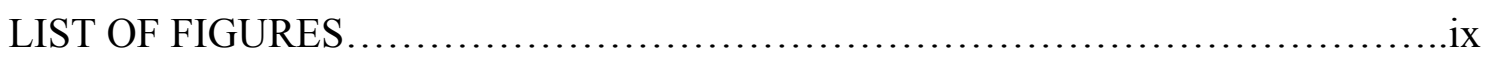

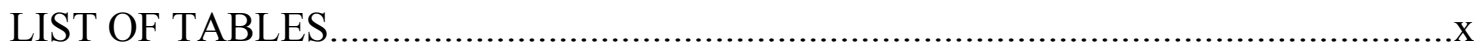

\section{CHAPTER I INTRODUCTION}

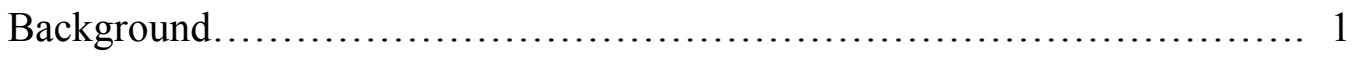

Statement of the Problem............................................ 1

Significance of the Problem........................................... 1

Null Hypothesis.................................................. 2

Definition of Terms................................................ 2

Assumptions.................................................. 4

Limitations....................................................... 4

Delimitations......................................................... 4

\section{CHAPTER II LITERATURE REVIEW}

Friction........................................................ 6

Wire Size........................................................ 8

Wire Shape....................................................... 9

Wire Material.................................................... 9

Ligation...................................................... 10

Brackets.............................................................. 12

Stainless Steel Brackets.............................................. 13

Ceramic Brackets..................................................... 13

Self Ligating Brackets............................................ 15

Bracket Width................................................... 18

Bracket-Archwire Angulation........................................ 19

Surface Roughness............................................... 19

Sliding Mechanics................................................. 20

Variable Moment................................................... 23

Contact Angle..................................................... 27

Saliva................................................................. 27 


\section{CHAPTER III MATERIALS AND METHODS}

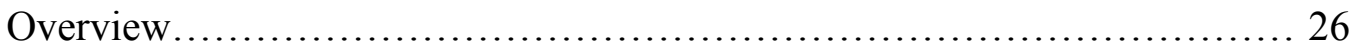

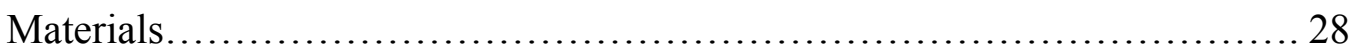

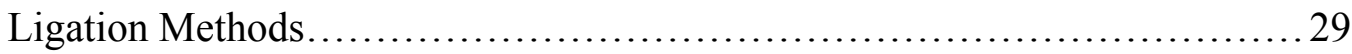

Test-Bracket Acrylic Rod Assembly......................................... 29

Apparatus Setup ............................................................. 31

Load Cells and Computer Setup............................................. 32

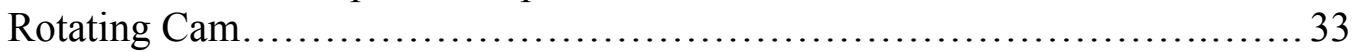

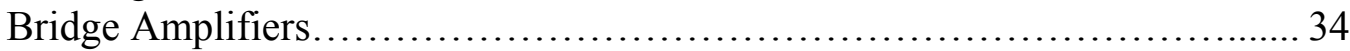

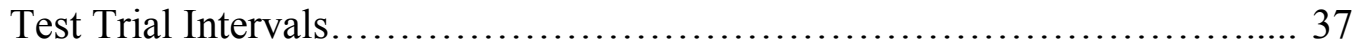

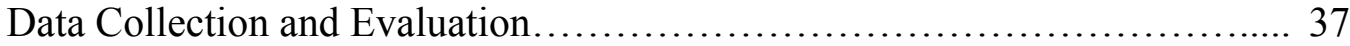

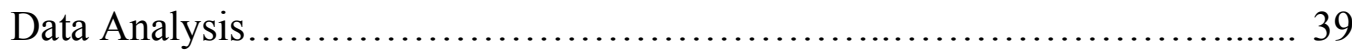

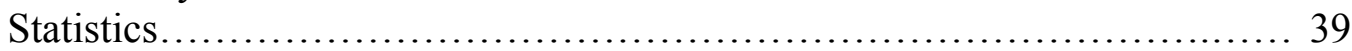

Standardization of the testing machine .................................... 40

\section{CHAPTER IV RESULTS AND DISCUSSION}

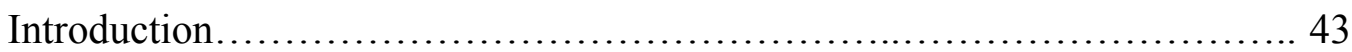

Overall Results............................................................ 43

Overview of the Project........................................................ 44

Experiment 1 (All Bracket Ligature Systems)............................... 45

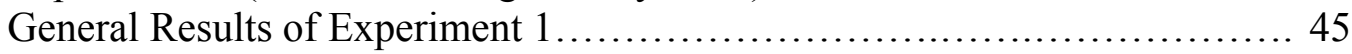

Wire-BLS Interaction.................................................. 49

018 Stainless Steel Wire ................................................ 50

19X25 Stainless Steel Wire ................................................ 52

21X25 Stainless Steel Wire ........................................... 52

Experiment 2 (Non-Self Ligating Brackets)............................... 53

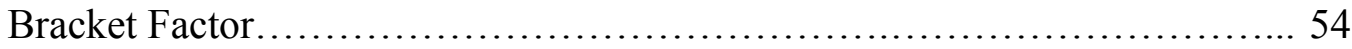

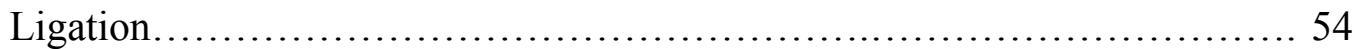

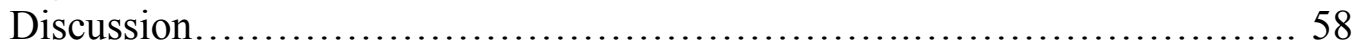

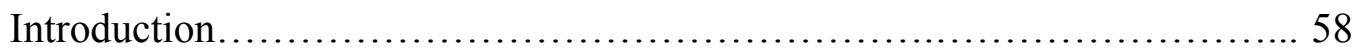

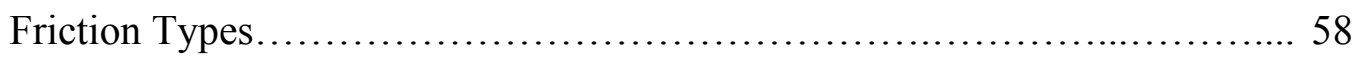

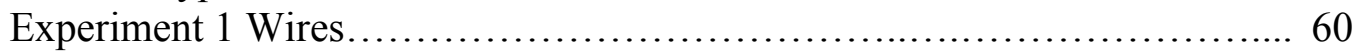

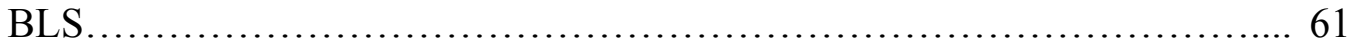

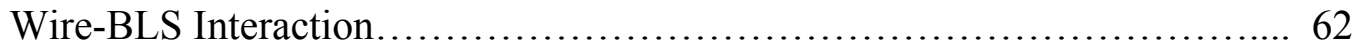

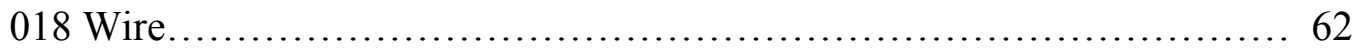

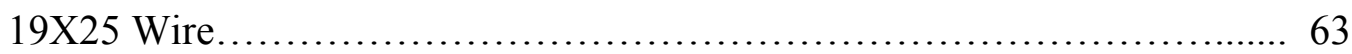

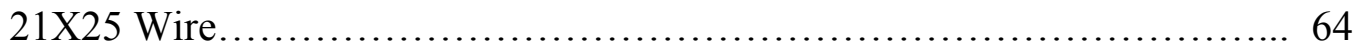

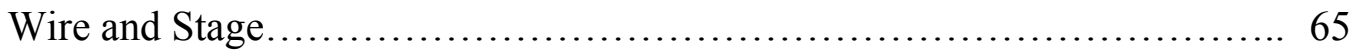

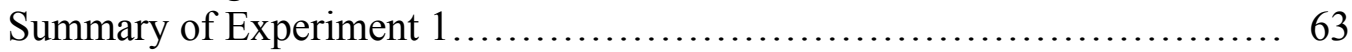

\section{CHAPTER V SUMMARY AND CONCLUSIONS}

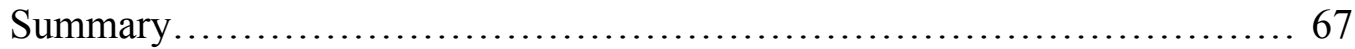

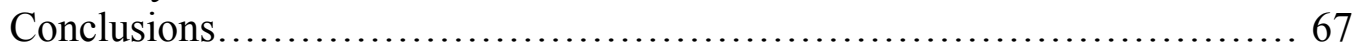




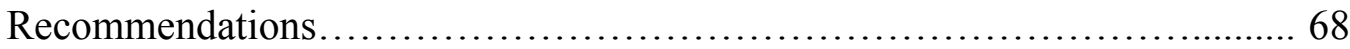

Reference List.................................................... 69

Appendix B

Friction Averages................................................... 77

Curriculum Vitae........................................................... 97 


\section{LIST OF FIGURES}

Figure 1. Friction-testing pparatus......................................... 29

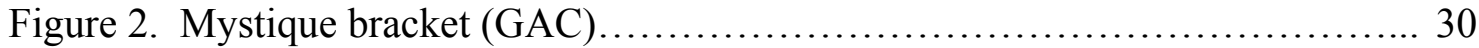

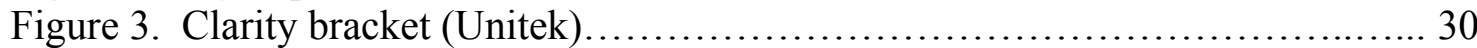

Figure 4. MicroArch bracket GAC) ....................................... 30

Figure 5. SmartClip (Unitek) .............................................. 31

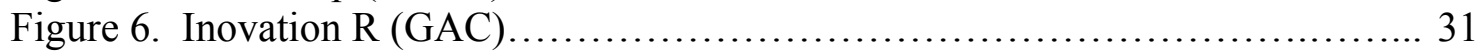

Figure 7. Surveyor pin aligning test bracket mounted on acrylic rod................... 33

Figure 8. Archwire in mounting plate.......................................... 34

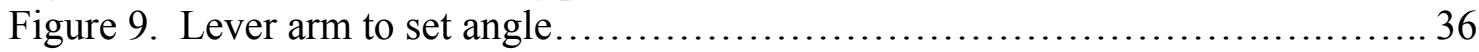

Figure 10. DC power supply and 2 bridge amplifiers............................. 37

Figure 11. Sample graph of raw data....................................... 40

Figure 12. Wire-BLS graph.............................................. 49

Figure 13. Stage and mean friction for all wires and bracket ligature systems....... 49

Figure 14. Wire-stage interaction........................................ 50

Figure 15. All brackets with ligation with 018 wire ............................ 55

Figure 16. All brackets with ligation with 19X25 wire.............................. 56

Figure 17. All brackets with ligation with $21 \mathrm{X} 25$ wire......................... 57 


\section{LIST OF TABLES}

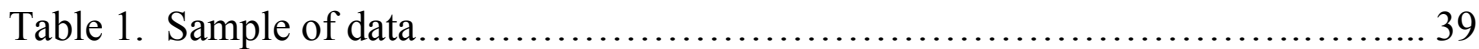

Table 2. Overall results (all brackets and ligation with all angles averaged)......... 45

Table 3. Mean friction for each wire, all BLS and stages averaged.................. 47

Table 4. Mean friction for each BLS......................................... 48

Table 5. 018 wire-BLS Tukey Kramer......................................... 51

Table 6. 19X25 wire Tukey Kramer.........................................52

Table 7. 21X25 Students' t test...................................................53

Table 8. Bracket factor Tukey Kramer......................................... 54

Table 9. Ligation factor Tukey Kramer.................................... 55 


\section{CHAPTER I INTRODUCTION}

\section{BACKGROUND}

Orthodontists are always seeking to reduce friction. The majority of friction investigations have been in vitro studies which involved pulling a straight wire through a bracket. The bracket had some form of archwire ligation and the mechanical testing machine measured the amount of force or frictional resistance that occurred while the bracket slid along the archwire. This technique does not mimic the clinical situation. To overcome some of these short comings, this research will vary the bracket/archwire angle to better simulate the clinical condition and allow clinicians to minimize friction of these appliances.

This study investigated the frictional resistance of two new ceramic brackets, two self-ligating bracket, and one standard stainless steel bracket with several methods of ligation. The size and composition of the archwires will also be varied. The frictional forces obtained in this study will be more useful when compared in a relative manner to one another, as opposed to the actual forces that will be measured.

\section{STATEMENT OF THE PROBLEM}

Do different methods of ligation, such as a stainless steel ligature tie, elastomeric tie, or self ligation with clips influence frictional resistance? Do different bracket slots such as stainless steel bracket slots, or silicated bracket slot influence frictional resistance during tooth movement?

\section{SIGNIFICANCE OF THE PROBLEM}


Frictional components have always been a major concern in orthodontics. Its innate ability to impede tooth movements can require greater force to move the teeth, prolong treatment and cause anchorage loss. It is a goal of every orthodontist and manufacturer to reduce the amount of friction, because this allows faster tooth movement and shorter treatment times. This investigation will study friction of stainless steel, ceramic, and self-ligating brackets under clinical simulation using variable tip and different size archwires.

\section{NULL HYPOTHESIS}

1) There is no significant difference in frictional resistance among various types of brackets: GAC Mystique brackets with silicated slots, 3M Clarity ceramic brackets with a metal slot, 3M SmartClip with a self ligating clip, GAC microArch (stainless steel twin bracket), or GAC's Inovation R brackets with a self ligating clip. 2) There is no difference in the frictional resistance among brackets with various types of ligation methods: Self ligating brackets of Inovation R and SmartClip, stainless steel tie or elastomeric tie. 3) There is no difference in the frictional resistance among the various types of archwires: 0.018 inch stainless steel, 0.019 inch X 0.025 inch stainless steel and 0.021 inch X 0.025 inch stainless steel archwire sizes.

\section{DEFINITION OF TERMS}

apparent stiffness - resistance to moments (stiffness) of an archwire measured when rotating the bracket.

coefficient of friction - the ratio of two forces; the weight (normal force) of an object being moved along a surface and the frictional force that resists 
movement. The coefficient is independent of the area of contact and independent of the sliding velocity.

conventional bracket - commonly used stainless steel or ceramic brackets that require the use of a steel or elastic tie to enclose the archwire.

dynamic friction - frictional force that occurs when the applied (normal) force is variable (dynamic load).

dynamic load - variable moment occurring between an archwire and bracket.

friction - the force that retards or resists the relative motion of two objects in contact; the direction is tangential to the common boundary of the two surfaces in contact. kinetic friction - the force that resists the sliding motion of one solid object over another at a constant speed.

noise - electronic variability within the system. oscillation - a single swing from one extreme limit to the other and back. resistance - a force that opposes or slows down another movement. self-ligating bracket - a bracket that completely encloses the archwire without the need for steel or elastic ties.

sliding - to move over a surface while maintaining smooth, continuous contact. sliding mechanics - the process of an archwire moving through the slot of a bracket to allow tooth movement.

static friction - the smallest force needed to start the motion of solid surfaces that were previously at rest with respect to each other. ${ }^{1}$

stiffness - a combination of modulus of elasticity and moment of inertia tipping - rotation about an axis perpendicular to the facial surface of a tooth 


\section{ASSUMPTIONS}

1) Brackets, archwires and elastic ties of each type were identical in physical attributes and composition.

2) Frictional force needs to be overcome in order to slide brackets along an archwire.

3) The brackets and wires were properly aligned in the testing apparatus.

\section{LIMITATIONS}

1) Force of elastic ties holding the archwire in the bracket slot varies and decays with time.

2) The stainless steel metal ligature ties were applied with the same force.

3) Application of this in vitro study to any in vivo situation has limitations.

With any testing situation, it is impossible to reproduce with exact precision the movements that will occur intra-orally. In the oral environment, saliva amount and content, bacteria type and concentration, types of liquids and solids ingested, force of oral musculature upon chewing, and periodontal health are some of the factors not encountered when performing this study in vitro.

4) Out of plane deformations were not evaluated.

\section{DELIMITATIONS}

1) Only maxillary first premolar orthodontic brackets with 0.022 -inch vertical slot and 0.028-inch slot depth were investigated.

2) Only 0.018-inch stainless steel, $0.019 \times 0.025$-inch stainless steel and $0.021 \times 0.025$ inch stainless steel were evaluated. 
3) Only injection molded O-ties (Ormco), which were more consistent in size and force, were used.

4) Amount and frequency of variable moments placed at the bracket-archwire interface were $1.00 \mathrm{~Hz}$ (60 cycles/minute).

5) All tests were run dry without the lubricating effects of saliva.

6) The angles were limited to $0,2.9,4.7$, and 5.4 degrees. 


\section{CHAPTER II LITERATURE REVIEW}

\section{FRICTION}

Friction is defined as the force that resists the motion of a body relative to another, and it operates in an opposite direction of the motion. ${ }^{1}$ It acts at the surface between two objects when one of the objects slides in comparison to the other. ${ }^{2}$ As these two surfaces are sliding against each other, two components of the force system are related, the frictional force and the normal force. ${ }^{3}$ Frictional force is proportional to the normal force acting perpendicular to the direction of motion. ${ }^{1,4}$ When two surfaces contacting are in motion, three forces are present. The first component is the force causing the motion, the second is the frictional force, which is opposite in direction of the motion. The last component is the normal force, which is perpendicular to the two surfaces in contact. It is also perpendicular to the frictional forces and the force causing motion. The magnitude of friction depends on the magnitude of the normal force pushing the two surfaces together. It will also rely on the roughness of the surfaces in contact and the composition of the materials involved. ${ }^{5,2}$ It is well documented by Kapur et al. ${ }^{6}$ that frictional forces in the contact areas between the two materials are greatest when atomic and molecular forces attract. As a result, friction would expect to be greater between two like materials rather than different compositions.

To reiterate from above, three principles have been discussed: ${ }^{2,7,8}$ The frictional force is proportional to normal force $\mathrm{F}=\mu \mathrm{N}$. $\mathrm{F}$ is the frictional force, $\mu$ is the coefficient of friction and $\mathrm{N}$ is the normal force. The coefficient of friction is always constant with regard to contact area, speed of movement and the normal force. The coefficient may be dependent on the roughness, texture or hardness of the surfaces. 
In order for one object to slide against the other the application of the force must overcome the frictional force. A distinction must be made between two types of friction: static and dynamic. Static friction is the smallest force needed to start the motion. Kinetic friction is the force that resists the sliding motion of one object over another which at a constant speed. ${ }^{9,10,11}$ Static friction is the force required for the initial movement and is always greater than the kinetic friction. ${ }^{1,4}$

Friction can be a major challenge when designing orthodontic appliances. A number of factors, both physical and biological, have been identified in influencing frictional forces during orthodontics:

1. Archwire properties: a) size and shape b) archwire material c) texture of wire d) apparent stiffness of wire. ${ }^{12}$

2. Ligation methods: a) steel ligature wires b) alastics c) ligation variables, operator dependent. ${ }^{12}$

3. Bracket properties: a) material b) manufacturing c) width and depth of the slot d) design e) prescription (bracket archwire angulation). ${ }^{12}$

4. Appliances: a) interbracket distance b) the level of the brackets compared to each other c) force levels used. ${ }^{12}$

5. Biological properties: a) plaque and oral hygiene b) saliva ${ }^{12,13,14,15,16}$ c) acquired pellicle d) corrosion e) food particles. f) temperature g) bite force and tooth mobility. ${ }^{17}$

\section{WIRE SIZE}

Most investigators agree that frictional resistance increases as the archwire increases in dimension. ${ }^{5,18,19,20}$ This has been noted from Andreasen's ${ }^{19}$ classic work in 
the area and confirmed by Frank and Nikolai, ${ }^{5}$ whom both ended by stating that with increased wire diameter the friction increased. When shape changes from round, to square, and finally rectangular, friction will increase at the bracket-wire interface. ${ }^{21,22,23,24}$ Moore concluded in his study that movement along a $21 \times 25$ inch wire produced almost three times as much friction as $19 \times 25$ stainless steel. ${ }^{25}$ Other researchers have reported archwire size does not necessary contribute to friction. Sims et al. ${ }^{26}$ reported that resistance did not rise steadily with progressively larger archwires. There is also evidence that while decreasing archwire size may reduce the friction temporarily, however, smaller archwires allow tooth tipping which causes more binding and may increase friction. ${ }^{27}$ Peterson and Vaughn ${ }^{28,29}$ noted that changing from a round to a rectangular nickel-titanium wire does not necessarily increase the frictional resistance.

\section{WIRE SHAPE}

Rectangular archwires generate greater friction than round wires because it has been shown there is more binding occurring at the bracket archwire interface. ${ }^{5,27,30,29}$ Translating teeth along 0.018 -inch or 0.016 round wire rather than rectangular wire is often suggested since there is belief that frictional forces are less and anchorage is better maintained. ${ }^{21}$ Frank and Nikolai ${ }^{5}$ in 1980 reported a conflicting study. They found that at binding angulations, stainless steel rectangular wires produced less friction than round wires. This resulted from greater pressures on the point of contact of round wires compared to line contacts of the rectangular.

\section{WIRE MATERIAL}

It is well established that the wire material affects the frictional resistance produced. ${ }^{15,31}$ However the debate on archwire friction continues. Stainless steel, nickel 
titanium, and beta titanium are three very popular wires. Each of the three wire types have been found to produce the least amount of friction, in at least one study, when compared to the other two wires. ${ }^{32}$

A very popular method of pulling a straight piece of wire through orthodontic brackets without any variable moment, found that nickel titanium produced the least amount of friction, then stainless steel and finally beta-titanium wires. ${ }^{33,11,34}$ There are also studies which suggest that stainless steel provides the least amount of friction when compared to the nickel-titanium. . $^{15,35,30}$

Beta-titanium was found to have the greater friction when compared to stainless steel and nickel-titanium. ${ }^{10,15}$ They have postulated that some adhesion occurs between the archwire and the bracket. With laser profileometer, stainless steel was the smoothest, followed by beta-titanium and nickel-titanium. ${ }^{36}$ Most studies are consistent with the fact however that nickel-titanium provides less friction than the beta-titanium wire. ${ }^{35,21}$ Mendes $^{37}$ et al. have shown that significantly lower frictional resistance are provided by certain wires and brackets. He showed that ion implanted nickel- titanium (Bioforce, GAC) and beta- titanium (TMA Colors, Ormco) wires had significant differences in frictional forces. The ion implanted wire had the lowest frictional resistance. ${ }^{37}$ Differences were also noted between different brackets. An ion implanted bracket (Omni Golden, GAC) demonstrated less friction with the untreated nickel- titanium wire, betatitanium, and rectangular stainless steel wire. ${ }^{37}$

\section{LIGATION}

Forces of normal ligation techniques can range from 50 to 300 grams. ${ }^{38}$ There is a wide range of variability that seems to be different from operator to operator. There are 
two main types of ligation widely used in orthodontics, elastomeric and stainless steel. Whichever method utilized, the forces that will be present are varied and differ from operator to operator. This variable component will ultimately affect frictional forces. ${ }^{33,39}$

Elastomeric modules will approximately apply 225 grams of force once activated. Khambay $^{40}$ in his study found significant differences in the mean force of seating the archwire with different ligation methods. The study also measured that grey alastic ligation produced the lowest force on the wire and stainless steel had the highest seating force. The exact opposite was true when a wire was passed through these different ligation methods, stainless steel having the lowest friction. ${ }^{40}$ It is important to note that this amount will invariably decrease because of module decay. ${ }^{41}$ This does not necessarily rise steadily with increasing archwire dimensions. ${ }^{31}$ With steel ligatures, seating forces can range from 0 to 300 grams. ${ }^{41}$ Schumacher et al. ${ }^{42}$ stated that friction was determined mostly by the nature of ligation and not by the sizes of the various archwires. Satisfying the first law of classical friction, resistance will proportionally increase with larger normal forces that are produced by the ligation. ${ }^{5,43,14}$ Loosely tied steel ligatures are thought to provide less friction than the elastic counterparts. ${ }^{44}$ Elastomerics can be prestretched before use to decrease friction and many advocate doing so. ${ }^{45,30}$ Also many clinicians prefer to "figure-eight" tie elastic ligatures. This will increase frictional resistance levels 70 to $220 \%$ depending on the size of the wire. ${ }^{26}$ Andreasen and Quevedo ${ }^{46}$ concluded that steel ligatures can be very "clinician sensitive", and that frictional resistance can be increased by increasing ligation forces. $5,15,47$ However, Riley et al. ${ }^{48}$ determined that steel ligatures generated more friction when applied on plastic brackets than elastic ligatures. 
Hain $^{49}$ et al. investigated a new elastic module from TP Orthodontics, a new "super slick" module incorporating new technology that is easier to use. They concluded that these modules generated significantly less friction than regular ties and they reduced friction when the modules were soaked in human saliva. The figure-eight ties that have previously reported higher friction, the authors here reported less friction with these new ties in human saliva. Hain ${ }^{49}$ also confirmed previous research that loosely tied stainless steel ligatures still provided the least amount of frictional forces. The debate still exists, Iwasaki $^{50}$ et. al. reported that loose stainless steel ligation was not associated with lower frictional levels.

The permanent deformation of elastomerics is related to time (stress relaxation), how fast they are stretched (strain rate), and hydrolysis due to water and moist heat in the

oral environment. ${ }^{51}$ Such deformation changes the degree of frictional resistance. ${ }^{52}$ Therefore, static friction decays over time with elastomeric modules. ${ }^{30}$ As mentioned earlier, the rapid rate of decay for these elastomeric ties and their history sequestering large amounts of plaque, these authors suggests that there is little merit in their use, especially in canine retraction and sliding mechanics. ${ }^{53}$

\section{BRACKETS}

Bracket designs can also be a factor. Wider bracket designs caused more stretching of elastomeric modules and increased the normal forces of friction. ${ }^{54}$ Some bracket designs, such as the Synergy bracket (RMO, Denver, CO), restrict the amount of force placed on the wire by the ligature tie..$^{22,55}$ 


\section{STAINLESS STEEL BRACKETS}

Stainless steel brackets exhibit lower coefficients of friction than the ceramic brackets. ${ }^{16,56}$ Angolkar $^{21}$ demonstrated in his research that stainless steel slots are relatively smooth as compared to their ceramic counterparts. Stainless steel brackets are manufactured by casting, sintering, and machining.

\section{CERAMIC BRACKETS}

Many ceramic brackets are processed by milling the material with diamond tools. This may leave rough edges and sharp angles. ${ }^{29}$ With many more adults seeking treatment, and the continual rise of esthetics in our culture, ceramic brackets are constantly being updated. Ceramic brackets come in two main types; 1)ceramic slot and 2)stainless steel slot. In most studies the stainless steel slot produced the least amount of friction when compared to the all ceramic bracket. ${ }^{57,58}$ This is most likely due to the increased roughness and porosity of the ceramic surface and a sharp bracket slot edge. $^{16,21,44}$ Rose and Zernik ${ }^{59}$ demonstrated this well in their study. They proved that by rounding the corners of ceramic brackets, this would significantly lower the frictional resistance. ${ }^{59,33}$ Saunders $^{60}$ et al. found that monocrystalline ceramics has a smoother surface than polycrystalline, but the differences in friction are very small. Ceramic brackets have reported to abrade the archwire. ${ }^{43}$ The ceramic bracket with stainless steel slot showed the surface finish of the slot to be smoother with fewer irregularities than the ceramic bracket slot. $^{24}$ Significantly higher forces would be needed clinically to overcome this polycrystalline rougher surface as compared to the stainless steel slot. Articolo and Kusy ${ }^{61}$ have also investigated the effects of ceramic slots on notching of archwires and inhibiting treatment mechanics. The static and kinetic coefficients of 
friction were often higher with ceramic than with stainless steel brackets. ${ }^{56}$ They found a larger percentage of notching for the ceramic brackets compared to the stainless steel.

Both types of brackets for two studies concluded that there are no frictional differences between ceramic and stainless steel brackets. ${ }^{27,62}$ In a study by Articolo, he discovered that most notching of the wire occurred in the canine area on the lingual surface of the wire. ${ }^{61}$ Downing $^{24}$, mentioned that there would be no disadvantage to using ceramic brackets when teeth require sliding. These studies pulled a straight wire through the bracket, therefore clinical simulations were not utilized, such as tipping and binding of the archwire into the bracket slot. DeFranco ${ }^{34}$ et al confirmed this theory. At $0^{\circ}$ angulation, there is really no room for contact between brackets and archwires, therefore minute changes in frictional forces were noted. With increased angulations and bracket and archwire contact, friction was significantly higher with the ceramic brackets. $^{32}$

Ceramic brackets have excellent esthetics but generally have plagued orthodontists with several problems, such as fracture during angular and tipping movements, ${ }^{63,64}$ enamel abrasion, ${ }^{65}$ enamel damage during debonding. ${ }^{66,67}$ Manufacturers have recognized these problems. The advent of the stainless steel slot in a ceramic bracket is one way in which frictional resistance can be reduced to almost a regular stainless steel bracket without compromising esthetics.

\section{SELF LIGATING BRACKETS}

Self ligating brackets have been around since 1935 when Stolzenberg described the Russell Lock appliance. ${ }^{68}$ Many designs have been patented but very few make it to the orthodontists office. Stolzenberg's design was then modified by Wildman in the 
Edgelok appliance in 1972 . The archwire was positioned by sliding a labially cap across the top of the archwire slot and locked. This created a rectangular slot, or tube, and the archwire had total freedom of movement. The Mobil-Lock bracket was introduced in 1980. In 1980 Hanson, ${ }^{69,70}$ created a different appliance consisting of a spring-loaded, self-adjusting ligature less design. This was different in that it could retain and actively influence control of the archwire. This was called the SPEED appliance. Other designs include the Activa and active Time bracket were introduced in 1986 and 1994 respectively. Damon ${ }^{71}$ in 1996 made a revolutionary passive self-ligating Damon SL bracket. When the slide is closed, the lumen of the slot is full-size, which is critical for rotational control. ${ }^{32}$ In 1998 Wildman $^{72}$ came out with another appliance called the Timelok. This was three designs in one decade. This trend continued in spite that selfligating brackets only captured a small percentage of the market. It wasn't until recently when Damon ${ }^{71}$ redesigned the Damon SL bracket and introduced the passive Damon System II bracket in 2000. Voudouris also designed a new active self-ligating bracket named In-Ovation in 2000. These latest and most significant changes have been in the last two systems mentioned. Both of these exhibit major advances in the self-ligating system and have gained extreme popularity. ${ }^{73}$

Haradine $^{73}$ now feels that self-ligating brackets have reached a stage of design and control, where the advantages far outweigh the remaining imperfections. There are many clinical advantages to the self-ligating system. There is a more certain engagement of the archwire. There is decrease in frictional resistance between the bracket and the archwire, ${ }^{73,74}$ both static and dynamic. ${ }^{75}$ Faster archwire removal and ligation, leading to perhaps the most significant aspect, less chair side assistance. ${ }^{73}$ The self-ligating bracket 
systems are also advantageous in that they generate a healthier tissue response because of better plaque control. ${ }^{55,73}$ The elastomeric ties accumulate plaque more than steel ties, however the ends of steel ties can possibly cause laceration and collect plaque. ${ }^{55,73}$ Harradine $^{73}$ also mentions that anchorage control is not as important of an issue as compared to the conventional bracket designs. Cacciafesta ${ }^{75}$ et al. also mentioned that from the patient's perspective, self-ligating brackets are more comfortable and also easier to clean. ${ }^{55,75}$

All the inventors report a significant reduction in friction, as well as shorter treatment time and chair-time, when compared with conventional bracket systems. ${ }^{76,72,77}$ All these opinions were promoted back in 1935 with the advent of the Russell Lock, which may lead to some confidence issues with current brackets. ${ }^{68}$

Sims et al found that self-ligating brackets produced substantially less friction than conventional elastomerically tied brackets, using archwires ranging from $0.016 \mathrm{x}$ 0.022 -inch to $0.019 \times 0.025$-inch. ${ }^{26,55}$ Cacciafesta $^{75}$ concluded that stainless steel selfligating brackets produced the lowest patterns of static and kinetic friction compared to the stainless steel and polycarbonate self-ligating. Perhaps one of the major differences between stainless steel brackets and self-ligating is the method of ligation. Ligating clips of the self-ligating brackets have a smaller magnitude of force on the archwire into the slot compared to the steel or elastomeric ligatures of the conventional systems. ${ }^{78,79}$ ReadWard $^{80}$ found some contradictory results. He concluded that self-ligating brackets showed reduced frictional resistance in comparison to steel ligated brackets only under certain conditions. 
Berger $^{81}$ et al. studied the three major popular uses of ligation; steel ligature, elastomeric, and self-ligating. They found that self-ligating brackets produced the lowest friction than either steel ligatures or elastomerics.

Damon concluded that self-ligating bracket design facilitates rapid leveling because teeth move along the path of least resistance with little or no resistance between the archwire and the slot of the bracket. The hinge mechanism of the self-ligating system eliminates the friction caused by conventional ligation. ${ }^{71}$

\section{BRACKET WIDTH}

Andreasen and Quevedo ${ }^{46}$ and Peterson ${ }^{28}$ et al. concluded that bracket width did not affect friction, whereas Nicolls ${ }^{48,72}$ and Frank and Nikolai ${ }^{5}$ found that friction increased with wider brackets. They also maintained that the larger contact surface area of the wire contacting more of the wider bracket resulted in increased friction. As mentioned earlier, wider brackets produce more frictional forces because of the greater stretch of the ligation over the bracket that is involved. Frank and Nikolai ${ }^{5}$ also found that narrower brackets produce less friction because of less binding of the narrower brackets. Yamaguchi ${ }^{83}$ et al. concluded that for retraction, the closer to the center of resistance, less tipping of the bracket would occur for the narrow bracket and therefore reduce the friction. However, many others such as Nicolls, ${ }^{82}$ Drescher, ${ }^{84,27}$ found that friction decreased as the bracket width increases because tipping and binding were reduced in the wider bracket. Omana, Sims, Moore, et al. also reported that wider brackets have less friction by allowing less angulation change of the archwire, and therefore less binding. ${ }^{33,85,86}$ 
Frictional resistance increases as the number of brackets included in the assembly increases. ${ }^{32}$ The greater the interbracket distance the longer the wire will be between the brackets therefore larger amounts of deflection, and flexibility, hence more leveling. ${ }^{87}$ The effects of bracket width and interbracket distance still remains uncertain, according to Frank and Nikolai, who found interbracket distance to have little if no effect on friction. $^{5}$

\section{BRACKET-ARCHWIRE ANGULATION}

As the angle between the bracket and the archwire increases, friction tends to increase, and more rapidly beyond the critical contact angle. ${ }^{88}$ Greater angulation between the archwire and bracket yielded greater friction. ${ }^{89,90,26,33}$ The dependence on angulation is more pronounced in stainless steel than nickel titanium archwires, a possible reason being the lower stiffness of the latter wire. ${ }^{10}$ Frank and Nikolai ${ }^{5}$ found that frictional resistance increased in a non-linear manner with increased bracket angulation. This is more correctly attributable to binding rather than true friction.

\section{SURFACE ROUGHNESS}

There has been no definite relationship between archwire and bracket surface roughness and friction. ${ }^{36,91}$ Generally, friction tends to be highest for surfaces that are similar. Rough surfaces generate a lot of friction because the peaks in between the roughness cause an interlocking relationship. ${ }^{18}$ Smooth surfaces interact via different mechanisms, the flat surfaces allow for a stronger adhesion and thereby increasing friction.

Kusy and Whitley showed that, while the smoothest wire surface did have the lowest coefficient of friction, surface roughness does not necessarily correlate with the 
coefficient. Studies using laser spectroscopy and profilometer showed no significant correlation between surface roughness and frictional forces for various kinds of archwires. $^{92}$

\section{SLIDING MECHANICS}

Sliding mechanics involves a relative displacement of wire through bracket slots. The problem still lies, whenever sliding teeth along an archwire, frictional resistance is encountered. The technique is commonly used and orthodontists are constantly striving to level arches to facilitate translation of teeth. It is widely used in achieving closure of extraction sites, distalization of teeth, eruption of high cuspids, rotations, leveling and modifying arch forms. Frictional forces developed between the bracket and archwire opposes such movements. ${ }^{32}$ Friction will ultimately lead to impaired tooth movements, therefore higher force levels and more anchorage will be needed. ${ }^{33,86}$ Also if extra bracket tip occurs the archwire is more likely to be permanently deformed ${ }^{86} \mathrm{Up}$ to $60 \%$ of the applied force to the archwire complex is dissipated as friction, ${ }^{18}$ which ultimately reduces the force available for tooth movement. ${ }^{93}$ Therefore, one can see why it is imperative for orthodontists to constantly seek techniques to reduce or even eliminate friction.

Bourauel $^{94}$ agreed and concluded friction increased appliance inefficiency. The force levels on specific teeth become difficult to access. Root surface area, bone density and occlusal interferences all effect the force on a tooth. ${ }^{28}$ It is also well documented that increasing force increases the rate of tooth movement only to a certain point. Once excessive force levels have been obtained there is no appreciable increase in tooth movement. ${ }^{95}$ It is counter-productive because it increases friction and has the potential to 
lose anchorage. ${ }^{33}$ In fact Swartz ${ }^{96}$ stated that a force as light as that of capillary blood pressure $\left(20-26 \mathrm{gm} / \mathrm{cm}^{2}\right)$ would produce tooth movement.

Proffit $^{90}$ in his textbook Contemporary Orthodontics said that the optimum force levels for orthodontic tooth movement would begin cellular activity within the periodontal ligament. If too great a force is used then occlusion of the blood vessels occurs and blood supply is lost. When this occurs the PDL goes through hyalinization and teeth cannot be moved. There is a point to which the PDL can have so much force placed upon it; it becomes necrotic. According to Proffit, ${ }^{90}$ as previously discussed, vascularity is critical to tooth movement. He and many others agree there is no doubt that light, continuous forces produce the most efficient tooth movement.

Static friction is more important in tooth movement than kinetic friction, in that static friction is the force to begin movement. The coefficient of static friction is always larger than kinetic friction. Forces tend to be higher because so much force is lost to the static frictional component. The static and kinetic frictional forces produced between bracket slots and archwires during sliding mechanics should be kept as low as possible to allow optimal tooth movement. ${ }^{97}$ Drescher ${ }^{18}$ et al. reported that even under the lowest velocity sliding mechanics, static and kinetic friction will always take place.

Orthodontic forces are usually applied at a distance from the center of resistance of the teeth. ${ }^{11}$ The orthodontic forces are not at the center of rotation and this causes interaction between tipping and uprighting of the tooth. The bracket will rotate with this movement and the tooth will translate along the wire, although constrained by the friction. In these interactions, the extent of force loss due to friction is proportional to the vertical and horizontal pressure of the archwire in the bracket-archwire complex. ${ }^{98}$ This 
pressure will be decided by the amount of force in the archwire. Therefore, a tooth moves along an archwire, tipping and uprighting.

The average PDL space in human beings is about $0.2 \mathrm{~mm}$. The space is larger for teeth receiving orthodontic treatment. During periods of orthodontic tooth movement, the distance between the root surface and the alveolar socket may double or triple in width. Due to the width and compressibility of the PDL, the teeth will tip within this freedom of the PDL until contact is established between the corners of the bracket and the archwire diagonally. These movements occur immediately, once the archwire is tied in, and before movement along the archwire occurs. ${ }^{11}$ Once the tooth has tipped all further movement will cease until subsequent remodeling occurs in the PDL. Each time the tooth moves, static frictional resistance must be overcome, and then kinetic friction occurs to further move the tooth. ${ }^{5}$ During tooth movement the teeth maintain this tipped position and move parallel to the archwire.

Orthodontists are constantly striving to maintain these light continuous forces; however, remodeling of periodontal tissues is rarely achieved in a healthy way. Tooth movement will change the gingiva, PDL and the bone. Oppenheim ${ }^{99}$ et al. hypothesized that the periodontal ligament will suffocate and this is the mechanism in which changes occur in bone; by undermining and frontal resorption.

Changes in blood supply can be noticed in the gingival tissues when subjected to variable moments, either with tooth brushing ${ }^{100}$ or orthodontic tooth movement. ${ }^{101}$ Tuncay $^{102}$ feels that the resistance to remodeling is more important in terms of efficiency of tooth movement than the remodeling of bone. All components are important however in the remodeling process. The ongoing challenge for the orthodontist is to place enough 
force to stimulate cellular activity in the periodontium without iatrogenic trauma causing cell death. Beginning the treatment with low force, low friction and small dimension wires will allow teeth to move more individually. They will also begin to level because they are linked together in a group.

There are many other factors which will affect the periodontium and ultimately tooth movement. Many of the studies mentioned were conducted in laboratory experiments, such as the fact that tooth movement occurs at a rate of $1 \mathrm{~mm}$ per month. There are many other variables intra-orally such as mastication, swallowing, and saliva to name a few have a large impact on tooth movement.

\section{VARIABLE MOMENT}

Liew's ${ }^{103}$ study in 1993, changed the way frictional resistance measurements were conducted in a steady state. Most friction tests were absent of any vibrations or disturbances at the bracket-archwire interface that would normally be produced by various everyday oral functions. He placed vertical displacements on the archwire under differing loads using low frequency (91.3 cycles/minute) vibrations. He found that the resistance to archwire movement through an orthodontic bracket was decreased by continuous repeated low frequency vertical displacement of the wire. With loads of 100250 grams he saw a reduction in friction by $85 \%$. When he used smaller loads of 25 grams, this reduced friction by more than $50 \%$. Therefore, several investigators figured that clinically vibrations must occur due to mastication and tooth mobility during movement. This will mean that friction encountered clinically will be less than measured in the laboratory. ${ }^{91}$ 
O’Reilly $^{9}$ et al. studied 0.022 x 0.028 -inch maxillary premolar stainless steel brackets with $0^{\circ}$ tip and $0^{\circ}$ torque. An alignment fixture was used to determine that the bracket was placed precisely at the center of each block and the slot was at right angles to the surface. The apparatus consisted of two parts: a lower member swivel mounting and an upper member slide, which supported the test bracket that supported the fixed brackets and the test archwire respectively. The distance between the two brackets on either side of the window measured $19.2 \mathrm{~mm}$. This is the average distance between the lateral incisor and the second bicuspid brackets. The test bracket was then placed in the window and the test wire was then placed through all four brackets in series.

A vibrating machine produced the bracket displacement. A frequency of $1.35 \mathrm{~Hz}$ (81 cycles/minute) was used, which simulates the normal chewing cycle. The archwire was drawn through the bracket at a crosshead speed of $1 \mathrm{~mm} / \mathrm{minute}$. A mechanical universal testing machine was used to measure the forces encountered. Each test run lasted one minute and the loads were recorded in newtons. Four amplitudes were chosen for investigation ranging from $0 \mathrm{~mm}$ to $1.0 \mathrm{~mm}$. A total of 16 cohorts (four wires and four amplitudes) with 20 specimens in each group were assembled. This study concluded that the effective sliding resistance between orthodontic brackets and archwires is substantially reduced by repeated displacement. The reduction in sliding resistance noted with displacement, depended on the archwire.

Braun $^{104}$ et al. also performed an investigation involving deflection of the archwire in bracket slots. He developed a bracket-holding jig to allow for changes in the bracket angle relative to the archwire. This would simulate clinical activity. The bracket angulations relative to the archwire were tested from $0^{\circ}$ (as in translatory movement) to a 
maximum of $25.5^{\circ}$, as in dental tipping. The crosshead speed was $0.1 \mathrm{~mm} /$ minute and all tests were conducted in a dry environment. Steel ties $(0.010$-inch) were used to ligate the archwires in the bracket slots. Deflections were applied to the bracket or archwire in random frequencies and in random directions in all three planes of space. The deflections were applied with finger touch, measured by a Correx gauge, to the bracket or archwire with a mean force of 87.2 grams (range 20 to 200 grams). This study concluded that frictional resistance momentarily became zero in $96 \%$ of the experiments. This reduction seemed to be independent of the archwire size. The use of steel ligation had no influence. Relative bracket-archwire angulations up to $25.5^{\circ}$, did not increase frictional resistance.

Omana's ${ }^{33}$ study compared the frictional effects of seven brands of ceramic brackets to those of a familiar type of metal bracket (Mini Diamond). Each bracket was tested on $0.018 \times 0.025$-inch straight pieces of nickel titanium and stainless steel wires. Load ranging from 50-150 grams were randomly placed on a $10 \mathrm{~mm}$ long counterweight arm to simulate the effects of varying amounts of bracket engagement during tooth movement. As the wire was drawn through the bracket, the static frictional forces were measured by a mechanical testing machine.

The results showed that increasing levels of bracket tip (load) resulted in a corresponding increase in frictional force, there was no appreciable difference between the frictional force values of the stainless steel and nickel titanium wires. In addition, smoother, injection-molded ceramic brackets appear to create less friction than other ceramic brackets, wider metal or ceramic brackets create less friction than narrower brackets of the same material and excessive force is counterproductive because of increased bracket friction and potential loss of posterior anchorage. 
In vitro frictional resistance experiments that did incorporate variable moments at the bracket-archwire interface concluded that the relationship between tip and friction appears to be linear. The effect of displacement was shown to have a significant effect on sliding resistance regardless of wire type.

If one considers the clinical situation, where there is intermittent movement between the bracket and archwire, then clinically we may not be looking at true friction, but rather a binding and releasing phenomenon. Kajdas ${ }^{105}$ et al. found that repeated displacement of a bracket, equivalent to as little as $0.16 \mathrm{~mm}$ of mesio-distal crown movement (which is within the range of normal tooth mobility), could reduce the sliding resistance by as much as $85 \%$. Assuming this fact, it is not unreasonable to conclude that the reduced sliding resistance observed in vivo may be a result of this intermittent movement between the bracket and archwire.

\title{
CONTACT ANGLE
}

The angle in the bracket slot before the archwire and bracket bind is called the contact angle. Archwires with smaller dimensions result in larger contact angles than archwires with larger dimensions, when using the same bracket. As the angle between the bracket and archwire increases, the frictional force will increase, more rapidly beyond a certain contact angle. ${ }^{88,106}$ created a formula that would calculate the contact angle.

\author{
Contact Angle $\left(\theta_{\mathrm{c}}\right)=\underline{57.3[1-(\text { size } / \text { slot })]}$ \\ $\left(2^{\text {nd }}\right.$ order angulation $) \quad($ Width $/$ slot $)$ \\ Size $=$ the archwire dimension that contacts the floor of the slot \\ Slot $=$ the bracket dimension at the floor of the slot
}


Width $=$ the mesial-distal dimension of the bracket

\section{SALIVA}

The presence of saliva has an inconsistent effect on the static frictional resistance, in some cases with saliva functioning as a lubricant and at other times acting to increase friction. ${ }^{80}$ Stainless steel brackets have been evaluated with inconsistent results of saliva on frictional properties. ${ }^{80,14,82}$

Many investigators have found that saliva acts to increase frictional resistance. ${ }^{80,14}$ Most would think that saliva is a natural lubricant. As Stannard ${ }^{14}$ mentions, water is made of polar molecules which attract to each other and therefore increase friction.

The greatest difference between dry and wet states occurred with beta-titanium archwires, the friction was reduced to half in the wet state. ${ }^{56}$ 


\section{CHAPTER III MATERIALS AND METHODS}

\section{OVERVIEW}

This research study investigated the effects of variable tipping angles and ligation methods on friction using different brackets and archwires, to evaluate the amount of static, kinetic and dynamic friction present. Friction is the force necessary to pull an archwire through a bracket. The force required to tip the bracket to create a constant bracket-archwire angulation was measured. The testing apparatus consisted of a frictiontesting apparatus, mechanical testing machine (Figure 1), two load cells, two signal amplifiers, two computers and a rotating cam. The testing machine engaged one end of the vertically oriented archwire, which was inserted in the bracket slot, and pulled the archwire superiorly. Each bracket-archwire and ligation combination was tested 5 times, which yielded friction and load data. During the 120 second trial, the archwire was pulled with and without any variable moments. The data was analyzed to determine which brackets, archwires, and ligation method yielded the least static, kinetic and dynamic friction. 




Figure 1. Friction-testing apparatus. 


\section{MATERIALS}

Maxillary right first premolar brackets with $0.022 \times 0.028$-inch slots were selected for this study. The brackets were chosen because of the increase in popularity of ceramic and self ligating brackets. The brackets were:

1) Mystique (GAC) $-7^{\circ}$ torque, $0^{\circ}$ tip (Lot \#16378) (Figure 2)

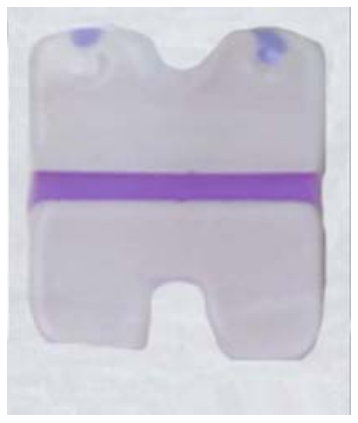

2) Clarity (Unitek) $-7^{\circ}$ torque, $0^{\circ}$ tip (Lot \#016525400) (Figure 3)

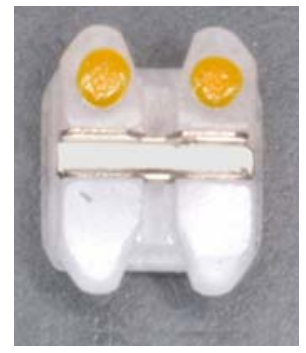

3) MicroArch (GAC) $-7^{\circ}$ torque $0^{\circ}$ tip (Lot \#15767) (Figure 4)

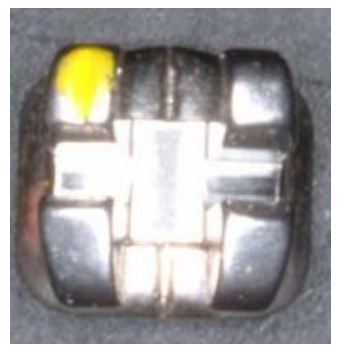


4) SmartClip (Unitek) $-7^{\circ}$ torque, $0^{\circ}$ tip (Lot \#G1068BN) (Figure 5)

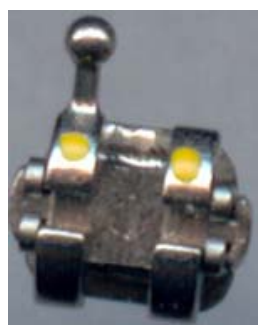

5) Inovation $\mathrm{R}(\mathrm{GAC})-7^{\circ}$ torque, $0^{\circ}$ tip (Lot \#0904) (Figure 6)

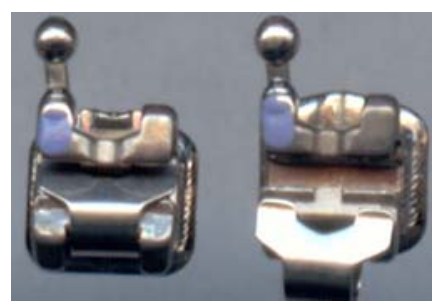

Open and Closed

All the archwires used in this study were provided by GAC:

1) 0.018 inch stainless steel (Lot \#02F10).

2) $0.019 \times 0.025$-inch stainless steel (19x25ss) (Lot \#024448).

3) $0.021 \times 0.025$-inch stainless steel $(21 \times 25 \mathrm{ss})$ (Lot \#021308)

\section{LIGATION METHODS}
1) Elastomeric tie from Ormco
2) .009 Stainless steel ligature tie from Masel
3) Self ligation bracket from Unitek-SmartClip
4) Self-ligation bracket from GAC-Inovation-R

\section{TEST BRACKET-ACRYLIC ROD ASSEMBLY}

A dental surveyor was utilized to align and mount the test brackets onto the ends

of fabricated acrylic rods. The acrylic rods were $6 \mathrm{~mm}$ in diameter and were $12.6 \mathrm{~mm}$ in 
length. A rectangular acrylic block, with a $6 \mathrm{~mm}$ diameter hole drilled in its center, was secured to the base of the surveyor table with caulking paste. This block will be used to center the acrylic rod beneath the pin of the surveyor. Gel superglue was placed on the mesh retention side of the bracket. The bracket was then inserted onto the rod on the surveyor to position it over the center of the acrylic rod and perpendicular to the long axis of the rod. The surveyor pin used to secure the bracket was ground into the shape of a blade, with its width equaling the bracket slot (.022). The pin was then inserted into the bracket slot to align and center the bracket on the acrylic rod surface: the bracket was held on the pin with a friction fit. The surveyor and plate negated the $-7^{0}$ torque prescription in the brackets (Figure 7). Isopropyl alcohol (200 Catalyst-C, M-Line Accessories, Measurements Group, Inc., Raleigh, N.C.) was painted onto the bracket-rod interface to accelerate bonding. 


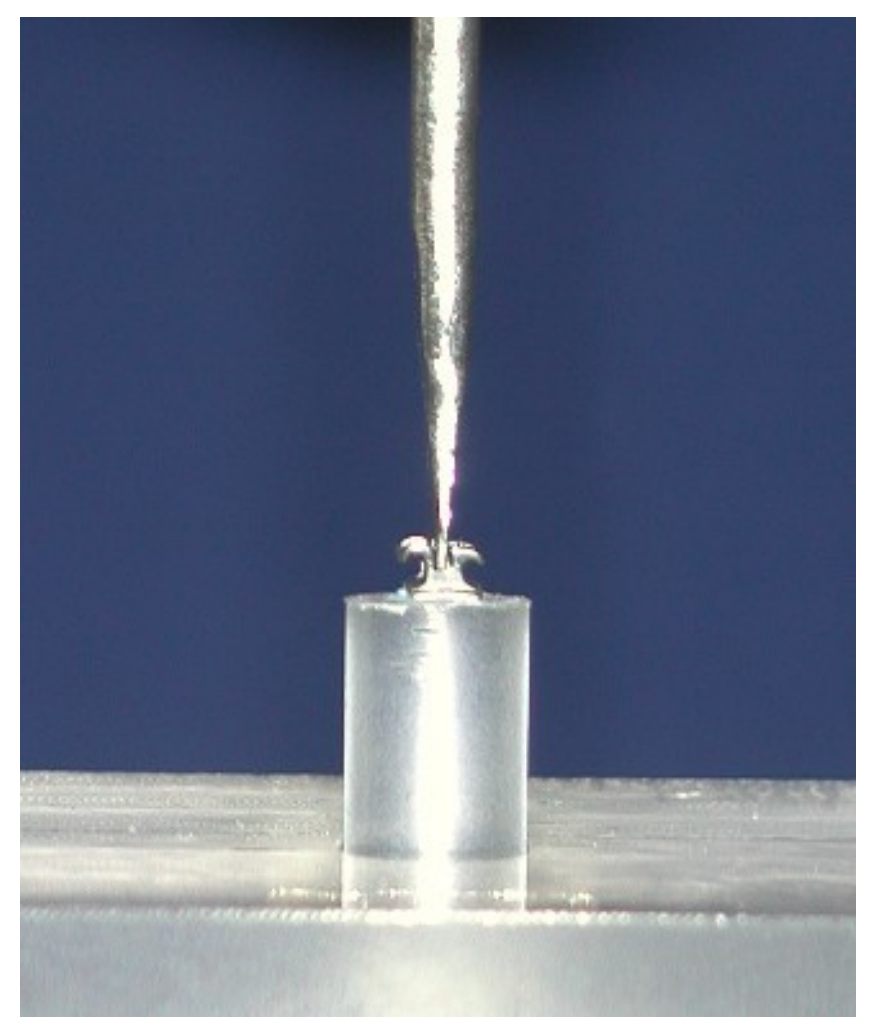

Figure 7. Surveyor pin aligning test bracket mounted on acrylic rod.

\section{APPARATUS SETUP}

The bracket/rod assembly was mounted to the test apparatus by sliding the rod into a sleeve with a locking set screw (Figure 8). The sleeve was free to rotate in the plane of the bracket slot. The angle of rotation was recorded via an electronic angle gauge. The sleeve was rigidly attached to a lever arm, see Figure 8 . The lever arm was connected to a rotating cam.

All brackets were orientated in the same direction, with the distogingival dot positioned superiorly and to the right. As a result, all bracket slots were vertically orientated.

Wires were rigidly fixed to a rod connected to the movable cross head and the load cell of the testing machine. The position of the bracket was adjusted by moving the 
test apparatus left and right, forward and back via an adjustable platform. This positioning and wire connection resulted in the wire being passively aligned through the bracket slot. After the bracket was properly positioned, ligation was engaged. Testing procedures pulled the wire through the bracket/ligature while monitoring the load.

Rotation of the cam moved one end of the lever arm up and down. The other end of the lever arm was fixed but allowed to rotate. Rotation of this end of the lever arm, rotated the rod/bracket assembly. (Figure 9) As the bracket rotated, the wire came into contact with the bracket slot. Rotation of the wire was limited by two low friction guide bearing (Figure 8). The force to rotate the bracket was recorded via the second load cell.

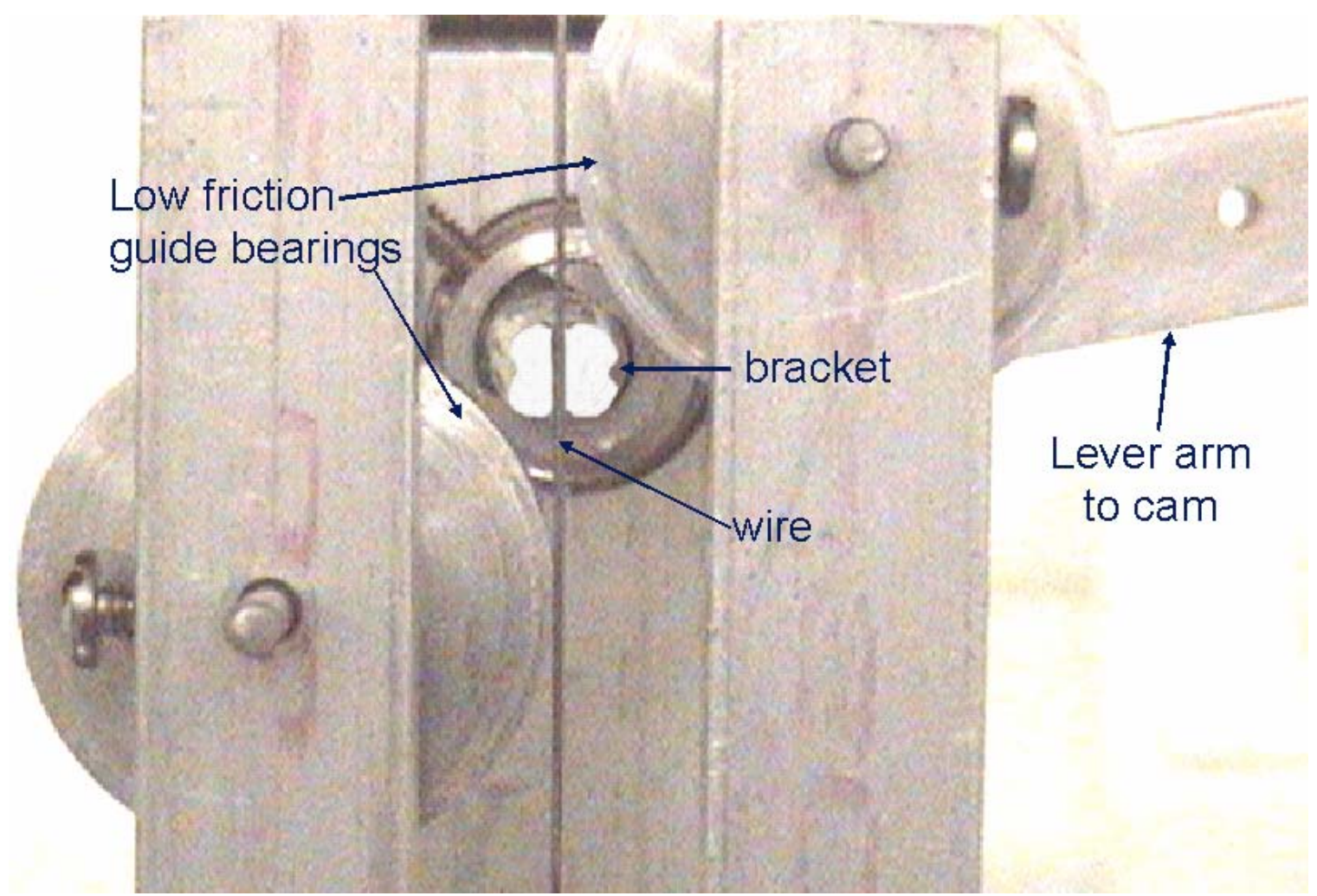

Figure 8. Archwire in mounting plate.

\section{LOAD CELLS AND COMPUTER SETUP}

Prior to data collection, a 50-gram weight was used to calibrate the 250 -gram load cell (Sensotec, Inc. Model 31/1435-03). This load cell measured the load required to tip 
the bracket/archwire to a predetermined angle. It was interfaced with a custom built computer containing an Intel Celeron processor and Labtech software (Laboratory Technologies Corporation (C 1999, Labtech Control Version 11, Universal) recording the data. It was attached superiorly to the lever arm and inferiorly to the rotating cam, which created the variable moments. The load cell was attached to the lever arm at a distance from the lever arm's center of rotation, which was directly behind the test bracket-rod assembly.

The second load cell, $\pm 1 \mathrm{kN}$ (Instron, UK 598) located on top of the Instron machine, was calibrated with a 1000-gram weight. This load cell recorded the force to pull the wire through the bracket, and friction at the bracket-archwire interface. This load cell was also interfaced with the same custom built computer utilizing the Labtech software. A Gateway E3000 system containing Merlin software (Instron Merlin Program, Version 3.23) controlled the crosshead speed of the archwire ( $5 \mathrm{~mm} / \mathrm{min})$.

\section{ROTATING CAM}

A DC Power Supply (Maxtel International Corporation, BK Precision, and Triple Output DC Power Supply 1651) powered the rotating cam. The cam was attached with a rod and load cell to a lever arm. The rotation of the cam oscillated the lever arm which rotated the bracket/rod assembly to produce the variable moments. The power was set to 11 volts, which correlated to 1 Hertz or 60 cycles/minute. As the rotating cam moved cyclically, the measured load would cyclically change. When the cam rotated to the highest vertical dimension, the minimum load was applied. Conversely, when the cam was rotated to its smallest vertical dimension, the maximum load was applied. The connection of the lever arm to the rotating cam was positioned to vary the rotation angle 
from zero to the maximum. Before the archwire was engaged in the test bracket, the rotating cam was turned until the 250 -gram load cell was at its most superior position, to apply the minimum load, at zero degrees (Figure 9).

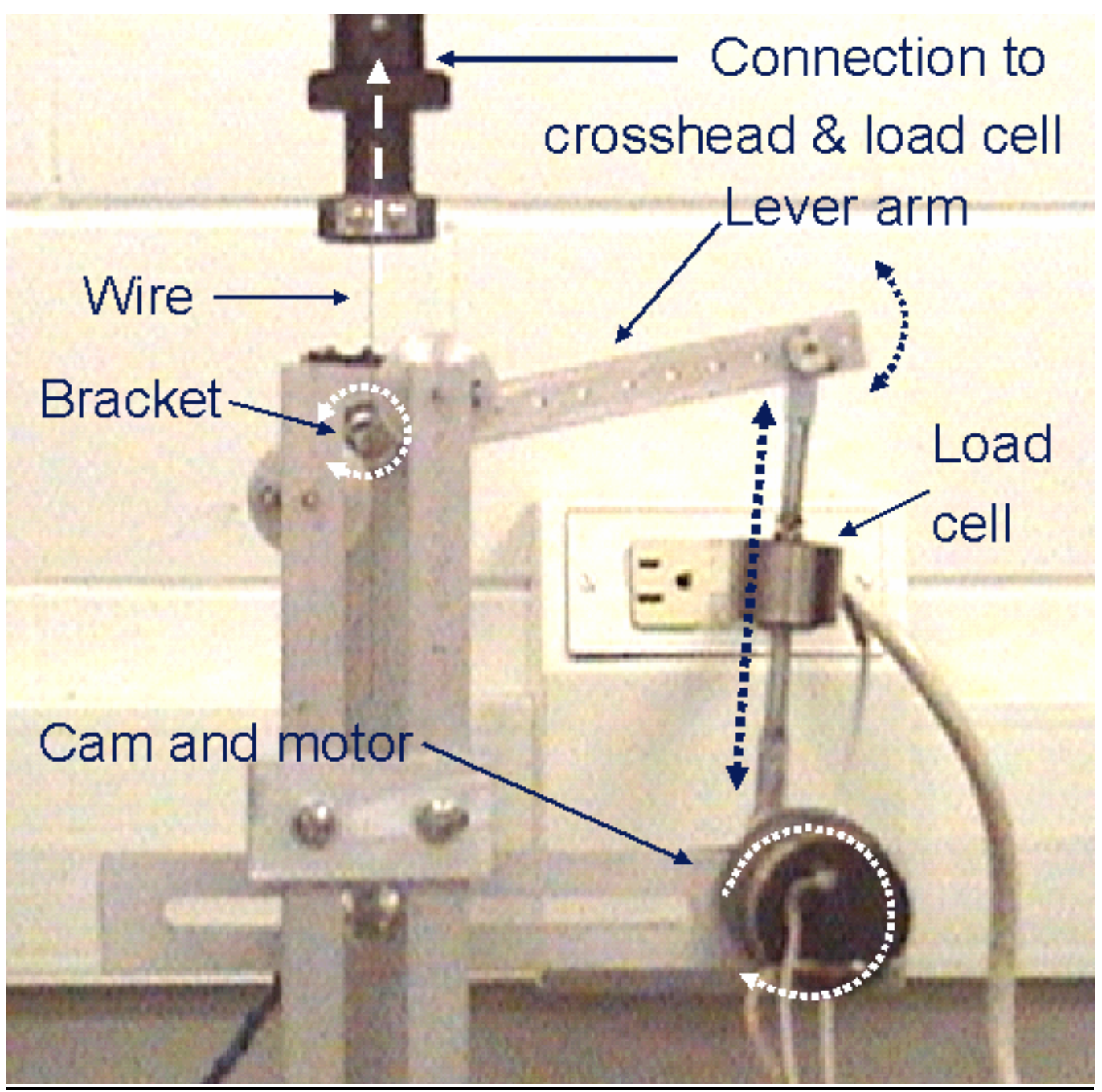

FIGURE 9. LEVER ARM TO SET ANGLE.

\section{BRIDGE AMPLIFIERS}

Two bridge amplifiers were used in this study to provide stimulation in the load cells and to amplify the signal voltage (proportional to load) (Figure 10). The Signal Conditioning Amplifier (Measurements Group, Instruments Division, Model 2311) 
attached to the $\pm 1 \mathrm{kN}$ load cell, to measure friction, was reset to zero prior to each trial. The second amplifier (Sensotec, Inc., Signal Conditioner-Indicator, Model GM), used to measure load and connected to the 250-gram load cell, was not reset to zero prior to each trial. 


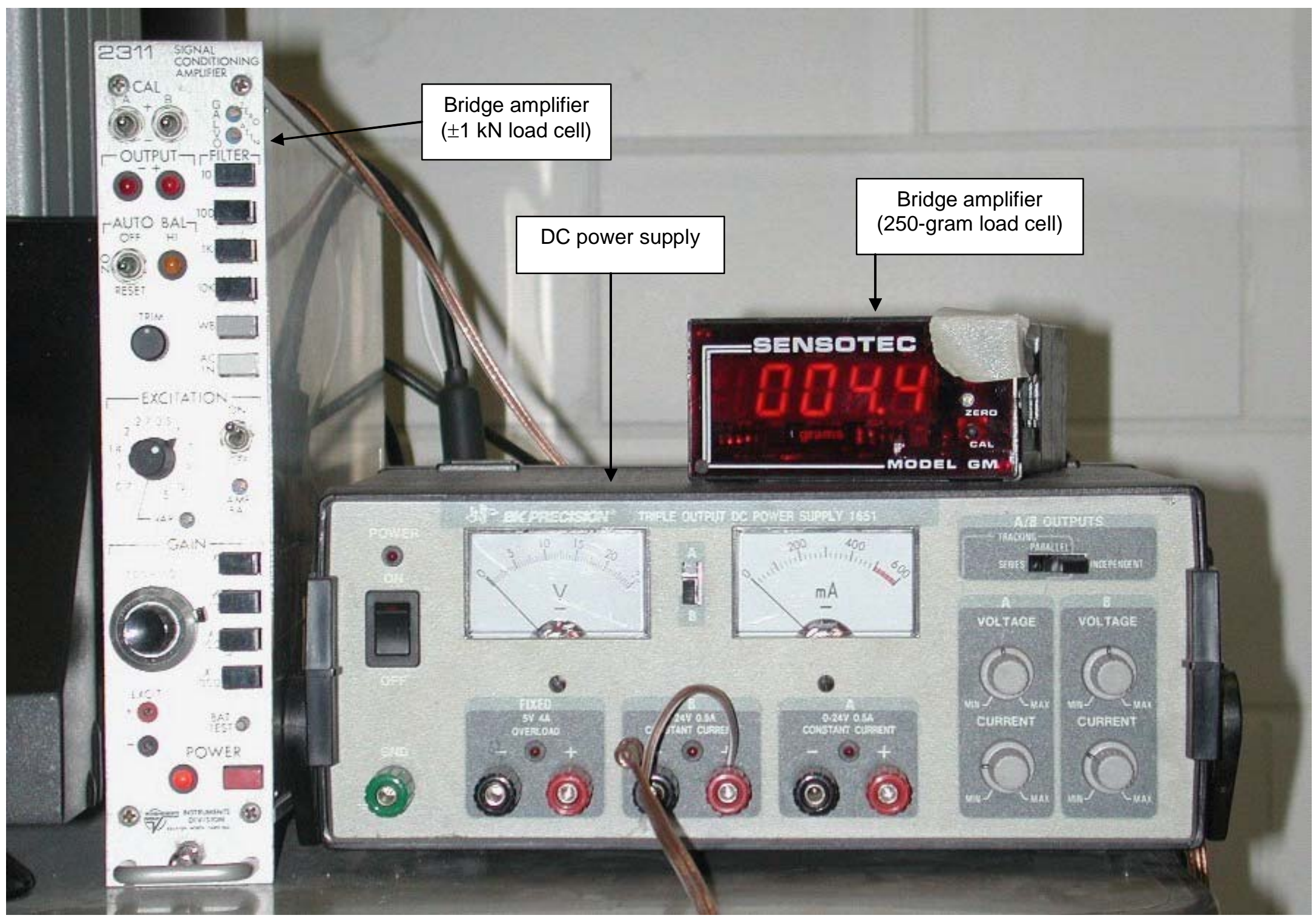

Figure 10. DC power supply and two bridge amplifiers. 


\section{TEST TRIAL INTERVALS}

Each trial will consist of 120 seconds in length and the intervals are provided below:

0-15 seconds noise /offset (no archwire pull and no variable moments)

15 seconds begin archwire pull superiorly at a crosshead speed of 5 $\mathrm{mm} / \mathrm{min}$

30 seconds bracket angle turned to 2.7 degrees

45 seconds $\quad$ bracket angle turned to 4.9 degrees

60 seconds $\quad$ bracket angle turned to 5.4 degrees

75 seconds $\quad$ Motor to rotating cam turned on.

105 seconds Instron machine stopped and only rotating cam on.

120 seconds All data collection finished.

At each of the time changes above, a trigger was used to identify points on the data screen.

After each trial, the archwire and bracket-rod assembly were removed and replaced with new ones. Ligation was also replaced each time.

\section{DATA COLLECTION AND EVALUATION}

As stated above, all data was collected (DC voltages) and scaled by the computer using Labtech software. Each bracket-archwire combination was tested 5 times. Measurements were taken every tenth of a second ( 0.10 seconds/measurement) for 120 seconds for both load and friction values. Load was in units of gram-centimeters, due to the lever arm length, while friction was in units of grams. The raw data was transferred to Microsoft Excel 2000, where the appropriate titles for archwires, brackets and trial number were placed. Headings for each of the 4 columns (time, load, friction, and 
trigger) were also assigned. The first 10 seconds of the load data was averaged and this value was then subtracted from all the load data and multiplied by 10 to obtain the true load. This was necessary because the amplifier connected to the 250-gram load cell recording the load data was not reset to zero prior to each trial. However, the friction data was not adjusted because the amplifier connected to the $\pm 1 \mathrm{kN}$ load cell used to measure friction was reset to zero prior to each trial. An example is shown below (Table 1).

\begin{tabular}{|c|c|c|c|c|}
\hline $\begin{array}{c}\text { Time } \\
\text { seconds }\end{array}$ & $\begin{array}{l}\text { torque } \\
\mathrm{gm}-\mathrm{cm}\end{array}$ & $\begin{array}{l}\text { friction } \\
\mathrm{gm}\end{array}$ & trigger & $\begin{array}{c}\text { angle } \\
\text { degrees }\end{array}$ \\
\hline 0 & -1.9453 & -4.8828 & 0 & 58.2563 \\
\hline 0.1 & -1.7021 & -4.8828 & 0 & 58.3555 \\
\hline 0.2 & -1.9453 & -4.8828 & 0 & 58.1572 \\
\hline 0.3 & -1.7021 & -4.8828 & 0 & 58.2563 \\
\hline 0.4 & -1.9453 & -4.8828 & 0 & 58.2563 \\
\hline 0.5 & -2.1885 & -4.8828 & 0 & 58.2563 \\
\hline 0.6 & -1.9453 & -4.8828 & 0 & 58.1572 \\
\hline 0.7 & -1.9453 & -4.8828 & 0 & 58.2563 \\
\hline 0.8 & -1.9453 & -4.8828 & 0 & 58.0581 \\
\hline 0.9 & -2.1885 & -4.8828 & 0 & 58.2563 \\
\hline 1 & -1.7021 & -4.8828 & 0 & 58.2563 \\
\hline
\end{tabular}

Table 1: Sample of data.

Data from every trial was graphed using Microsoft Excel 2000. Two y-axes were placed on each graph. Friction (gm) was on the left y-axes and Load $(\mathrm{gm}-\mathrm{cm})$ was on the right y-axes. The x-axis was labeled Time (seconds). An example is shown below in Figure 11.

For each trial of bracket/wire/ligature, static friction was calculated as the maximum friction value between 14 and 16 seconds. Kinetic friction was calculated at each test angle by averaging data for a ten second interval. Dynamic friction was calculated by averaging data for a ten second interval while the cam rotated. 


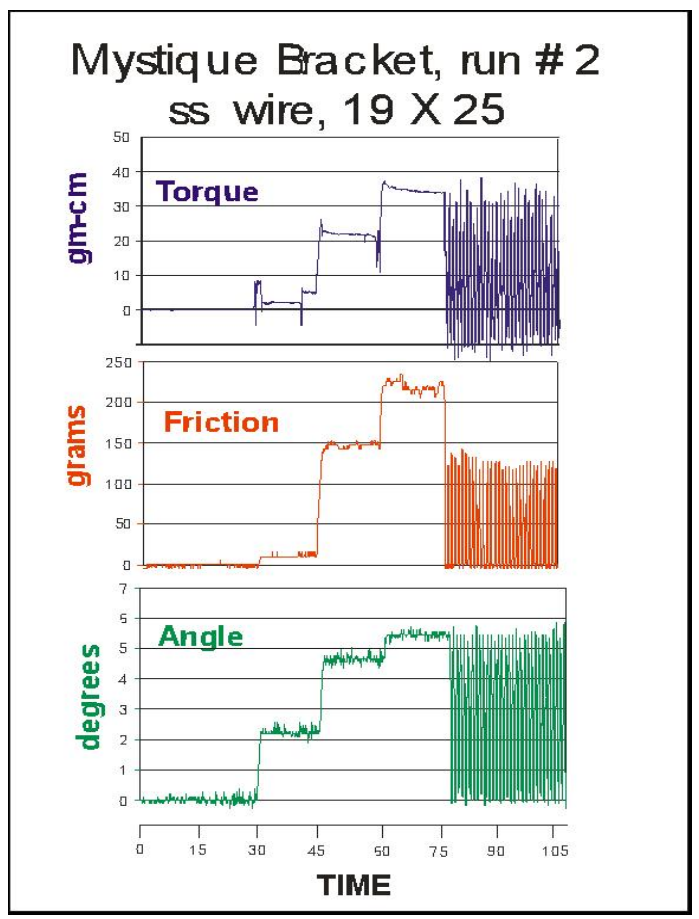

Figure 11. Sample graph of raw data.

\section{DATA ANALYSIS}

Data was analyzed to compare:

1) static, kinetic and dynamic friction

2) dynamic friction and dynamic load

3) dynamic load and apparent stiffness

4) ligation method

5) archwire sizes

6) contact angles

\section{STATISTICS}

JMP version 3.1.5 statistical analysis software was used to calculate ANOVA $(p<0.0001)$ and Tukey-Kramer Honest Significant Difference (HSD) $(p<0.05)$. Microsoft Excel 2000 was used to calculate the average friction and standard deviation. 


\section{STANDARDIZATION OF THE TESTING MACHINE}

A preliminary standardizing technique was conducted to determine:

1) if the apparatus and data collection software were functioning properly

2) if the frictional resistance at the bracket-archwire interface was proportional to the load

3) to see if the brackets being tested had indeed differing amounts of friction

4) if the cyclic rotating variable moment at the bracket-archwire interface influenced friction.

Brackets used in the standardization were: Transcend (Unitek), Mystique (GAC), Clarity (Unitek), and MicroArch (GAC). The pilot study did not use any method of ligation. Two archwires were used: .014 Round Nickel-Titanium and 18X25 Stainless Steel, with upper bicuspid brackets with .022 slots. Four brackets were tested: GAC's Mystique and MicroArch along with Unitek's Clarity and Transcend. The Transcend bracket was added as a positive control, a bracket with a significant friction and antidotal prolonged treatment times. The metal MicroArch bracket served as a negative control, a bracket with minimal friction.

Brackets were bonded to one end of a quarter inch diameter acrylic rods with cyanoacrylate cement. A dental surveyor and modified pin were utilized to position the bracket slot in the middle of the acrylic rod. In addition, the surveyor pin positioned each bracket's slot perpendicular to the long axis of the acrylic rod negating the effects of bracket prescription. 
The testing apparatus of Mah et al (Mah J Dent Res, 2003) was modified to enable the application of a variable tipping torque to be applied to the bracket while recording the friction, tipping torque and angle similar to Omana (Omana JCO, 1992).

The bracket-acrylic rod assembly was mounted in the test fixture. The archwire was inserted into the bracket slot and attached to the crosshead of the testing machine. The wire was guided by the bearing of the test fixture. No ligatures were used. Ligatures are a confounding variable. Without ligatures, an extraneous variable is eliminated. The measurements focused on the friction of the bracket/wire interface. In the test fixture, the acrylic rod was connected to the lever arm of the offset cam. The rotating cam moved the lever up and down on one end, rotating the acrylic rod and the bracket on the other end.

The bracket was tipped to four fixed angles: $0,2.7,4.9$, and 5.9 degrees by hand and friction measured by pulling the wire through the bracket. After measuring friction at each fixed angle, variable cyclical tipping angle and torque from 0 to 5.9 degrees was applied via the rotating cam and lever arm, and dynamic friction measured. Each combination of bracket and archwire was tested three (Ni-Ti) or five (SS) times. Each test run utilized a new bracket and wire segment.

Multiple data channels were recorded via an analog to digital conversion board in a PC. Data was analyzed with the MS Excel spreadsheets and JUMP statistical software. The information obtained from the pilot study enabled us to replicate results of previous research and to predict the data obtained when the remaining brackets and archwires were studied.

The wires were pulled through the bracket without any ligation first to establish a baseline. The ligation methods were then employed in the following order: 
1)Elastomeric 2).009 Stainless steel ligature wires 3) self ligation. Each combination was run 5 successive times, changing the ligation method and wire each time.

The ceramic brackets were selected due to their popularity and the original Transcend ceramic bracket for its alleged high friction. The SmartClip self-ligating brackets were chosen due to their new design, a nickel-titanium clip that requires no opening or closing. Perhaps most important with this bracket is the familiar twin bracket design that lets orthodontist keep their preferred treatment mechanics. The wires were chosen due to their popularity and frequent use in sliding mechanics. 


\section{CHAPTER IV RESULTS AND DISCUSSION}

\section{INTRODUCTION}

The main objective of this project was to study friction between brackets, wires, and ligation methods. There are three types of friction. Static friction is the smallest force needed to begin the movement of an object across another that was previously at rest with each other; kinetic friction is the force that resists the sliding of these objects past one another at a constant speed; dynamic friction was defined in this study as the frictional force that occurs when the applied (normal) force is variable (dynamic load). Static and kinetic frictions were very similar and were combined and presented as a zero degree angle data. Friction was measured and analyzed for each combination of bracket, wire, ligation method, and angle.

\section{OVERALL RESULTS}

The results of the entire study are presented in Table 2. Each bracket and wire combination for both the self ligating brackets and the non-self ligating brackets/(BLS) are shown with data for all angles averaged. The BLS had two different methods of ligation: stainless steel and alastic o-rings, both of which are presented. The table indicates that with each bracket the friction increased with increasing wire size $(018$, 19X25, and 21X25). The friction of the 018 wire, was the lowest with the SmartClip and highest with the Clarity ligated bracket. With the 19X25 stainless steel wire, the friction was again lowest for the SmartClip and highest for the Clarity ligated bracket. Lastly, for the $21 \mathrm{X} 25$ wire, the metal bracket with the stainless steel ligature had the lowest amount of friction and the Mystique bracket with stainless steel ligation had the highest. 


\begin{tabular}{|c|c|c|c|c|c|}
\hline $\begin{array}{c}\text { Bracket } \\
\text { Types }\end{array}$ & $\begin{array}{l}\text { Wire } \\
\text { Size }\end{array}$ & $\frac{\text { Alastic Ligation }}{\begin{array}{c}\text { Mean Friction } \\
\text { (grams) }\end{array}}$ & S.E. & $\frac{\text { SS Ligation }}{\begin{array}{c}\text { Mean Friction } \\
\text { (grams) }\end{array}}$ & S.E. \\
\hline Clarity & 18 & 150 & 46 & 58 & 50 \\
\hline Clarity & $19 \times 25$ & 182 & 60 & 404 & 117 \\
\hline Clarity & $21 \times 25$ & 293 & 92 & 296 & 88 \\
\hline Metal & 18 & 150 & 81 & 59 & 58 \\
\hline Metal & $19 \times 25$ & 130 & 145 & 185 & 172 \\
\hline Metal & $21 \times 25$ & 217 & 92 & 343 & 257 \\
\hline Mystique & 18 & 94 & 56 & 93 & 55 \\
\hline Mystique & $19 \times 25$ & 229 & 139 & 371 & 279 \\
\hline Mystique & $21 \times 25$ & 422 & 247 & 439 & 298 \\
\hline $\begin{array}{l}\text { SmartClip } \\
\text { self ligating }\end{array}$ & 18 & 43 & 59 & & \\
\hline SmartClip & $19 \times 25$ & 120 & 142 & & \\
\hline SmartClip & $21 X 25$ & 347 & 315 & & \\
\hline $\begin{array}{l}\text { InvR } \\
\text { self ligating }\end{array}$ & 18 & 70 & 95 & & \\
\hline InvR & $19 \times 25$ & 299 & 193 & & \\
\hline InvR & $21 \times 25$ & 417 & 301 & & \\
\hline
\end{tabular}

Table 2. Overall Results (all brackets and ligation with all angles averaged). OVERVIEW OF THE PROJECT

The results were separated into two experiments (Experiment 1 and Experiment

2), since two types of bracket/ligation systems were used in this study; self ligating and 
non-self ligating brackets. With the increasing popularity of self ligating brackets, two brackets of this group were used. Self ligating brackets have a method of securing the wire into place incorporated into the bracket system. They are noted for reducing friction

during tooth movement. ${ }^{73}$ Three non-self ligating brackets were used; GAC MicroArch metal (control), 3M Unitek Clarity, and GAC Mystique. The latter two are ceramic brackets which are increasing in popularity with treatment of the adult population. The non-self ligation brackets were used with two ligation techniques, alastic and stainless steel ligation.

Experiment 1 analyzed all BLS. The rationale for including all systems was to compare the self ligating brackets with the non-self ligating brackets. The non-self ligating brackets had to be ligated, hence bracket ligature system, (BLS) were analyzed in Experiment 1.

Experiment 2 analyzed data from only the non-self ligating brackets to focus on the effects of ligation method. It was designed to compare the importance of the bracket with the ligature factor.

\section{EXPERIMENT 1 (ALL BRACKET LIGATURE SYSTEMS)}

ANOVA showed significant differences among the: wire size, bracket-ligature system (BLS), wire-BLS interaction, stage (tipping angle), and wire-stage interaction. Dynamic friction was not considered.

\section{GENERAL RESULTS FOR EXPERIMENT 1}

Mean differences in friction were grouped by wire size, Table 3. Significant differences were found at $p<.0001$. All wire sizes were significantly different from the others based on the Tukey-Kramer analysis. Generally, as wire size increased the mean 
friction also increased. The 018 stainless steel wire had the lowest mean friction and the $21 \mathrm{X} 25$ stainless steel wire had the highest friction. The data range was 257 grams. There was a wide range of friction between the wire sizes, indicating that there was a significant friction component depending on the wire used.

\begin{tabular}{|c|c|c|cr|}
\hline Wire Size & $\begin{array}{c}\text { Mean Friction } \\
\text { (grams) }\end{array}$ & S.E. & \multicolumn{2}{|c|}{ Level } \\
\hline 21 X25 & 347 & 13 & A & \\
\hline 19 X25 & 240 & 13 & & B \\
\hline 018 & 90 & 13 & & C \\
\hline
\end{tabular}

Levels not connected by same letter are significantly different

Table 3. Mean friction for each wire, all BLS and stages averaged.

The BLS was also a significant factor at $p<.0001$. The brackets with the stainless steel ligature system on the average had a higher friction than those with the alastic method of ligation. All wires at every stage in the testing procedure were averaged together in table 4 . The data range from the 018 stainless steel to the $21 \mathrm{X} 25$ stainless steel wires was 135 grams within the BLS for eight different bracket combinations. The significance was not as much for the bracket ligature systems as was seen with the wire sizes only. 


\begin{tabular}{|c|c|c|c|}
\hline Bracket Ligature System & $\begin{array}{c}\text { Mean Friction } \\
\text { (grams) }\end{array}$ & S.E. & Level \\
\hline MystiqueSS & 301 & 21 & $\mathrm{~A}$ \\
\hline InvRselflig & 262 & 21 & A B \\
\hline ClaritySS & 248 & 21 & A $\quad$ B $\quad$ C \\
\hline MystiqueAlastic & 209 & 21 & A $\mathrm{B} \quad \mathrm{C}$ \\
\hline ClarityAlastic & 209 & 21 & $\mathrm{~B} \quad \mathrm{C}$ \\
\hline MetalSS & 196 & 21 & $\mathrm{~B} \quad \mathrm{C}$ \\
\hline SmartClipselflig & 170 & 21 & $\mathrm{C}$ \\
\hline MetalAlastic & 166 & 21 & $\mathrm{C}$ \\
\hline
\end{tabular}

Levels not connected by same letter are significantly different Table 4. Mean friction for each BLS.

The wire-bracket ligature system (BLS) interaction was also found to be significant at $p<.0001$ (Figure 12). The differences in the mean friction between the wires depended on different bracket ligature system used. When using the 21X25 stainless steel archwire generally experienced higher friction regardless of the bracket ligature system. The Clarity with stainless steel ligation had a lower friction with the 21X25 wire than the 19X25 wire. Figure 12 shows the different wire sizes with each bracket ligature system. 


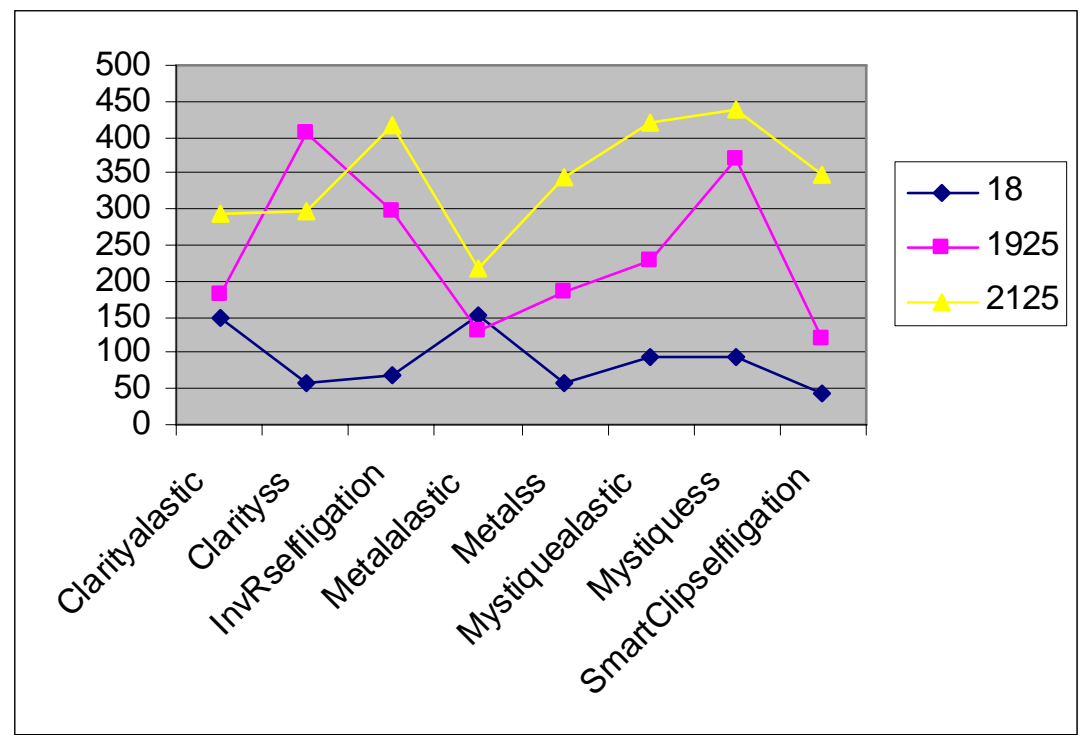

Figure 12. Wire-BLS graph.

The stage or the tipping angle factor that was used was also significant at $\mathrm{p}<.0001$. As the angle increased from 0 degrees to 5.4 degrees, the mean friction gradually increased as seen in Figure 13. Certain angles were significantly different than others when analyzed with the Tukey-Kramer. For 0 to 2.7 degrees there was no significance and from 4.9 to 5.4 degrees there was also no significance in the angle. All other angles were significant from one another. The range for the stage factor was 131 grams, although statistically significant the range was not as great as with other factors, Figure 13.

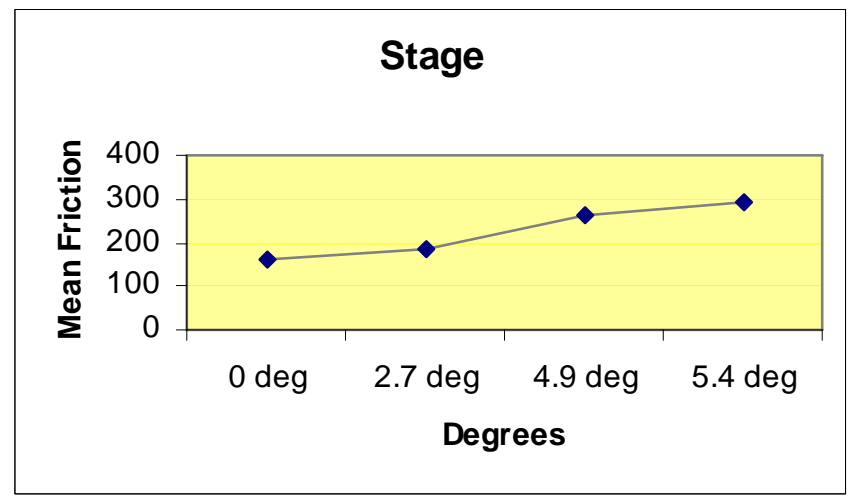

Figure 13. Stage and mean friction for all wires and bracket ligature systems. 
The wire-stage interaction was significant at $p<.0006$. As mentioned before the wire size and the angle both increased the friction. There were differences in the friction between the wires used depending on the angle that was involved. When the wire increased in size and at the same time increased to a larger angle, the friction increased gradually. Figure 14 shows the lowest friction to be the 018 stainless steel wire at 0 degrees. The $21 \mathrm{X} 25$ stainless steel wire had the highest friction at 5.4 degrees.

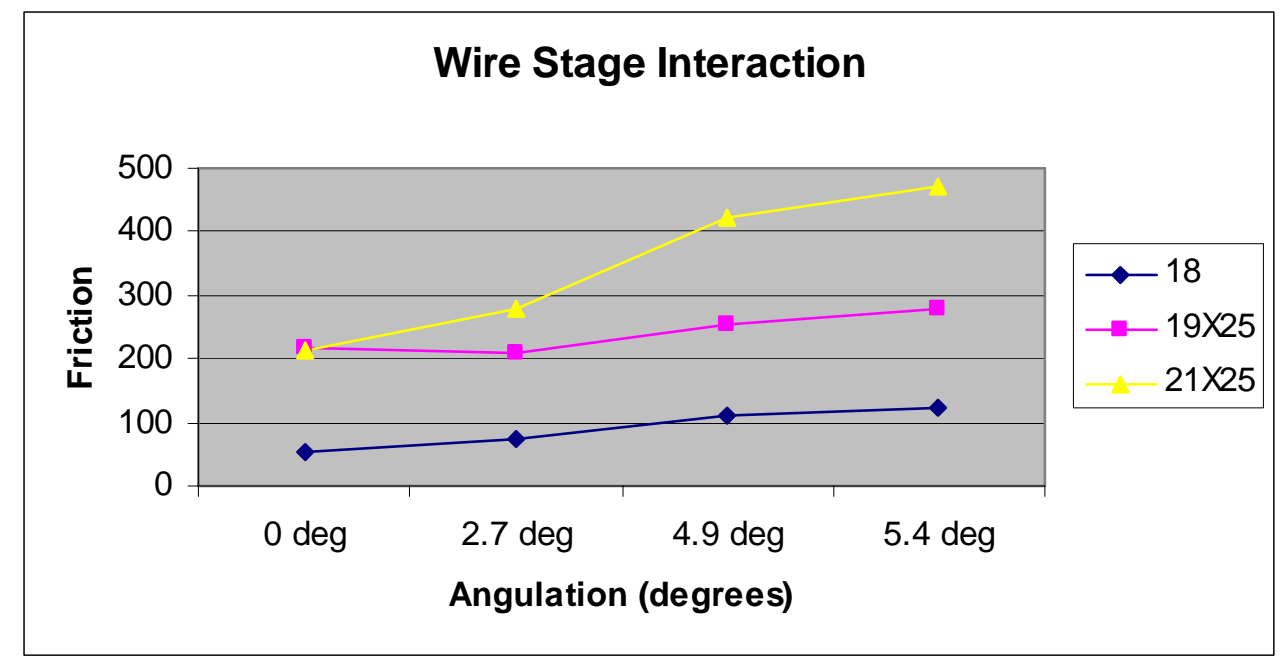

Figure 14. Wire-stage interaction.

\section{WIRE-BLS INTERACTION}

Since there was a significant BLS- wire interaction, each wire/bracket ligature system (BLS) combination was analyzed. This included all the brackets, self ligating and non-self ligating brackets. Mean friction for each BLS was compared for each wire size. Wire size as mentioned previously is essential to maintain lower friction during tooth 
movement. The range of friction in grams for wire size has had the greatest impact of all other factors and interactions, therefore each wire will be analyzed within each BLS.

\section{STAINLESS STEEL WIRE}

For the .018 stainless steel wire, the alastic method of ligation had a higher friction when compared to the stainless steel ligation for all brackets. The Metal bracket with the alastic ligation had the highest friction. The SmartClip bracket had the lowest mean friction. The range in the friction averages was 92 grams. The results of the Tukey-Kramer are shown below in Table 5.

\begin{tabular}{|c|c|c|c|}
\hline Bracket Ligature System & $\begin{array}{c}\text { Mean Friction } \\
\text { (grams) }\end{array}$ & S.E. & Level \\
\hline MetalAlastic & 151 & 14 & A \\
\hline ClarityAlastic & 150 & 14 & A \\
\hline MystiqueAlastic & 94 & 14 & A B \\
\hline MystiqueSS & 93 & 14 & A B \\
\hline InvRselfligation & 70 & 14 & B \\
\hline MetalSS & 59 & 14 & B \\
\hline ClaritySS & 58 & 14 & B \\
\hline SmartClip selfligation & 43 & 14 & B \\
\hline
\end{tabular}

Levels not connected by same letter are significantly different

Table 5. 018wire-BLS Tukey-Kramer. 


\section{X25 STAINLESS STEEL WIRE}

The Clarity with stainless steel ligation had the highest friction and the SmartClip self ligation had the lowest. There was also a broad range of 284 grams in the mean friction. As can be seen in Table 6, the range for this wire was not as large as it was between some of the other bracket ligature systems. The results of the Tukey-Kramer are shown in Table 6.

\begin{tabular}{|c|c|c|ccc|}
\hline Bracket Ligature System & $\begin{array}{c}\text { Mean Friction } \\
\text { (grams) }\end{array}$ & S.E. & Level & \\
\hline ClaritySS & 404 & 37 & A & \\
\hline MystiqueSS & 371 & 37 & A & B \\
\hline InovationRselfligation & 299 & 37 & A B C & \\
\hline MystiqueAlastic & 229 & 37 & 37 & C \\
\hline MetalSS & 185 & 37 & & C D \\
\hline ClarityAlastic & 182 & 37 & & D & D \\
\hline MetalAlastic & 130 & 37 & & D \\
\hline SmartClipselfligation & 120 & 37 & & \\
\hline
\end{tabular}

Levels not connected by same letter are significantly different

Table 6. 19X25 Tukey Kramer.

\section{X25 STAINLESS STEEL WIRE}

The one way ANOVA showed a significant difference among BLS for this wire. However no significant differences were found with the Tukey-Kramer. A Student's test did yield significant differences. Again, like the 19X25 stainless steel wire group the stainless steel method of ligation yielded the higher friction compared to the alastic. The Mystique with the stainless steel ligation exhibited the highest friction and the metal with 
the alastic had the lowest friction. The range here was also very large at 222 grams of friction between the highest friction and the lowest friction. Some of the bracket ligature systems however were very comparable in the amounts of mean friction. Results of the Tukey-Kramer and Students' t test are shown in Table 7.

\begin{tabular}{|c|c|c|c|}
\hline $\begin{array}{c}\text { Bracket Ligature } \\
\text { System }\end{array}$ & $\begin{array}{c}\text { Mean Friction } \\
\text { (grams) }\end{array}$ & S.E. & Level \\
\hline MystiqueSS & 439 & 52 & $\mathrm{~A}$ \\
\hline MystiqueAlastic & 422 & 52 & A $B$ \\
\hline InovationRselfligation & 417 & 52 & A $\mathrm{B}$ \\
\hline SmartClipselfligation & 347 & 52 & A $\quad$ B $\quad$ C \\
\hline MetalSS & 343 & 52 & A $\quad$ B $\quad$ C \\
\hline ClaritySS & 296 & 52 & A $B \quad C$ \\
\hline ClarityAlastic & 293 & 52 & B C \\
\hline MetalAlastic & 217 & 52 & $\mathrm{C}$ \\
\hline
\end{tabular}

Levels not connected by same letter are significantly different

Table 7. 21X25 Students' t test.

\section{EXPERIMENT 2 (NON-SELF LIGATING BRACKETS)}

Friction was analyzed to compare two factors, ligation and bracket.

It was important to compare the two ligation components where they could be changed. The two ligation methods were stainless steel and alastic rubber bands. Brackets were two ceramics, Clarity and Mystique, and one metal bracket (control). ANOVA analyzed the bracket and the ligation factors only. 


\section{BRACKET FACTOR}

The ANOVA and Tukey Kramer analyses showed significant differences between the brackets. The Mystique bracket overall had the highest friction. The metal bracket had the lowest overall friction. The range for these three brackets was not that large, approximately 94 grams of friction. The results of the different bracket types are seen in Table 8.

\begin{tabular}{|c|c|c|cc|}
\hline Bracket & $\begin{array}{c}\text { Mean Friction } \\
\text { (grams) }\end{array}$ & S.E. & \multicolumn{2}{|c|}{ Level } \\
\hline Mystique & 275 & 13 & $\mathrm{~A}$ & \\
\hline Clarity & 231 & 13 & \multicolumn{2}{|c|}{$\mathrm{B}$} \\
\hline Metal & 181 & 13 & & $\mathrm{C}$ \\
\hline
\end{tabular}

Levels not connected by same letter are significantly different

Table 8. Bracket Factor Tukey-Kramer.

\section{LIGATION}

The ligation component was also significant with the ANOVA and Tukey Kramer analysis. The stainless steel method of ligation had the highest overall friction and the alastic had the lowest. The range was approximately 42 grams of friction. The results are described in Table 9. 


\begin{tabular}{|c|c|c|c|}
\hline Ligation Component & $\begin{array}{c}\text { Mean Friction } \\
\text { (grams) }\end{array}$ & S.E. & Level \\
\hline SS & 250 & 11 & A \\
\hline Alastic & 208 & 11 & B \\
\hline
\end{tabular}

Levels not connected by the same letter are significantly different.

Table 9. Ligation Factor Tukey-Kramer.

\section{COMPARISONS OF LIGATION METHOD FOR EACH WIRE}

All the brackets and all the tipping angles averaged together to compare the friction utilizing each ligation method in the three different wire sizes. The 018 stainless steel archwire exhibited the highest amount of friction in the alastic method of ligation and the self ligation had the lowest amount of friction. The overall results can be seen in Figure 15.

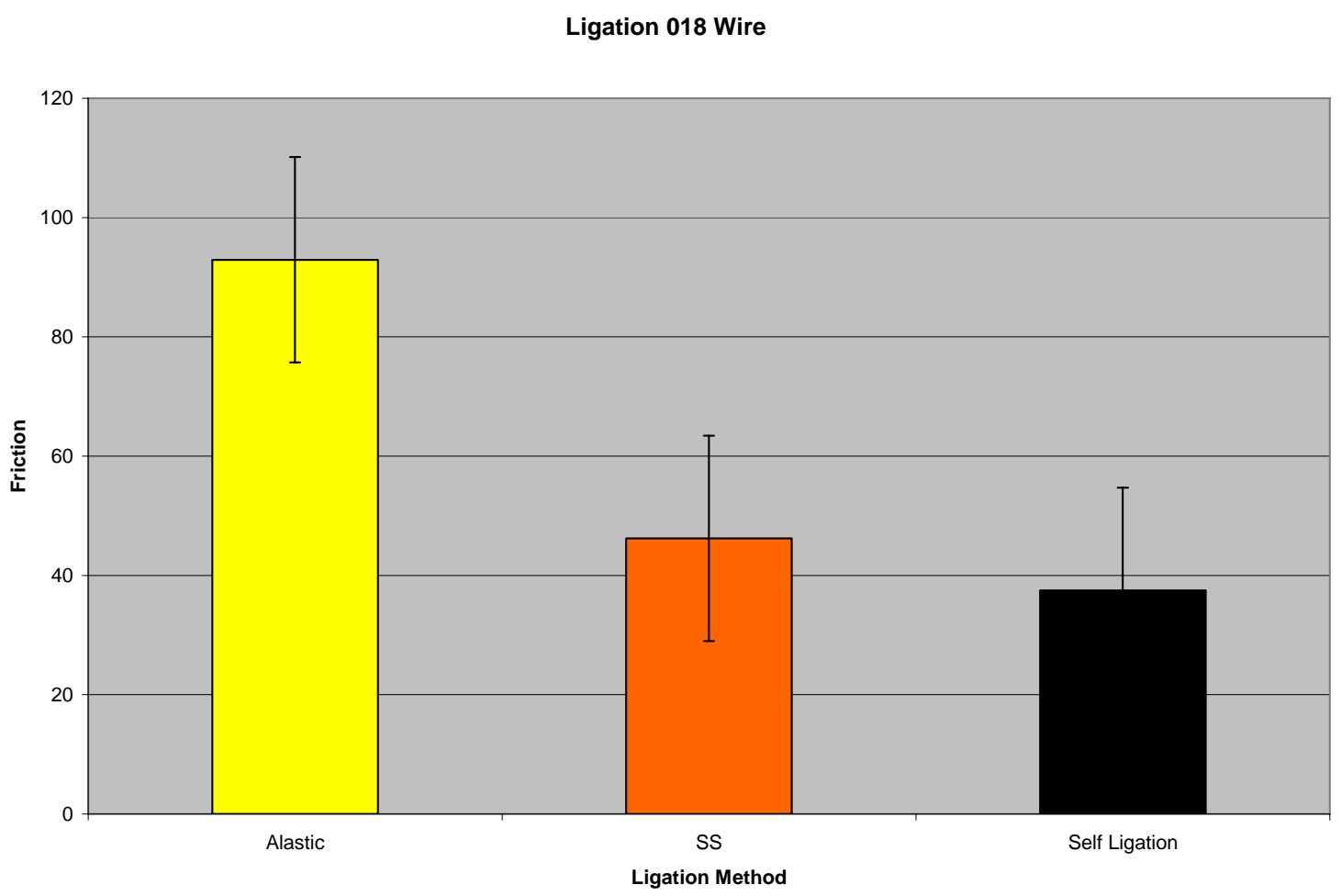

Figure 15. All brackets and ligation with 018 wire. 
When the 19X25 stainless steel archwire was compared utilizing all brackets and tipping angles the results were different than the 018 stainless steel archwire. The stainless steel method of ligation had the highest friction and the alastic had the lowest, however the self ligation was also low in friction. These results can be seen in Figure 16.

Ligation 19x25

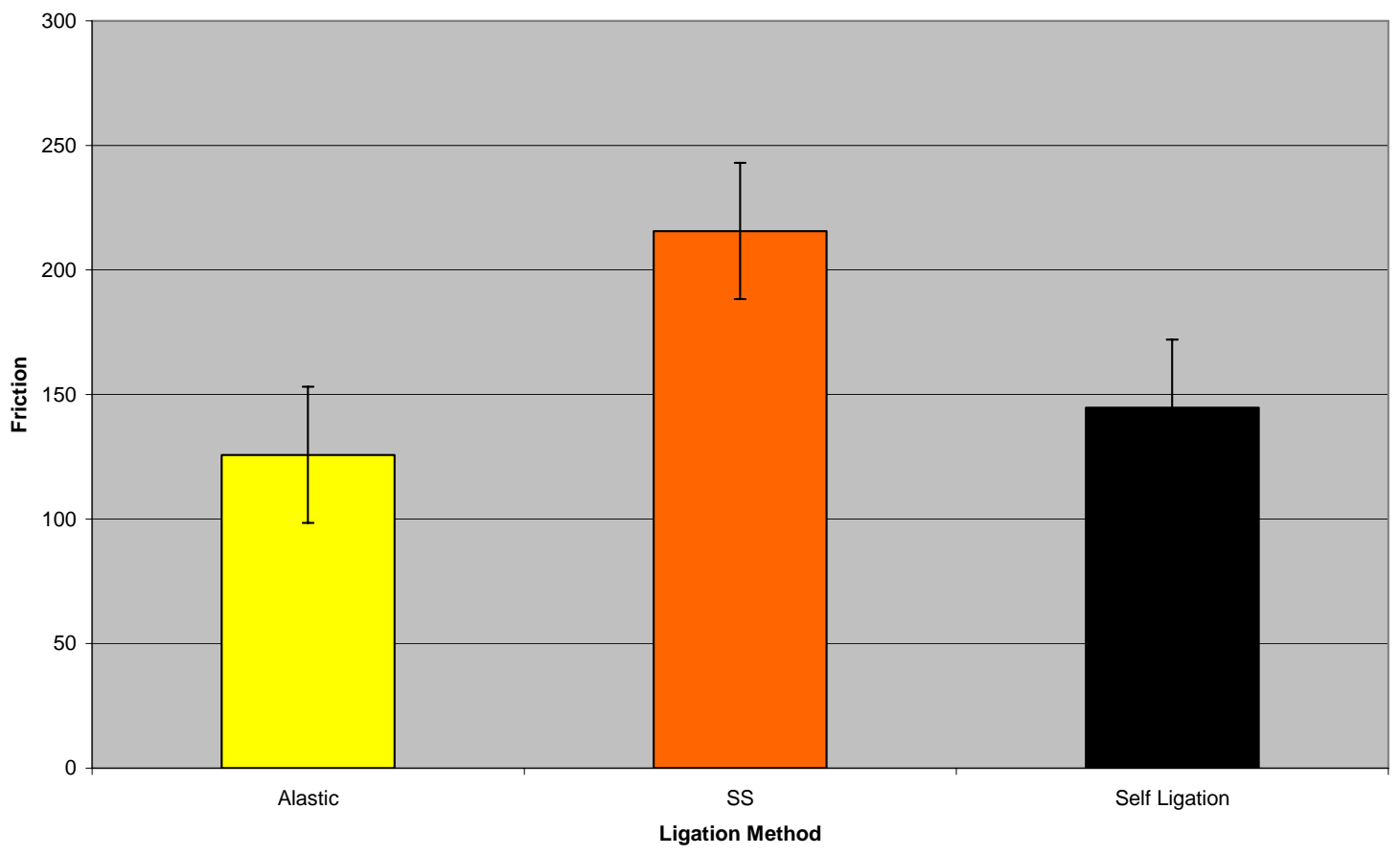

Figure 16. All brackets and ligation with 19X25 wire.

The 21X25 wire had different results also. The self ligating group of brackets had the highest amount of friction and the alastic method of ligation had the lowest. The range between the groups here was very small. The results can be seen in Figure 17. 
Ligation 21×25

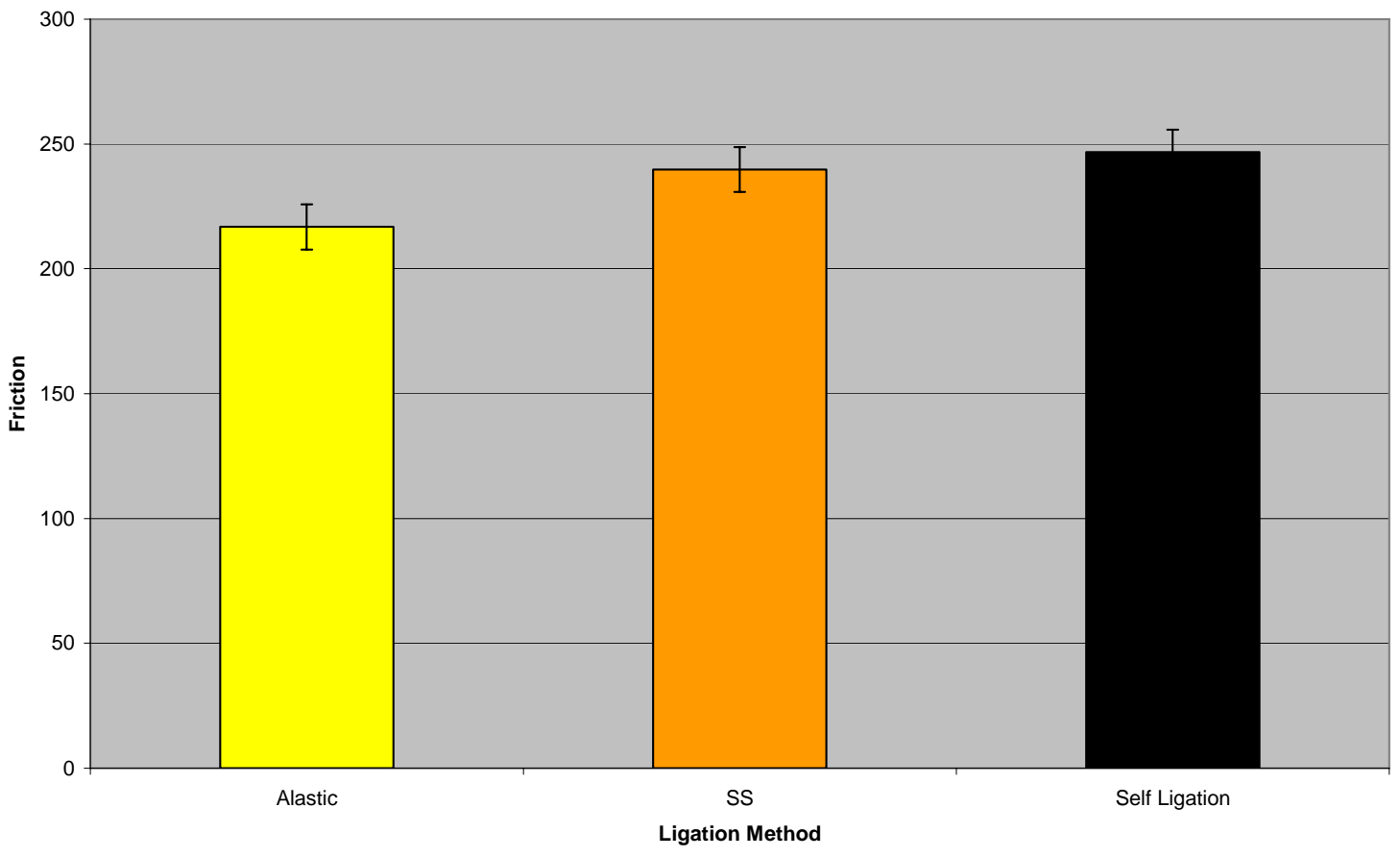

Figure 17. All brackets and ligation with 21X25 wire. 


\section{DISCUSSION}

\section{INTRODUCTION}

Many studies have been done involving friction and archwires. Most of these studies rely on simply pulling an archwire superiorly and quantifying the friction present in the wire. ${ }^{11,33,39}$ The focus of this study was to simulate a more realistic setup with archwires ligated to the brackets and then placing variable moments on bracket and wire. The angulations that was present of the wire/bracket imitated movement of teeth. More specifically, three stainless steel archwires were tested with five different brackets, and four different angles. In addition, the ligation factor included: self-ligation, alastic, and stainless steel ligation.

\section{FRICTION TYPES}

Static friction and kinetic friction in this study were similar. Previous research stated that static friction was greater than kinetic friction ${ }^{1,4}$ however this amount was negligible and was not presented in the results section. The difference when evaluated by the Tukey-Kramer HSD analysis, at an alpha level of 0.05 , was not statistically significant.

These results are clinically significant during tooth movement. There is always static friction present between the archwire and bracket and this force must be overcome if a tooth is allowed to move. Once this initial tooth movement has occurred, the kinetic friction must be overcome to allow the tooth to continue to move. ${ }^{1}$ This is most often accomplished with orthodontic devices such as rubber bands, power chain, nickeltitanium coils, or closing loops incorporated into the archwire. 
A tooth does not translate linearly along an archwire. Tooth movement occurs by a process of the crown tipping then crown uprighting. The tooth tips and uprights along the archwire, therefore archwire binding occurs during various times along the wire. This is an extremely important concept and must be recognized. When the crown tips it will bind to the archwire and at that point increase friction. ${ }^{5}$ Tooth movement during that binding moment, the friction is the greatest and must be overcome. In a clinical setting, friction is a dynamic phenomena. Dynamic friction is overcome and a force must be placed on the tooth that is greater than the binding force that impedes tooth movement.

Variable moments tipped the bracket to a total range of 0 to $5.4^{\circ}$, creating a variable bracket-archwire angle to study dynamic friction. The archwire was subjected to cyclical binding and releasing actions against the bracket slot, due to bracket tipping. As binding occurred, the friction increased until the moment (angulation) was rotated back to zero degrees. Clinically, this tooth movement would occur if 1) a release of any binding present at the bracket-archwire interface and 2) if the bracket ligation system was deemed to have lower friction so kinetic friction could be overcome sooner.

This study attempted to clarify the effects of bracket, ligation, angle, and archwire on friction. Actually, if the right combination is used at the right time, friction will be reduced significantly. Elastomeric and stainless steel ties along with self-ligating clips were investigated. The results of this study were similar to those earlier done by O'Reilly, Braun and Liew. ${ }^{9104,103}$ They stated that with variable archwire deflection, frictional resistance was either reduced or momentarily became zero, due to the release of binding. This was evident when the angle was reduced, when the angle was 5.4 degrees the most binding occurred and when it was 0 degrees the friction was the lowest. 


\section{EXPERIMENT 1}

\section{WIRES}

When all of the brackets were grouped together to compare the non-self ligating brackets to the self ligating brackets, self ligating brackets had lower friction. This was consistent with previous research. ${ }^{73}$ The smaller the wire size had the lower mean friction within the bracket system. The friction steadily increased with the larger archwires used in the study $19 \mathrm{X} 25$, and $21 \mathrm{X} 25$ stainless steel. This is consistent with previous studies including the classic work by Frank and Nikolai when they stated that increased wire diameter increased friction. ${ }^{5,18,19,20}$ At the same time this study contradicted the results of Sims study where he found that archwire size does not necessarily contribute to friction. ${ }^{26}$ Therefore in an ideal situation tooth movement should occur with a smaller round wire and have the least amount of binding within the bracket. This opposes the idea of Tidy et al, he stated that decreasing archwire size allowed more tipping and causes more binding to occur. ${ }^{27}$

Friction has always been a factor during tooth translation. Most orthodontists will work up to a larger rectangular stainless steel archwire to translate teeth. There is a larger frictional value with increasing wire size, therefore the clinician must overcome this increase in friction with larger forces in order to successfully move teeth. There are some benefits to the larger archwire. When teeth are being translated the torque, tip, and angulation are prebuilt into the bracket prescription. Also, the more the archwire fills the slot size of the bracket the more the expression of the prescription will be seen. Therefore, if there is a larger distance for tooth translation to occur, and torque and angulation is of concern to the clinician, a higher friction $19 \mathrm{X} 25$ or $21 \mathrm{X} 25$ wires should 
be used. On the other hand, if the movement is minimal and these factors are not a concern, the 018 wire would clearly be the better choice due to lower friction.

\section{BLS}

When all the bracket systems were compared with all types of ligation (alastic, stainless steel, and self ligation) the results were variable.

The stainless steel method of ligation was the most variable during the laboratory simulation. This was consistent with previous reports by Nanda, he stated ligation techniques can range from 50 to 300 grams. ${ }^{38}$ Braun's et al study was also done with variable tipping angles and he found that steel ligation had no influence on the friction. ${ }^{104,33}$ The operator tried to be consistent on tying each archwire into the bracket, regardless of the attempted consistency; the alastic and self ligation were much more consistent. The orthodontist will face this same situation clinically where friction can be increased or reduced depending on how the bracket was tied in with the stainless steel method of ligation. These findings in the laboratory are similar to those found by Bednar $^{44}$, he stated that loosely tied ligatures are thought to provide less friction than the elastic counterparts. Therefore the operator can increase or decrease the friction that is placed on the wire by the technique that is used.

The twin metal bracket with alastic ligation, which served as our control, had the lowest friction. The self ligation brackets as well as the ceramic brackets had a higher amount of friction. This was consistent with the previous results done by Pratten and Kusy, they stated that stainless steel brackets had lower friction than the ceramic brackets. ${ }^{16,56}$ This friction takes into account all methods of ligation analyzed together. With the increased awareness of ceramic brackets and esthetic brackets the orthodontist 
must recognize that ligation affects the friction. Depending on the bracket and ligation method used the friction can increase significantly. With self ligating brackets, chair time will be reduced because the orthodontist does not have to take the time to ligate every bracket to the wire. Whereas simply using a self ligating bracket may not reduce friction.

\section{WIRE-BLS INTERACTION}

This perhaps is the most important interaction measured in Experiment 1 with all the brackets. Differences between BLS depended on the wire used. Although a system was created with multiple variables, wire, bracket, angle, and ligation; the most important factor still is the wire size. Clinically smaller round wires will reduce friction significantly more than larger rectangular stainless steel ones. For simplicity the bracket ligature systems were analyzed by the different wire sizes. This takes into account tooth movement in the mouth without the tipping of the brackets. Although this is not realistic clinically, it is reliable from the standpoint of the wire being seating into the bracket slot by the ligation method.

\section{WIRE}

The size of the wire has already proven to be significant when translating teeth. In an ideal situation teeth would be translated on an 018 stainless steel wire because the friction is significantly reduced. The results were then broken into wire types with the different ligation methods.

For simplicity all the brackets were grouped together with all three ligation methods. This allows the orthodontist to evaluate which of the ligation methods had the highest friction. Therefore it can be helpful when choosing a ligation component for the 
018 wire. Overall the alastic method of ligation in general had the higher friction when compared to the stainless steel and the self ligation. This agreed with the results found by Khambay ${ }^{40}$ where he stated that stainless steel ligation methods had the lowest amount of friction when compared to alastic. It was interesting to note that the stainless steel method of ligation was the lowest for the 018 wire and highest for the 19X25 and 21X25 wires. These results contradicted those results found by Ireland ${ }^{31}$, he found that friction did not raise steadily with increasing archwire dimensions. The results of this study found that with increasing wire size with the stainless steel method of ligation the friction also increased more than the alastic counterpart. The alastic was the lowest with the latter two. Therefore when using the lower wire size stainless steel ligation may be more beneficial because of it lack of contact with the wire.

\section{X25 WIRE}

The 19X25 wire showed different results compared to the 018 stainless steel wire. The stainless steel method of ligation compared with the alastic ligation, generally had a higher friction, except as mentioned before with the 018 stainless steel. Again this could be related to the operator and how the stainless steel ligature is tied into place. The self ligation group exhibited a higher overall friction than the alastic group in this wire group. This study contradicted previous results found by Harradine and Cacciafesta. They found that there was a decrease in frictional resistance between the bracket and archwire. ${ }^{73,74,75}$ There is a drastic difference in the ligation method between the 018 and the 19X25 wire sizes, this may be of importance to the operator as they would increase in wire size. Sims et al showed that less friction occurred in archwires ranging from 16X22 inch to 19X25 with self ligating brackets compared to alastic tied conventional brackets. ${ }^{26,53,75}$ These 
results contradict those results. The Inovation- $\mathrm{R}$ bracket becomes an active appliance as the progression through the archwires and the SmartClip remains passive. Both brackets have a beneficial component; the Inovation-R will express more torque and tip and the SmartClip will have less friction.

\section{X25 WIRE}

In the $21 X 25$ stainless steel wire group the results were similar to the 19X25 in terms of the stainless steel method of ligation having an overall higher friction when compared to the alastic method of ligation. The striking difference when progressing up in wire size is the increasingly more friction in the self ligating brackets. This group exhibits the higher friction, more than stainless steel and alastic ligation methods. This is important clinically because the operator may want to have a lower friction in the beginning of treatment to correct rotations and leveling the curve of spee, in the final stages of treatment when translating teeth some friction is wanted. Friction can be good to build up anchorage units to move other teeth too. The other issue is the increased friction in relation to the overall tooth movement. Most orthodontists will wait until they get into a rectangular stainless steel to translate teeth, therefore friction has to be considered.

\section{WIRE AND STAGE}

As discussed previously the increase in wire size will invariably increase the friction. With that said the friction also will increase with increasing tip on the wire bracket interface. Braun, Omana and others found similar results with increasing tip the friction will also increase. Although the angles in these studies were different than the angles presented here, the friction invariably increases. ${ }^{104,33}$ Therefore the friction will be 
the highest with the $21 \mathrm{X} 25$ stainless steel wire and 5.4 degrees of angulation. The more rotated a tooth during the initial stages of treatment the more friction will be placed on that bracket ligature system to unravel this tooth crowding. Smaller round wires will be the method of choice.

\section{EXPERIMENT 2}

The results were also analyzed to compare the effects of bracket and ligation in the non-self ligating brackets. The self ligating brackets were intentionally deleted from this part of the study to examine fairly the effect of bracket and ligation alone since the ligation factor could be removed and interchanged in these three non-self ligating brackets.

\section{BRACKET FACTOR}

The Mystique ceramic bracket with the silicated slot had the highest amount of friction compared with the Clarity and metal brackets. This was clinically significant even though the range is only 45 grams. The Clarity bracket has a stainless steel slot and may mimic the properties of the twin metal bracket. The effect of the bracket slot could have increased the friction significantly in this study and this agrees with previous studies. Ceramic material has been reported to abrade the archwire and actually notch the stainless steel wire. ${ }^{39}$ Cacciafesta and others found that the stainless steel slot had a lower amount of friction than the others and this could be related to the surface roughness and porosity of the ceramic slots. ${ }^{57,58,16,21,44}$ The silicated slot here in the Mystique bracket did not seem to reduce friction as well as the stainless steel slot of the Clarity. The twin metal bracket proved to have the least amount of friction and the range is broader, almost 100 grams between the Mystique bracket and the twin metal bracket. Clinically when 
choosing between metal and ceramic brackets, the metal and the Clarity will provide the least amount of clinically significant friction.

\section{Ligation}

The stainless steel method of ligation had the higher amount of friction than the alastic tie. These results are similar to those found in experiment 1 with the self ligating brackets included. The stainless steel method of ligation here also had the highest amount of friction compared to the alastic counterpart. The range was approximately 40 grams. This was clinically significant from one another. This was different from previous research were stainless steel ligation had generally the least amount of friction. ${ }^{40}$ This could be operator error in how tight the ligature wire was ligated. Friction could actually be increased or decreased depending on how tight the ligature was tied to the bracket.

As previously stated, the ligation component in the BLS was not as relevant as the wire size. The wire size seemed to have the most effect on friction. Although the clinician must also consider the ligation method used and attempt to reduce friction if that is the treatment plan. 


\section{CHAPTER V SUMMARY AND CONCLUSIONS}

\section{SUMMARY}

Objectives: To 1) determine if self ligating brackets have a comparable friction to the conventional metal twin brackets; 2) determine if the type of slot in the ceramic bracket decreases friction; 3) determine if the ligation component that is utilized had an effect on friction; 4) determine what wires produce the greatest and least amount of friction during tooth movement.

The study utilized four different brackets, microArch twin metal (GAC), Clarity ceramic (3M Unitek), Mystique ceramic (GAC), and two self ligating brackets SmartClip (3M Unitek) and Inovation R (GAC). Three wires, 018, 19X25, and 21X25 stainless steel were utilized. The ligation component was also important and consisted of three different methods; alastic o-rings, stainless steel, and self ligating. The bracket/wire/ligation combination was then placed in a mechanical testing apparatus and subjected to various tipping angles $(0,2.7,4.9$, and 5.4 degrees $)$ to evaluate the friction involved with each bracket system. The bracket, wire, and ligation method were all analyzed to determine any significant differences.

\section{CONCLUSIONS}

The smaller the archwire size typically had the lowest amount of friction. This ultimately among all other factors was the most clinically significant. The 018 stainless steel wire had the lowest and the 21 X25 wire had the highest friction. The Mystique ceramic bracket on the average had a higher friction than the Clarity bracket. The SmartClip self ligating bracket had lower friction generally when compared to the Inovation R. The alastic method of ligation showed the lowest amount of friction when 
compared to the stainless steel, however the self ligating had the lowest friction when compared to the lower wires, and increased with increasing wire size. When looking at the results as a whole the self ligating brackets had a higher friction in the larger archwire sizes however this was most likely due to the Inovation- $\mathrm{R}$ being an interactive appliance. This seemed to increase the levels of friction for the self ligating appliances.

\section{RECOMMENDATIONS}

Future studies could further investigate the use of new self ligating brackets, such as the Damon 3, ceramic Inovation R, and Time 2. Many self ligation systems claim to be passive, active, or interactive. It can be determined by another in vitro investigation the amount of friction present. Another project could be done in vivo, with the extraction of teeth. It would be beneficial to utilize a split arch technique and use different bracket systems while retracting canines and quantifying how much tooth movement occurred during a specified period of time. There have been very few studies done in vivo on the friction involved with different bracket systems. There are many claims that note that self ligating brackets have less friction, a clinical study would be beneficial to verify these claims. 


\section{Reference List}

1. Besançon RM, Robert M. The Encyclopedia of physics. New York, Van Nostrand Reinhold Co., 1985.

2. Rabinowicz E. Friction and wear of materials. New York, Wiley, 1965.

3. Dickson JA, Jones SP, Davies EH. A comparison of the frictional characteristics of five initial alignment wires and stainless steel brackets at three bracket to wire angulations--an in vitro study. $\mathrm{Br} \mathrm{J}$ Orthod 1994; 21 : 15-22.

4. Giancoli DC. Physics : principles with applications. Englewood Cliffs, N.J., Prentice-Hall, 1980.

5. Frank CA, Nikolai RJ. A comparative study of frictional resistances between orthodontic bracket and arch wire. Am J Orthod 1980; 78: 593Kapur 609.

6. Sinha PK, Nanda RS. Comparison of frictional resistance in titanium and sainless steel brackets. Am J Orthod Dentofacial Orthop 1999; 116: 271-4.

7. Bowden FP, Tabor D, joint a. The friction and lubrication of solids. Oxford, Clarendon Press, 1950.

8. Kusy RP, Whitley JQ. Friction between different wire-bracket configurations and materials. Semin Orthod 1997; 3: 166-77.

9. O'Reilly D, Dowling PA, Lagerstrom L, Swartz ML. An ex-vivo investigation into the effect of bracket displacement on the resistance to sliding. Br J Orthod 1999; 26: 219-27.

10. Pizzoni L, Ravnholt G, Melsen B. Frictional forces related to self-ligating brackets. Eur J Orthod 1998; 20: 283-91.

11. Loftus BP, Artun J, Nicholls JI, Alonzo TA, Stoner JA. Evaluation of friction during sliding tooth movement in various bracket-arch wire combinations. Am J Orthod Dentofacial Orthop 1999; 116: 336-45.

12. Rossouw P. Emile. Friction: An Overview. Seminars in Orthodontics 2003;9:218.

13. Baker KL, Nieberg LG, Weimer AD, Hanna M. Frictional changes in force values caused by saliva substitution. Am J Orthod Dentofacial Orthop 1987;91:316-320.

14. Stannard JG, Gau JM, Hanna MA. Comparative friction of orthodontic wires under dry and wet conditions. Am J Orthod 1986; 89: 485-91. 
15. Kapila S, Angolkar PV, Duncanson MG, Jr., Nanda RS. Evaluation of friction between edgewise stainless steel brackets and orthodontic wires of four alloys. Am J Orthod Dentofacial Orthop 1990; 98: 117-26.

16. Pratten DH, Popli K, Germane N, Gunsolley JC. Frictional resistance of ceramic and stainless steel orthodontic brackets. Am J Orthod Dentofacial Orthop 1990; 98: 398-403.

17. Jost-Brinkmann P, Miethke RR. [The effect of physiological tooth mobility on the friction between the bracket and the arch]. Fortschr Kieferorthop 1991; 52: 102-9.

18. Drescher D, Bourauel C, Schumacher HA. Frictional forces between bracket and arch wire. Am J Orthod Dentofacial Orthop 1989; 96: 397404.

19. Andreasen G, Quevedo F. Evaluation of friction forces in the .022 by .028 by edgewise bracket in vitro. Am J Orthod 1969; 55: 201.

20. Peterson L, Spencer R, Andreasen G. A comparison of friction resistance for Nitinol and stainless steel wire in edgewise brackets. Quintessence Int 1982; 13: 563-71.

21. Angolkar PV, Kapila S, Duncanson MG, Jr., Nanda RS. Evaluation of friction between ceramic brackets and orthodontic wires of four alloys. Am J Orthod Dentofacial Orthop 1990; 98: 499-506.

22. Ogata RH, Nanda RS, Duncanson MG, Jr., Sinha PK, Currier GF. Frictional resistances in stainless steel bracket-wire combinations with effects of vertical deflections. Am J Orthod Dentofacial Orthop 1996; 109: $535-42$.

23. Tanne K, Matsubara S, Shibaguchi T, Sakuda M. Wire friction from ceramic brackets during simulated canine retraction. Angle Orthod 1991; 61: 285-90.

24. Downing A, McCabe J, Gordon P. A study of frictional forces between orthodontic brackets and archwires. Br J Orthod 1994; 21: 349-57.

25. Moore MM, Harrington E, Rock WP. Factors affecting friction in the preadjusted appliance. Eur J Orthod 2004; 26: 579-83.

26. Sims AP, Waters NE, Birnie DJ, Pethybridge RJ. A comparison of the forces required to produce tooth movement in vitro using two self-ligating brackets and a pre-adjusted bracket employing two types of ligation. Eur J Orthod 1993; 15: 377-85. 
27. Tidy DC. Frictional forces in fixed appliances. Am J Orthod Dentofacial Orthop 1989; 96: 249-54.

28. Peterson L, Spencer R, Andreasen GF. A Comparison of Friction Resistance for Nitinol and Stainless Steel Wire in Edgewise Brackets. 1982;13:563-71:Quintesscence International.

29. Vaughan JL, Duncanson MG, Jr., Nanda RS, Currier GF. Relative kinetic frictional forces between sintered stainless steel brackets and orthodontic wires. Am J Orthod Dentofacial Orthop 1995; 107: 20-7.

30. Taylor NG, Ison K. Frictional resistance between orthodontic brackets and archwires in the buccal segments. Angle Orthod 1996; 66: 215-22.

31. Ireland AJ, Sherriff M, McDonald F. Effect of bracket and wire composition on frictional forces. Eur J Orthod 1991; 13: 322-8.

32. Mah, Edward. Investigation of Frictional Resistance on Orthodontic Brackets when Subjected to Variable Moments. 6-36. 2002 Thesis.

33. Omana HM, Moore RN, Bagby MD. Frictional properties of metal and ceramic brackets. J Clin Orthod 1992; 26: 425-32.

34. De Franco DJ, Spiller RE, Jr., von Fraunhofer JA. Frictional resistances using Teflon-coated ligatures with various bracket-archwire combinations. Angle Orthod 1995; 65: 63-72.

35. Kusy RP, Whitley JQ. Coefficients of friction for arch wires in stainless steel and polycrystalline alumina bracket slots. I. The dry state. Am J Orthod Dentofacial Orthop 1990; 98: 300-12.

36. Prososki RR, Bagby MD, Erickson LC. Static frictional force and surface roughness of nickel-titanium arch wires. Am J Orthod Dentofacial Orthop 1991;100: 341-8.

37. Mendes K, Rossouw P. Friction: Validation of Manufacturer's Claim. Semin Orthod 2003;9: 236-50.

38. Nanda r, Ghosh J. Biomechanical considerations in sliding mechanics. Biomechanics in Clinical Orthodontics. Philadelphia: WB Saunders; 1997: 188-217.

39. Keith O, Kusy RP, Whitley JQ. Zirconia brackets: an evaluation of morphology and coefficients of friction. Am J Orthod Dentofacial Orthop 1994; 106: 605-14. 
40. Khambay B, Millett D, McHugh S. Archwire seating forces produced by different ligation methods and their effect on frictional resistance. Eur $\mathrm{J}$ Orthod 2005; 27: 302-8.

41. Semin Orthod 2003;9: 262-80.

42. Schumacher HA, Bourauel C, Drescher D. [The effect of the ligature on the friction between bracket and arch]. Fortschr Kieferorthop 1990; 51: 106-16.

43. Keith O, Jones SP, Davies EH. The influence of bracket material, ligation force and wear on frictional resistance of orthodontic brackets. $\mathrm{Br}$ J Orthod 1993; 20:109-15.

44. Bednar JR, Gruendeman GW, Sandrik JL. A comparative study of frictional forces between orthodontic brackets and arch wires. Am J Orthod Dentofacial Orthop 1991; 100: 513-22.

45. Tselepis $\mathbf{M}$, Brockhurst $\mathbf{P}$, West VC. The dynamic frictional resistance between orthodontic brackets and arch wires. Am J Orthod Dentofacial Orthop 1994; 106: 131-8.

46. Andreasen GF, Quevedo FR. Evaluation of friction forces in the $0.022 \times$ 0.028 edgewise bracket in vitro. J Biomech 1970; 3: 151-60.

47. Halderson H. Routine Use of Minute Forces. Am J Orthod Dentofacial Orthop 1975; 43: 750-68.

48. Riley JL, Garrett SG, Moon PC. Journal of Dental Research. Frictional Forces of Ligated Plastic and Metal Edgewise Brackets 1979; 58.

49. Hain $\mathbf{M}$, Dhopatkar A, Rock $\mathbf{P}$. The effect of ligation method on friction in sliding mechanics. Am J Orthod Dentofacial Orthop 2003; 123: 416-22.

50. Iwasaki LR, Beatty MW, Randall CJ, Nickel JC. Clinical ligation forces and intraoral friction during sliding on a stainless steel archwire. Am J Orthod Dentofacial Orthop 2003; 123: 408-15.

51. Wong AK. Orthodontic Elastic Materials. Angle Orthod 1976;46:196-05.

52. Ash JL, Nikolai RJ. Relaxation of Orthodontic Elastomeric Chains and Modules In Vitro and In Vivo. J Dent Research 1978;57: 685-90.

53. Shivapuja PK, Berger J. A comparative study of conventional ligation and self-ligation bracket systems. Am J Orthod Dentofacial Orthop 1994; 106: $472-80$. 
54. Kapila S, Sachdeva R. Mechanical properties and clinical applications of orthodontic wires. Am J Orthod Dentofacial Orthop 1989; 96: 100-9.

55. Kuroe K, Tajiri T, Nakayama T, Nagakubo C, Kubota S, Matsuda T et al. Frictional forces with the friction-free edgewise bracket. J Clin Orthod 1994; 28: 347-51.

56. Kusy RP, Whitley JQ, Prewitt MJ. Comparison of the frictional coefficients for selected archwire-bracket slot combinations in the dry and wet states. Angle Orthod 1991; 61: 293-302.

57. Cacciafesta V, Sfondrini MF, Scribante A, Klersy C, Auricchio F. Evaluation of friction of conventional and metal-insert ceramic brackets in various bracket-archwire combinations. Am J Orthod Dentofacial Orthop 2003; 124: 403-9.

58. Bazakidou E, Nanda RS, Duncanson MG, Jr., Sinha P. Evaluation of frictional resistance in esthetic brackets. Am J Orthod Dentofacial Orthop 1997; 112: 138-44.

59. Rose CM, Zernik JH. Reduced resistance to sliding in ceramic brackets. J Clin Orthod 1996; 30: 78-84.

60. Saunders CR, Kusy RP. Surface topography and frictional characteristics of ceramic brackets. Am J Orthod Dentofacial Orthop 1994; 106: 76-87.

61. Articolo LC, Kusy K, Saunders CR, Kusy RP. Influence of ceramic and stainless steel brackets on the notching of archwires during clinical treatment. Eur J Orthod 2000; 22: 409-25.

62. Kusy RP, Whitely JQ. Effect of Surface Roughness of Frictional Coefficients of Arch Wires. Journal of Dental Research 1988; 67.

63. Aknin PC, Nanda RS, Duncanson MG, Jr., Currier GF, Sinha PK. Fracture strength of ceramic brackets during arch wire torsion. $A m \mathrm{~J}$ Orthod Dentofacial Orthop 1996; 109: 22-7.

64. Rhodes RK. Fracture Strengths of Ceramic Brackets Subjected to MesialDistal Arch Wire Tipping Forces. Angle Orthod 1992; 62: 67-75.

65. Douglass JB. Enamel Wear Caused By Ceramic Brackets. Am J Orthod Dentofacial Orthop 1989; 95: 96-8.

66. Swartz ML. Ceramic brackets. J Clin Orthod 1988; 22:82-8.

67. Winchester LJ. A comparison between the old Transcend and the new Transcend series 2000 bracket. Br J Orthod 1992; 19: 109-16. 
68. Stolzenberg J. The Efficiency of the Russell Attachment. International Journal of Orthodontics and Dental Children. 1935; 9: 837-40.

69. Hanson GH. The SPEED system: a report on the development of a new edgewise appliance. Am J Orthod 1980; 78: 243-65.

70. Viazis AD, Cavenaugh G, Bevis RR. Bond Strength of Ceramic Brackets Under Shear Stress: An in-vitro Report. Am J Orthod Dentofacial Orthop. 1990; 98: 214-21.

71. Damon DH. The rationale, evolution and clinical application of the selfligating bracket. Clin Orthod Res 1998; 1: 52-61

72. Wildman AJ. Round Table-The Edgelok Bracket. Journal of Clinical Orthodontics. 1972; 6: 613-23.

73. Harradine NW. Self-ligating brackets: where are we now? J Orthod 2003; 30: 262-73.

74. Redlich M, Mayer Y, Harari D, Lewinstein I. In vitro study of frictional forces during sliding mechanics of "reduced-friction" brackets. Am J Orthod Dentofacial Orthop 2003; 124: 69-73.

75. Cacciafesta V, Sfondrini MF, Ricciardi A, Scribante A, Klersy C, Auricchio F. Evaluation of friction of stainless steel and esthetic selfligating brackets in various bracket-archwire combinations. Am J Orthod Dentofacial Orthop 2003; 124: 395-402

76. Farrant SD. An evaluation of different methods of canine retraction. British Journal of Orthodontics. 1976.

77. Hanson H. Herbert Hanso on the SPEED Bracket. Journal Clinical Orthodontics. 1986; 10: 183-9.

78. A Comparative Analysis of Frictional Forces Between Self-Ligating and Conventional Edgewise Orthodontic Brackets. University of Toronto 1992.

79. Thomas S, Sherriff M, Birnie D. A comparative in vitro study of the frictional characteristics of two types of self-ligating brackets and two types of pre-adjusted edgewise brackets tied with elastomeric ligatures. Eur J Orthod 1998; 20: 589-96.

80. Read-Ward GE, Jones SP, Davies EH. A comparison of self-ligating and conventional orthodontic bracket systems. Br J Orthod 1997; 24: 309-17.

81. Berger JL, Grundemann GW, Sandrik JL. A Comparitive Study of Frictional Forces Between Orthodontic Brackets and Arch Wires. Am J Orhtod Dentofacial Orthop 1991; 97: 219-28. 
82. Nicholls Jl. Frictional Forces in Fixed Orthodontic Appliances. Dental Practitioner 1968; 18: 362-6.

83. Yamaguchi K, Nanda RS, Morimoto N, Oda Y. A study of force application, amount of retarding force, and bracket width in sliding mechanics. Am J Orthod Dentofacial Orthop 1996; 109: 50-6.

84. Drescher D, Bourauel C, Schumacher HA. [The loss of force by friction in arch-guided tooth movement]. Fortschr Kieferorthop 1990; 51: 99-105.

85. Sims AP, Waters NE, Birnie DJ. A comparison of the forces required to produce tooth movement ex vivo through three types of pre-adjusted brackets when subjected to determined tip or torque values. $\mathrm{Br} \mathrm{J}$ Orthod 1994; 21: 367-73.

86. Moore JC, Waters NE. Factors Affecting Tooth Movement in Sliding Mechanics. Eur J Orthod 1993; 3: 235-41.

87. Creekmore TD. The importance of interbracket width in orthodontic tooth movement. J Clin Orthod 1976; 10: 530-4.

88. Thorstenson GA, Kusy RP. Resistance to sliding of self-ligating brackets versus conventional stainless steel twin brackets with second-order angulation in the dry and wet (saliva) states. Am J Orthod Dentofacial Orthop 2001; 120: 361-70.

89. Dickson JAS, Jones SP, Davies EH. A Comparison of the Frictional Characteristics of Five Initial Alignment Wires and Stainless Steel Brackets at Three Bracket to Wire Angulations- an In Vitro Study. $\mathrm{Br} \mathrm{J}$ Orthod 1994; 21: 15-22.

90. Proffit WR. Contemporary orthodontics. St. Louis, Mosby, 1986.

91. Ho KS, West VC. Friction ... Friction resistance between edgewise brackets and archwires. Aust Orthod J 1991; 12: 95-9.

92. Kusy RP, Whitley JQ, Mayhew MJ, Buckthal JE. Surface roughness of orthodontic archwires via laser spectroscopy. Angle Orthod 1988; 58: 3345.

93. Berger JL. The influence of the SPEED Bracket's Self-Ligating Design of Force levels in Tooth Movement. Am J Orthod Dentofacial Orthop 1990; 97: 219.

94. Bourauel C, Drescher D, Their M. An Experimental Set Up for the Simulation of Three Dimensional Movements in Orthodontics. Journal Biomedical Engineering 1992; 14: 371-8. 
95. Quinn TB, Yoshikawa DK. A Reassessment of Force Magnitude in Orthodontics. Am J Orthod Dentofacial Orthop 1985; 88: 252-60.

96. Schwartz AM. Tissue Changes Incidental to Tooth Movement. Am J Orthod Dentofacial Orthop 1932; 18: 331-52.

97. Nikolai RJ. Bioengineering analysis of orthodontic mechanics. Philadelphia, Lea \& Febiger, 1985.

98. Schumacher HA, Bourauel C, Drescher D. The influence of bracket design on frictional losses in the bracket/arch wire system. J Orofac Orthop 1999; 60: 335-47.

99. Oppenheim A. Tissue changes particularly of the bone, Incident to tooth movement. Am J Orthod Dentofacial Orthop 1911; 3: 57-67.

100. Atkins SE, Tuncay OC. Tooth Brushing Induced Changes of Blood Flow in Human Gingiva. Mississippi Dental Association Journal 1993; 49: 27-9.

101. Yamaguchi K, Nanda RS. Blood Flow Changes in Gingival Tissues due to the Displacement of Teeth. Angle Orthod 1992; 62: 257-64.

102. Tuncay OC, Killiany DM. The Effect of Gingival Fiberotomy on the Rate of Tooth Movement. Am J Orthod Dentofacial Orthop 1986; 89: 212-5.

103. Liew CF. The Reduction of Sliding Friction Between an Orthodontic Bracket Archwire by Repeated Vertical Disturbance. University of Queensland: Australia 1993.

104. Braun S, Bluestein M, Moore BK, Benson G. Friction in perspective. Am J Orthod Dentofacial Orthop 1999; 115: 619-27.

105. Kajdas C, Harvey SSK, 1932-, Wilusz E, 1948-. Encyclopedia of tribology. Amsterdam ; New York, Elsevier ; New York, NY, U.S.A. : Distributors for the U.S. and Canada, Elsevier Science Pub. Co., 1990.

106. Kusy RP, Whitley JQ. Influence of archwire and bracket dimensions on sliding mechanics: derivations and determinations of the critical contact angles for binding. Eur J Orthod 1999; 21: 199-208. 


\section{APPENDIX B}

\section{FRICTION AVERAGES}

\begin{tabular}{|c|c|c|c|c|c|c|c|}
\hline Clarity & 18 & alastic & 1 & static & -0.16121 & 4.668264 & -0.00979 \\
\hline Clarity & 18 & alastic & 1 & kinetic/0 & -0.30997 & 107.9585 & -0.00762 \\
\hline Clarity & 18 & alastic & 1 & $2.7 \mathrm{deg}$ & 5.956182 & 104.739 & 1.998758 \\
\hline Clarity & 18 & alastic & 1 & $4.9 \mathrm{deg}$ & 23.10326 & 162.8499 & 4.452811 \\
\hline Clarity & 18 & alastic & 1 & $5.4 \mathrm{deg}$ & 29.37476 & 175.8349 & 5.250157 \\
\hline Clarity & 18 & alastic & 1 & dyn frict & 7.621587 & 82.8904 & 2.654491 \\
\hline Clarity & 18 & alastic & 1 & $\begin{array}{l}\text { appar } \\
\text { stiff }\end{array}$ & 7.444855 & 48.17844 & 2.522619 \\
\hline Clarity & 18 & alastic & 2 & static & 0.040079 & 5.634 & 0.010525 \\
\hline Clarity & 18 & alastic & 2 & kinetic/0 & 4.21396 & 101.8952 & -0.75919 \\
\hline Clarity & 18 & alastic & 2 & $2.7 \mathrm{deg}$ & 10.92103 & 184.3128 & 1.883304 \\
\hline Clarity & 18 & alastic & 2 & $4.9 \mathrm{deg}$ & 16.12367 & 181.6836 & 3.750265 \\
\hline Clarity & 18 & alastic & 2 & $5.4 \mathrm{deg}$ & 20.98693 & 194.454 & 4.595526 \\
\hline Clarity & 18 & alastic & 2 & dyn frict & 6.352513 & 118.959 & 1.956469 \\
\hline Clarity & 18 & alastic & 2 & $\begin{array}{l}\text { appar } \\
\text { stiff }\end{array}$ & 5.624954 & 85.45112 & 1.886646 \\
\hline Clarity & 18 & alastic & 3 & static & -0.06948 & 4.024286 & -0.06173 \\
\hline Clarity & 18 & alastic & 3 & kinetic/0 & -0.0187 & 63.90586 & 0.026141 \\
\hline Clarity & 18 & alastic & 3 & $2.7 \mathrm{deg}$ & 2.428967 & 75.28117 & 2.345131 \\
\hline Clarity & 18 & alastic & 3 & $4.9 \mathrm{deg}$ & 14.31728 & 120.9972 & 4.443021 \\
\hline Clarity & 18 & alastic & 3 & $5.4 \mathrm{deg}$ & 17.66547 & 141.6016 & 5.371062 \\
\hline Clarity & 18 & alastic & 3 & dyn frict & 1.465376 & 63.12824 & 2.745503 \\
\hline Clarity & 18 & alastic & 3 & $\begin{array}{l}\text { appar } \\
\text { stiff }\end{array}$ & 0.788651 & 31.87086 & 2.726888 \\
\hline Clarity & 18 & alastic & 4 & static & -0.08106 & 6.3852 & 0.015966 \\
\hline Clarity & 18 & alastic & 4 & kinetic/0 & 0.382103 & 200.8928 & -0.02723 \\
\hline Clarity & 18 & alastic & 4 & $2.7 \mathrm{deg}$ & -1.81438 & 167.6253 & 1.99004 \\
\hline Clarity & 18 & alastic & 4 & $4.9 \mathrm{deg}$ & 4.630804 & 177.1763 & 4.544302 \\
\hline Clarity & 18 & alastic & 4 & $5.4 \mathrm{deg}$ & 16.11563 & 190.376 & 5.209857 \\
\hline Clarity & 18 & alastic & 4 & dyn frict & -0.59072 & 135.8891 & 2.664976 \\
\hline Clarity & 18 & alastic & 4 & $\begin{array}{l}\text { appar } \\
\text { stiff }\end{array}$ & -0.21806 & 95.001 & 2.661914 \\
\hline Clarity & 18 & alastic & 5 & static & -0.06947 & 4.99021 & 0.034493 \\
\hline Clarity & 18 & alastic & 5 & kinetic/0 & 0.836386 & 97.11972 & -0.0109 \\
\hline Clarity & 18 & alastic & 5 & $2.7 \mathrm{deg}$ & 11.56232 & 135.6457 & 2.16323 \\
\hline Clarity & 18 & alastic & 5 & $4.9 \mathrm{deg}$ & 29.01134 & 207.2245 & 4.522527 \\
\hline Clarity & 18 & alastic & 5 & $5.4 \mathrm{deg}$ & 38.60698 & 214.4682 & 5.327496 \\
\hline Clarity & 18 & alastic & 5 & dyn frict & 13.92534 & 102.5007 & 2.759718 \\
\hline Clarity & 18 & alastic & 5 & $\begin{array}{l}\text { appar } \\
\text { stiff }\end{array}$ & 14.09492 & 60.77994 & 2.767916 \\
\hline Clarity & 18 & ss & 1 & static & 0.00892 & 5.741314 & -0.03451 \\
\hline Clarity & 18 & ss & 1 & kinetic/0 & -1.90523 & 56.17923 & -0.01526 \\
\hline Clarity & 18 & ss & 1 & $2.7 \mathrm{deg}$ & 4.048287 & 50.11597 & 2.704574 \\
\hline Clarity & 18 & SS & 1 & $4.9 \mathrm{deg}$ & 8.427908 & 53.12077 & 4.64342 \\
\hline
\end{tabular}




\begin{tabular}{|c|c|c|c|c|c|c|c|}
\hline Clarity & 18 & ss & 1 & $5.4 \mathrm{deg}$ & 18.64614 & 66.96431 & 5.478881 \\
\hline Clarity & 18 & Ss & 1 & dyn frict & 0.969289 & 41.57295 & 2.512919 \\
\hline Clarity & 18 & sS & 1 & $\begin{array}{l}\text { appar } \\
\text { stiff }\end{array}$ & 0.334043 & 25.61103 & 2.449181 \\
\hline Clarity & 18 & Ss & 2 & static & 0.174588 & 4.990114 & -0.00944 \\
\hline Clarity & 18 & Ss & 2 & kinetic/0 & -0.00802 & 5.2584 & 0.014164 \\
\hline Clarity & 18 & SS & 2 & $2.7 \mathrm{deg}$ & 5.726369 & 9.980229 & 2.467133 \\
\hline Clarity & 18 & SS & 2 & $4.9 \mathrm{deg}$ & 11.19356 & 29.2969 & 4.411431 \\
\hline Clarity & 18 & SS & 2 & $5.4 \mathrm{deg}$ & 16.35879 & 38.36496 & 5.310065 \\
\hline Clarity & 18 & SS & 2 & dyn frict & 2.834171 & 11.52482 & 2.711144 \\
\hline Clarity & 18 & ss & 2 & $\begin{array}{l}\text { appar } \\
\text { stiff }\end{array}$ & 2.702978 & 5.183493 & 2.745392 \\
\hline Clarity & 18 & SS & 3 & static & -0.01158 & -0.05366 & -0.05337 \\
\hline Clarity & 18 & SS & 3 & kinetic/0 & -0.29662 & 22.91167 & -0.06862 \\
\hline Clarity & 18 & SS & 3 & $2.7 \mathrm{deg}$ & 12.70332 & 80.59323 & 2.494374 \\
\hline Clarity & 18 & Ss & 3 & $4.9 \mathrm{deg}$ & 26.6091 & 163.0645 & 4.481152 \\
\hline Clarity & 18 & SS & 3 & $5.4 \mathrm{deg}$ & 34.95684 & 202.5026 & 5.217477 \\
\hline Clarity & 18 & SS & 3 & dyn frict & 11.69607 & 67.30971 & 2.62135 \\
\hline Clarity & 18 & ss & 3 & $\begin{array}{l}\text { appar } \\
\text { stiff }\end{array}$ & 11.80911 & 38.62208 & 2.589253 \\
\hline Clarity & 18 & SS & 4 & static & -0.30284 & 4.346229 & -0.01744 \\
\hline Clarity & 18 & SS & 4 & kinetic/0 & -1.80101 & 9.819257 & -0.03813 \\
\hline Clarity & 18 & SS & 4 & $2.7 \mathrm{deg}$ & 9.007774 & 33.4285 & 2.548829 \\
\hline Clarity & 18 & SS & 4 & $4.9 \mathrm{deg}$ & 11.12945 & 74.63729 & 4.555218 \\
\hline Clarity & 18 & SS & 4 & $5.4 \mathrm{deg}$ & 22.83873 & 89.55397 & 5.24798 \\
\hline Clarity & 18 & SS & 4 & dyn frict & 4.430488 & 20.33076 & 2.71316 \\
\hline Clarity & 18 & ss & 4 & $\begin{array}{l}\text { appar } \\
\text { stiff }\end{array}$ & 3.885876 & -4.40415 & 2.716048 \\
\hline Clarity & 18 & SS & 5 & static & 0.038293 & 2.897486 & -0.00146 \\
\hline Clarity & 18 & SS & 5 & kinetic/0 & 0.040079 & 18.72637 & $-5.5 E-06$ \\
\hline Clarity & 18 & SS & 5 & $2.7 \mathrm{deg}$ & 7.687731 & 20.81903 & 2.446431 \\
\hline Clarity & 18 & SS & 5 & $4.9 \mathrm{deg}$ & 16.39354 & 68.94963 & 4.499663 \\
\hline Clarity & 18 & SS & 5 & $5.4 \mathrm{deg}$ & 21.94355 & 75.28117 & 5.286098 \\
\hline Clarity & 18 & Ss & 5 & dyn frict & 4.801169 & 27.4816 & 2.682915 \\
\hline Clarity & 18 & ss & 5 & $\begin{array}{l}\text { appar } \\
\text { stiff }\end{array}$ & 4.762739 & 0.383566 & 2.630189 \\
\hline Clarity & 1925 & alastic & 1 & static & 0.06146 & 1.502431 & 0.03632 \\
\hline Clarity & 1925 & alastic & 1 & kinetic/0 & -1.13834 & 220.1021 & 0.009808 \\
\hline Clarity & 1925 & alastic & 1 & $2.7 \mathrm{deg}$ & 4.884644 & 186.4054 & 2.347326 \\
\hline Clarity & 1925 & alastic & 1 & $4.9 \mathrm{deg}$ & 15.57318 & 194.1857 & 4.379851 \\
\hline Clarity & 1925 & alastic & 1 & $5.4 \mathrm{deg}$ & 23.88084 & 186.6737 & 5.276301 \\
\hline Clarity & 1925 & alastic & 1 & dyn frict & 3.294818 & 202.4751 & 2.661928 \\
\hline Clarity & 1925 & alastic & 1 & $\begin{array}{l}\text { appar } \\
\text { stiff }\end{array}$ & 3.37529 & 112.4534 & 2.638882 \\
\hline Clarity & 1925 & alastic & 2 & static & 0.044536 & 0 & 0.043214 \\
\hline Clarity & 1925 & alastic & 2 & kinetic/0 & -0.95395 & 163.7083 & -0.01852 \\
\hline Clarity & 1925 & alastic & 2 & $2.7 \mathrm{deg}$ & 7.583516 & 177.7129 & 2.213348 \\
\hline Clarity & 1925 & alastic & 2 & $4.9 \mathrm{deg}$ & 25.39863 & 314.2707 & 4.303597 \\
\hline Clarity & 1925 & alastic & 2 & $5.4 \mathrm{deg}$ & 35.28552 & 359.1818 & 5.164108 \\
\hline Clarity & 1925 & alastic & 2 & dyn frict & 11.86384 & 158.0476 & 2.636138 \\
\hline
\end{tabular}




\begin{tabular}{|c|c|c|c|c|c|c|c|}
\hline Clarity & 1925 & alastic & 2 & $\begin{array}{l}\text { appar } \\
\text { stiff }\end{array}$ & 11.37305 & 59.41559 & 2.550348 \\
\hline Clarity & 1925 & alastic & 3 & static & 0.184368 & 4.1316 & -0.01052 \\
\hline Clarity & 1925 & alastic & 3 & kinetic/0 & -0.52372 & 148.6307 & -0.04357 \\
\hline Clarity & 1925 & alastic & 3 & $2.7 \mathrm{deg}$ & 7.989679 & 133.7677 & 2.561905 \\
\hline Clarity & 1925 & alastic & 3 & $4.9 \mathrm{deg}$ & 10.4801 & 150.0794 & 4.290525 \\
\hline Clarity & 1925 & alastic & 3 & $5.4 \mathrm{deg}$ & 25.95709 & 171.3278 & 5.158653 \\
\hline Clarity & 1925 & alastic & 3 & dyn frict & 5.789245 & 113.9585 & 2.630588 \\
\hline Clarity & 1925 & alastic & 3 & $\begin{array}{l}\text { appar } \\
\text { stiff }\end{array}$ & 6.162355 & 62.33865 & 2.585031 \\
\hline Clarity & 1925 & alastic & 4 & static & 0.142511 & 7.619314 & -0.03449 \\
\hline Clarity & 1925 & alastic & 4 & kinetic/0 & -0.72414 & 154.5866 & -0.08387 \\
\hline Clarity & 1925 & alastic & 4 & $2.7 \mathrm{deg}$ & 3.043553 & 143.3186 & 2.412675 \\
\hline Clarity & 1925 & alastic & 4 & $4.9 \mathrm{deg}$ & 10.89696 & 127.3824 & 4.391827 \\
\hline Clarity & 1925 & alastic & 4 & $5.4 \mathrm{deg}$ & 18.23195 & 115.6851 & 5.246886 \\
\hline Clarity & 1925 & alastic & 4 & dyn frict & 0.422834 & 77.58204 & 2.691515 \\
\hline Clarity & 1925 & alastic & 4 & $\begin{array}{l}\text { appar } \\
\text { stiff }\end{array}$ & 0.206938 & 27.77909 & 2.637899 \\
\hline Clarity & 1925 & alastic & 5 & static & -0.11045 & 5.794971 & -0.00508 \\
\hline Clarity & 1925 & alastic & 5 & kinetic/0 & -0.86043 & 161.9377 & 0.023958 \\
\hline Clarity & 1925 & alastic & 5 & $2.7 \mathrm{deg}$ & 11.22563 & 135.9676 & 2.484556 \\
\hline Clarity & 1925 & alastic & 5 & $4.9 \mathrm{deg}$ & 19.49053 & 198.1563 & 4.517096 \\
\hline Clarity & 1925 & alastic & 5 & $5.4 \mathrm{deg}$ & 20.76247 & 200.5173 & 5.28392 \\
\hline Clarity & 1925 & alastic & 5 & dyn frict & 5.413887 & 133.0153 & 2.683589 \\
\hline Clarity & 1925 & alastic & 5 & $\begin{array}{l}\text { appar } \\
\text { stiff }\end{array}$ & 5.351168 & 66.12918 & 2.615853 \\
\hline Clarity & 1925 & Ss & 1 & static & -0.49524 & 2.307257 & 0.029418 \\
\hline Clarity & 1925 & SS & 1 & kinetic/0 & -0.41953 & 449.3261 & 0.013066 \\
\hline Clarity & 1925 & ss & 1 & $2.7 \mathrm{deg}$ & 7.412492 & 301.5002 & 2.493274 \\
\hline Clarity & 1925 & ss & 1 & $4.9 \mathrm{deg}$ & 20.49259 & 316.7926 & 4.465887 \\
\hline Clarity & 1925 & SS & 1 & $5.4 \mathrm{deg}$ & 24.09997 & 330.6361 & 5.351451 \\
\hline Clarity & 1925 & ss & 1 & dyn frict & 4.07269 & 203.7658 & 2.716734 \\
\hline Clarity & 1925 & SS & 1 & $\begin{array}{l}\text { appar } \\
\text { stiff }\end{array}$ & 3.596139 & 111.953 & 2.648609 \\
\hline Clarity & 1925 & ss & 2 & static & 0.138048 & 1.663371 & 0.011259 \\
\hline Clarity & 1925 & ss & 2 & kinetic/0 & -3.3081 & 734.4072 & -0.02723 \\
\hline Clarity & 1925 & ss & 2 & $2.7 \mathrm{deg}$ & 5.290813 & 585.8839 & 2.541195 \\
\hline Clarity & 1925 & ss & 2 & $4.9 \mathrm{deg}$ & 28.29254 & 516.2904 & 4.481133 \\
\hline Clarity & 1925 & ss & 2 & $5.4 \mathrm{deg}$ & 29.67135 & 486.2423 & 5.30788 \\
\hline Clarity & 1925 & ss & 2 & dyn frict & 11.86523 & 383.1301 & 2.723237 \\
\hline Clarity & 1925 & ss & 2 & $\begin{array}{l}\text { appar } \\
\text { stiff }\end{array}$ & 11.65848 & 177.8797 & 2.68182 \\
\hline Clarity & 1925 & ss & 3 & static & -0.09977 & 0.965829 & -0.03849 \\
\hline Clarity & 1925 & ss & 3 & kinetic/0 & 0.109548 & 469.7695 & $-4.4 \mathrm{E}-06$ \\
\hline Clarity & 1925 & ss & 3 & $2.7 \mathrm{deg}$ & 5.956168 & 438.4873 & 2.423555 \\
\hline Clarity & 1925 & ss & 3 & $4.9 \mathrm{deg}$ & 20.29485 & 316.3633 & 4.426677 \\
\hline Clarity & 1925 & ss & 3 & $5.4 \mathrm{deg}$ & 26.67588 & 331.602 & 5.340558 \\
\hline Clarity & 1925 & SS & 3 & dyn frict & 7.039609 & 208.3518 & 2.744365 \\
\hline Clarity & 1925 & ss & 3 & $\begin{array}{l}\text { appar } \\
\text { stiff }\end{array}$ & 6.539148 & 94.8512 & 2.672077 \\
\hline
\end{tabular}




\begin{tabular}{|c|c|c|c|c|c|c|c|}
\hline Clarity & 1925 & ss & 4 & static & 0.096194 & 1.073143 & -0.06791 \\
\hline Clarity & 1925 & Ss & 4 & kinetic/0 & -0.12558 & 280.1447 & 0.016335 \\
\hline Clarity & 1925 & SS & 4 & $2.7 \mathrm{deg}$ & 16.98142 & 285.7251 & 2.755768 \\
\hline Clarity & 1925 & SS & 4 & $4.9 \mathrm{deg}$ & 25.92504 & 365.8354 & 4.52361 \\
\hline Clarity & 1925 & SS & 4 & $5.4 \mathrm{deg}$ & 23.79268 & 361.6501 & 5.283922 \\
\hline Clarity & 1925 & Ss & 4 & dyn frict & 13.82297 & 197.8675 & 2.715165 \\
\hline Clarity & 1925 & ss & 4 & $\begin{array}{l}\text { appar } \\
\text { stiff }\end{array}$ & 13.34538 & 106.7063 & 2.668042 \\
\hline Clarity & 1925 & SS & 5 & static & 0.077488 & 1.395086 & -0.03667 \\
\hline Clarity & 1925 & SS & 5 & kinetic/0 & -0.60659 & 305.0417 & 0.051201 \\
\hline Clarity & 1925 & SS & 5 & $2.7 \mathrm{deg}$ & 9.918953 & 326.3973 & 2.562992 \\
\hline Clarity & 1925 & SS & 5 & $4.9 \mathrm{deg}$ & 23.30634 & 472.7207 & 4.520347 \\
\hline Clarity & 1925 & SS & 5 & $5.4 \mathrm{deg}$ & 31.06621 & 408.7075 & 5.337303 \\
\hline Clarity & 1925 & SS & 5 & dyn frict & 7.307775 & 201.7119 & 2.719697 \\
\hline Clarity & 1925 & ss & 5 & $\begin{array}{l}\text { appar } \\
\text { stiff }\end{array}$ & 6.498806 & 94.21692 & 2.702597 \\
\hline Clarity & 2125 & alastic & 1 & static & 0.033855 & 1.5024 & -0.00834 \\
\hline Clarity & 2125 & alastic & 1 & kinetic/0 & -1.26125 & 154.5866 & -0.04466 \\
\hline Clarity & 2125 & alastic & 1 & $2.7 \mathrm{deg}$ & 8.884842 & 206.3122 & 2.717669 \\
\hline Clarity & 2125 & alastic & 1 & $4.9 \mathrm{deg}$ & 29.57517 & 310.3537 & 4.39402 \\
\hline Clarity & 2125 & alastic & 1 & $5.4 \mathrm{deg}$ & 37.48201 & 292.2176 & 5.178263 \\
\hline Clarity & 2125 & alastic & 1 & dyn frict & 5.884647 & 86.13781 & 2.628546 \\
\hline Clarity & 2125 & alastic & 1 & $\begin{array}{l}\text { appar } \\
\text { stiff }\end{array}$ & 6.053332 & 11.8965 & 2.696014 \\
\hline Clarity & 2125 & alastic & 2 & static & 0.130936 & 0 & 0.02651 \\
\hline Clarity & 2125 & alastic & 2 & kinetic/0 & -0.75621 & 403.5028 & 0.013074 \\
\hline Clarity & 2125 & alastic & 2 & $2.7 \mathrm{deg}$ & 48.72634 & 291.4127 & 2.384363 \\
\hline Clarity & 2125 & alastic & 2 & $4.9 \mathrm{deg}$ & 59.75956 & 397.8688 & 4.609688 \\
\hline Clarity & 2125 & alastic & 2 & $5.4 \mathrm{deg}$ & 68.21954 & 382.6301 & 5.215298 \\
\hline Clarity & 2125 & alastic & 2 & dyn frict & 39.81144 & 260.1252 & 2.650237 \\
\hline Clarity & 2125 & alastic & 2 & $\begin{array}{l}\text { appar } \\
\text { stiff }\end{array}$ & 39.78593 & 157.9905 & 2.653902 \\
\hline Clarity & 2125 & alastic & 3 & static & 0.02048 & 4.131621 & -0.02324 \\
\hline Clarity & 2125 & alastic & 3 & kinetic/0 & 0.916535 & 130.7091 & 0.034857 \\
\hline Clarity & 2125 & alastic & 3 & $2.7 \mathrm{deg}$ & 15.68007 & 141.2796 & 2.571715 \\
\hline Clarity & 2125 & alastic & 3 & $4.9 \mathrm{deg}$ & 38.89556 & 350.704 & 4.578104 \\
\hline Clarity & 2125 & alastic & 3 & $5.4 \mathrm{deg}$ & 40.18619 & 446.7505 & 5.300256 \\
\hline Clarity & 2125 & alastic & 3 & dyn frict & 14.07371 & 112.2094 & 2.743635 \\
\hline Clarity & 2125 & alastic & 3 & $\begin{array}{l}\text { appar } \\
\text { stiff }\end{array}$ & 14.20952 & 25.83835 & 2.696308 \\
\hline Clarity & 2125 & alastic & 4 & static & 0.042752 & 4.077943 & -0.0777 \\
\hline Clarity & 2125 & alastic & 4 & kinetic/0 & -1.79834 & 230.8873 & -0.02723 \\
\hline Clarity & 2125 & alastic & 4 & $2.7 \mathrm{deg}$ & 10.0499 & 259.8622 & 2.506358 \\
\hline Clarity & 2125 & alastic & 4 & $4.9 \mathrm{deg}$ & 18.29076 & 293.5054 & 4.497504 \\
\hline Clarity & 2125 & alastic & 4 & $5.4 \mathrm{deg}$ & 24.40192 & 278.9106 & 5.232718 \\
\hline Clarity & 2125 & alastic & 4 & dyn frict & 1.495874 & 166.5955 & 2.67586 \\
\hline Clarity & 2125 & alastic & 4 & $\begin{array}{l}\text { appar } \\
\text { stiff }\end{array}$ & 1.247235 & 112.3701 & 2.652647 \\
\hline Clarity & 2125 & alastic & 5 & static & 0.010678 & 7.780286 & -0.03595 \\
\hline Clarity & 2125 & alastic & 5 & kinetic/0 & 0.379426 & 227.5069 & -0.03158 \\
\hline
\end{tabular}




\begin{tabular}{|c|c|c|c|c|c|c|c|}
\hline Clarity & 2125 & alastic & 5 & $2.7 \mathrm{deg}$ & 19.05228 & 295.8126 & 2.744903 \\
\hline Clarity & 2125 & alastic & 5 & $4.9 \mathrm{deg}$ & 22.61959 & 369.4304 & 4.55414 \\
\hline Clarity & 2125 & alastic & 5 & $5.4 \mathrm{deg}$ & 38.93829 & 401.5175 & 5.264304 \\
\hline Clarity & 2125 & alastic & 5 & dyn frict & 10.66512 & 198.04 & 2.735575 \\
\hline Clarity & 2125 & alastic & 5 & $\begin{array}{l}\text { appar } \\
\text { stiff }\end{array}$ & 10.24764 & 107.2253 & 2.761325 \\
\hline Clarity & 2125 & SS & 1 & static & 0.138063 & 5.151181 & 0.041399 \\
\hline Clarity & 2125 & SS & 1 & kinetic/0 & 1.589934 & 271.0766 & -0.0196 \\
\hline Clarity & 2125 & SS & 1 & $2.7 \mathrm{deg}$ & 30.95401 & 246.7699 & 2.568462 \\
\hline Clarity & 2125 & Ss & 1 & $4.9 \mathrm{deg}$ & 33.44443 & 243.8188 & 2.643618 \\
\hline Clarity & 2125 & SS & 1 & $5.4 \mathrm{deg}$ & 47.8499 & 254.6575 & 4.981119 \\
\hline Clarity & 2125 & SS & 1 & dyn frict & 26.4487 & 158.486 & 2.535709 \\
\hline Clarity & 2125 & ss & 1 & $\begin{array}{l}\text { appar } \\
\text { stiff }\end{array}$ & 24.345 & 115.0869 & 2.535134 \\
\hline Clarity & 2125 & SS & 2 & static & -0.17726 & 2.038971 & -0.02795 \\
\hline Clarity & 2125 & Ss & 2 & kinetic/0 & 2.209842 & 254.8184 & 0.006535 \\
\hline Clarity & 2125 & SS & 2 & $2.7 \mathrm{deg}$ & 8.526769 & 208.8878 & 2.675203 \\
\hline Clarity & 2125 & SS & 2 & $4.9 \mathrm{deg}$ & 28.72275 & 302.1441 & 4.575926 \\
\hline Clarity & 2125 & SS & 2 & $5.4 \mathrm{deg}$ & 35.27749 & 331.4947 & 5.227278 \\
\hline Clarity & 2125 & SS & 2 & dyn frict & 11.37191 & 159.3092 & 2.699888 \\
\hline Clarity & 2125 & ss & 2 & $\begin{array}{l}\text { appar } \\
\text { stiff }\end{array}$ & 10.7093 & 94.66734 & 2.706689 \\
\hline Clarity & 2125 & SS & 3 & static & 0.027622 & 0.7512 & -0.02143 \\
\hline Clarity & 2125 & SS & 3 & kinetic/0 & -0.86312 & 205.722 & 0.006535 \\
\hline Clarity & 2125 & SS & 3 & $2.7 \mathrm{deg}$ & 14.84902 & 226.0581 & 1.73298 \\
\hline Clarity & 2125 & SS & 3 & $4.9 \mathrm{deg}$ & 39.98043 & 390.5713 & 3.907119 \\
\hline Clarity & 2125 & SS & 3 & $5.4 \mathrm{deg}$ & 57.03933 & 454.3162 & 4.566096 \\
\hline Clarity & 2125 & SS & 3 & dyn frict & 16.8232 & 147.6485 & 2.075118 \\
\hline Clarity & 2125 & ss & 3 & $\begin{array}{l}\text { appar } \\
\text { stiff }\end{array}$ & 16.13398 & 42.42429 & 2.044595 \\
\hline Clarity & 2125 & SS & 4 & static & 0.098879 & 1.23414 & -0.03267 \\
\hline Clarity & 2125 & ss & 4 & kinetic/0 & 0.037415 & 166.2303 & -0.00435 \\
\hline Clarity & 2125 & SS & 4 & $2.7 \mathrm{deg}$ & 18.25067 & 249.3454 & 2.407236 \\
\hline Clarity & 2125 & ss & 4 & $4.9 \mathrm{deg}$ & 27.02862 & 260.5597 & 4.193602 \\
\hline Clarity & 2125 & SS & 4 & $5.4 \mathrm{deg}$ & 34.77781 & 284.1153 & 5.161924 \\
\hline Clarity & 2125 & SS & 4 & dyn frict & 6.267838 & 101.8055 & 2.615633 \\
\hline Clarity & 2125 & ss & 4 & $\begin{array}{l}\text { appar } \\
\text { stiff }\end{array}$ & 6.044526 & 30.24092 & 2.652014 \\
\hline Clarity & 2125 & SS & 5 & static & 0.147854 & 3.863314 & 0.033037 \\
\hline Clarity & 2125 & SS & 5 & kinetic/0 & 1.902568 & 254.8184 & 0.015248 \\
\hline Clarity & 2125 & SS & 5 & $2.7 \mathrm{deg}$ & 14.75285 & 429.5265 & 2.55863 \\
\hline Clarity & 2125 & SS & 5 & $4.9 \mathrm{deg}$ & 28.01731 & 462.6331 & 4.450643 \\
\hline Clarity & 2125 & Ss & 5 & $5.4 \mathrm{deg}$ & 35.04503 & 419.9219 & 5.28064 \\
\hline Clarity & 2125 & SS & 5 & dyn frict & 3.26095 & 161.3765 & 2.795252 \\
\hline Clarity & 2125 & ss & 5 & $\begin{array}{l}\text { appar } \\
\text { stiff }\end{array}$ & 1.924421 & 25.28001 & 2.772021 \\
\hline Metal & 18 & alastic & 1 & static & 0.099767 & 4.936457 & -0.01125 \\
\hline Metal & 18 & alastic & 1 & kinetic/0 & -0.34472 & 55.5889 & 0.003267 \\
\hline Metal & 18 & alastic & 1 & $2.7 \mathrm{deg}$ & 17.59865 & 108.1194 & 2.853811 \\
\hline Metal & 18 & alastic & 1 & $4.9 \mathrm{deg}$ & 26.54496 & 169.7179 & 4.829685 \\
\hline
\end{tabular}




\begin{tabular}{|c|c|c|c|c|c|c|c|}
\hline Metal & 18 & alastic & 1 & $5.4 \mathrm{deg}$ & 37.5969 & 187.2639 & 5.813271 \\
\hline Metal & 18 & alastic & 1 & dyn frict & 11.49372 & 57.96721 & 2.936025 \\
\hline Metal & 18 & alastic & 1 & $\begin{array}{l}\text { appar } \\
\text { stiff }\end{array}$ & 11.30192 & -6.56958 & 3.003407 \\
\hline Metal & 18 & alastic & 2 & static & -0.16122 & 8.263201 & 0.023611 \\
\hline Metal & 18 & alastic & 2 & kinetic/0 & -0.43288 & 66.91056 & 0.009805 \\
\hline Metal & 18 & alastic & 2 & $2.7 \mathrm{deg}$ & 22.88681 & 172.1325 & 2.84621 \\
\hline Metal & 18 & alastic & 2 & $4.9 \mathrm{deg}$ & 39.05321 & 244.3016 & 4.940805 \\
\hline Metal & 18 & alastic & 2 & $5.4 \mathrm{deg}$ & 44.40284 & 277.0325 & 5.871023 \\
\hline Metal & 18 & alastic & 2 & dyn frict & 18.54099 & 138.6416 & 3.082203 \\
\hline Metal & 18 & alastic & 2 & $\begin{array}{l}\text { appar } \\
\text { stiff }\end{array}$ & 18.39927 & 39.44551 & 3.152538 \\
\hline Metal & 18 & alastic & 3 & static & 0.11 & 2.63 & 0.05 \\
\hline Metal & 18 & alastic & 3 & kinetic/0 & 0.22 & 117.56 & -0.01 \\
\hline Metal & 18 & alastic & 3 & $2.7 \mathrm{deg}$ & 14.19 & 193.33 & 2.56 \\
\hline Metal & 18 & alastic & 3 & $4.9 \mathrm{deg}$ & 31.51 & 278.21 & 4.81 \\
\hline Metal & 18 & alastic & 3 & $5.4 \mathrm{deg}$ & 38.74 & 300.70 & 5.74 \\
\hline Metal & 18 & alastic & 3 & dyn frict & 12.28 & 148.31 & 2.90 \\
\hline Metal & 18 & alastic & 3 & $\begin{array}{l}\text { appar } \\
\text { stiff }\end{array}$ & 12.14 & 84.33 & 2.96 \\
\hline Metal & 18 & alastic & 4 & static & 0.071256 & 5.043771 & -0.02432 \\
\hline Metal & 18 & alastic & 4 & kinetic/0 & -0.11758 & 62.61808 & -0.0098 \\
\hline Metal & 18 & alastic & 4 & $2.7 \mathrm{deg}$ & 3.762352 & 60.0962 & 2.760155 \\
\hline Metal & 18 & alastic & 4 & $4.9 \mathrm{deg}$ & 10.91566 & 72.06174 & 4.823152 \\
\hline Metal & 18 & alastic & 4 & $5.4 \mathrm{deg}$ & 17.70019 & 81.77369 & 5.753369 \\
\hline Metal & 18 & alastic & 4 & dyn frict & 3.380321 & 50.44665 & 2.932398 \\
\hline Metal & 18 & alastic & 4 & $\begin{array}{l}\text { appar } \\
\text { stiff }\end{array}$ & 2.503463 & 3.545105 & 2.989632 \\
\hline Metal & 18 & alastic & 5 & static & 0.350953 & 4.346229 & 0.027973 \\
\hline Metal & 18 & alastic & 5 & kinetic/0 & 0.342044 & 76.40797 & 0.004358 \\
\hline Metal & 18 & alastic & 5 & $2.7 \mathrm{deg}$ & 19.04429 & 100.3392 & 2.740546 \\
\hline Metal & 18 & alastic & 5 & $4.9 \mathrm{deg}$ & 37.2816 & 190.376 & 4.940795 \\
\hline Metal & 18 & alastic & 5 & $5.4 \mathrm{deg}$ & 43.79626 & 194.3467 & 5.81656 \\
\hline Metal & 18 & alastic & 5 & dyn frict & 18.73136 & 82.27694 & 3.00709 \\
\hline Metal & 18 & alastic & 5 & $\begin{array}{l}\text { appar } \\
\text { stiff }\end{array}$ & 18.60488 & 7.101914 & 3.061414 \\
\hline Metal & 18 & ss & 1 & static & 0.03921 & -0.59023 & 0.030136 \\
\hline Metal & 18 & Ss & 1 & kinetic/0 & 0.136287 & -0.3756 & 0.007625 \\
\hline Metal & 18 & SS & 1 & $2.7 \mathrm{deg}$ & 13.4034 & 68.57403 & 2.780832 \\
\hline Metal & 18 & SS & 1 & $4.9 \mathrm{deg}$ & 27.06335 & 152.2794 & 4.672838 \\
\hline Metal & 18 & SS & 1 & $5.4 \mathrm{deg}$ & 29.05676 & 179.6446 & 5.609602 \\
\hline Metal & 18 & SS & 1 & dyn frict & 9.254528 & 51.27446 & 2.683711 \\
\hline Metal & 18 & SS & 1 & $\begin{array}{l}\text { appar } \\
\text { stiff }\end{array}$ & 8.955648 & 15.31516 & 2.545122 \\
\hline Metal & 18 & SS & 2 & static & -0.06947 & 3.595029 & 0.007993 \\
\hline Metal & 18 & SS & 2 & kinetic/0 & -0.10422 & 46.41353 & 0.018524 \\
\hline Metal & 18 & Ss & 2 & $2.7 \mathrm{deg}$ & 13.66797 & 106.0268 & 2.62833 \\
\hline Metal & 18 & SS & 2 & $4.9 \mathrm{deg}$ & 17.06158 & 136.8261 & 4.693529 \\
\hline Metal & 18 & SS & 2 & $5.4 \mathrm{deg}$ & 26.97785 & 154.372 & 5.543146 \\
\hline Metal & 18 & SS & 2 & dyn frict & 7.420742 & 52.18025 & 2.787176 \\
\hline
\end{tabular}




\begin{tabular}{|c|c|c|c|c|c|c|c|}
\hline Metal & 18 & ss & 2 & $\begin{array}{l}\text { appar } \\
\text { stiff }\end{array}$ & 7.446593 & 28.10579 & 2.715422 \\
\hline Metal & 18 & ss & 3 & static & -0.07393 & 1.448743 & 0.000367 \\
\hline Metal & 18 & ss & 3 & kinetic/0 & 0.053438 & 0.965829 & 0.049011 \\
\hline Metal & 18 & Ss & 3 & $2.7 \mathrm{deg}$ & 10.35985 & 2.414571 & 2.488902 \\
\hline Metal & 18 & ss & 3 & $4.9 \mathrm{deg}$ & 14.05274 & 43.73067 & 4.520332 \\
\hline Metal & 18 & ss & 3 & $5.4 \mathrm{deg}$ & 21.82063 & 79.09083 & 5.375398 \\
\hline Metal & 18 & ss & 3 & dyn frict & 5.585552 & 17.6762 & 2.702828 \\
\hline Metal & 18 & ss & 3 & $\begin{array}{l}\text { appar } \\
\text { stiff }\end{array}$ & 5.578113 & 8.216994 & 2.74789 \\
\hline Metal & 18 & ss & 4 & static & 0.128252 & 5.473042 & -0.06609 \\
\hline Metal & 18 & ss & 4 & kinetic/0 & 0.146963 & 12.77041 & 0.009804 \\
\hline Metal & 18 & ss & 4 & $2.7 \mathrm{deg}$ & 8.109914 & -8.69254 & 2.405044 \\
\hline Metal & 18 & ss & 4 & $4.9 \mathrm{deg}$ & 12.77814 & 22.16041 & 4.600937 \\
\hline Metal & 18 & ss & 4 & $5.4 \mathrm{deg}$ & 18.08499 & 27.52613 & 5.421155 \\
\hline Metal & 18 & Ss & 4 & dyn frict & 5.003468 & 2.436436 & 2.75883 \\
\hline Metal & 18 & ss & 4 & $\begin{array}{l}\text { appar } \\
\text { stiff }\end{array}$ & 5.243643 & -25.2259 & 2.853757 \\
\hline Metal & 18 & ss & 5 & static & -0.05523 & 4.775486 & -0.00508 \\
\hline Metal & 18 & Ss & 5 & kinetic/0 & 0.061459 & 1.180457 & 0.005446 \\
\hline Metal & 18 & ss & 5 & $2.7 \mathrm{deg}$ & 9.814747 & 31.1749 & 2.75032 \\
\hline Metal & 18 & ss & 5 & $4.9 \mathrm{deg}$ & 11.43407 & 60.1498 & 4.590055 \\
\hline Metal & 18 & Ss & 5 & $5.4 \mathrm{deg}$ & 22.35239 & 70.18374 & 5.463637 \\
\hline Metal & 18 & ss & 5 & dyn frict & 5.557775 & 17.06754 & 2.791159 \\
\hline Metal & 18 & ss & 5 & $\begin{array}{l}\text { appar } \\
\text { stiff }\end{array}$ & 4.756935 & 8.449686 & 2.854615 \\
\hline Metal & 1925 & alastic & 1 & static & 0.187053 & 0.3756 & -0.00508 \\
\hline Metal & 1925 & alastic & 1 & kinetic/0 & -2.25795 & 159.845 & 0.005446 \\
\hline Metal & 1925 & alastic & 1 & $2.7 \mathrm{deg}$ & 7.391109 & 108.817 & 2.75032 \\
\hline Metal & 1925 & alastic & 1 & $4.9 \mathrm{deg}$ & 12.09139 & 126.0946 & 4.590055 \\
\hline Metal & 1925 & alastic & 1 & $5.4 \mathrm{deg}$ & 22.05845 & 150.0258 & 5.463637 \\
\hline Metal & 1925 & alastic & 1 & dyn frict & 5.719507 & 44.36949 & 2.791159 \\
\hline Metal & 1925 & alastic & 1 & $\begin{array}{l}\text { appar } \\
\text { stiff }\end{array}$ & 5.494007 & 2.841166 & 2.854615 \\
\hline Metal & 1925 & alastic & 2 & static & 0.109568 & 2.6292 & -0.00508 \\
\hline Metal & 1925 & alastic & 2 & kinetic/0 & 0.09353 & 1.609714 & 0.005446 \\
\hline Metal & 1925 & alastic & 2 & $2.7 \mathrm{deg}$ & 16.03011 & -119.602 & 2.75032 \\
\hline Metal & 1925 & alastic & 2 & $4.9 \mathrm{deg}$ & 22.01034 & -101.573 & 4.590055 \\
\hline Metal & 1925 & alastic & 2 & $5.4 \mathrm{deg}$ & 27.98256 & -103.666 & 5.463637 \\
\hline Metal & 1925 & alastic & 2 & dyn frict & 13.76596 & -66.7019 & 2.791159 \\
\hline Metal & 1925 & alastic & 2 & $\begin{array}{l}\text { appar } \\
\text { stiff }\end{array}$ & 13.50489 & -65.6335 & 2.854615 \\
\hline Metal & 1925 & alastic & 3 & static & -0.11936 & 5.2584 & -0.00508 \\
\hline Metal & 1925 & alastic & 3 & kinetic/0 & -2.21253 & 180.4495 & 0.005446 \\
\hline Metal & 1925 & alastic & 3 & $2.7 \mathrm{deg}$ & 5.379015 & 104.2561 & 2.75032 \\
\hline Metal & 1925 & alastic & 3 & $4.9 \mathrm{deg}$ & 15.10824 & 80.64689 & 4.590055 \\
\hline Metal & 1925 & alastic & 3 & $5.4 \mathrm{deg}$ & 22.72916 & 75.17386 & 5.463637 \\
\hline Metal & 1925 & alastic & 3 & dyn frict & 6.700136 & 53.11484 & 2.791159 \\
\hline Metal & 1925 & alastic & 3 & $\begin{array}{l}\text { appar } \\
\text { stiff }\end{array}$ & 6.904316 & -7.98804 & 2.854615 \\
\hline
\end{tabular}




\begin{tabular}{|c|c|c|c|c|c|c|c|}
\hline Metal & 1925 & alastic & 4 & static & 0.034741 & 1.770722 & -0.00508 \\
\hline Metal & 1925 & alastic & 4 & kinetic/0 & -0.88181 & 117.0802 & 0.005446 \\
\hline Metal & 1925 & alastic & 4 & $2.7 \mathrm{deg}$ & 10.52019 & 85.58338 & 2.75032 \\
\hline Metal & 1925 & alastic & 4 & $4.9 \mathrm{deg}$ & 24.9203 & 220.746 & 4.590055 \\
\hline Metal & 1925 & alastic & 4 & $5.4 \mathrm{deg}$ & 35.67831 & 264.5304 & 5.463637 \\
\hline Metal & 1925 & alastic & 4 & dyn frict & 10.39694 & 103.5081 & 2.791159 \\
\hline Metal & 1925 & alastic & 4 & $\begin{array}{l}\text { appar } \\
\text { stiff }\end{array}$ & 10.63731 & 14.87209 & 2.854615 \\
\hline Metal & 1925 & alastic & 5 & static & -0.02673 & 3.541371 & -0.00508 \\
\hline Metal & 1925 & alastic & 5 & kinetic/0 & -0.46763 & 163.1182 & 0.005446 \\
\hline Metal & 1925 & alastic & 5 & $2.7 \mathrm{deg}$ & 15.29526 & 285.8324 & 2.75032 \\
\hline Metal & 1925 & alastic & 5 & $4.9 \mathrm{deg}$ & 33.46845 & 389.2299 & 4.590055 \\
\hline Metal & 1925 & alastic & 5 & $5.4 \mathrm{deg}$ & 45.26857 & 416.4342 & 5.463637 \\
\hline Metal & 1925 & alastic & 5 & dyn frict & 10.68424 & 207.1863 & 2.791159 \\
\hline Metal & 1925 & alastic & 5 & $\begin{array}{l}\text { appar } \\
\text { stiff }\end{array}$ & 10.65666 & 102.1646 & 2.854615 \\
\hline Metal & 1925 & SS & 1 & static & 0.061467 & 7.726646 & -0.01889 \\
\hline Metal & 1925 & SS & 1 & kinetic/0 & 0.323314 & 60.52537 & -0.01198 \\
\hline Metal & 1925 & SS & 1 & $2.7 \mathrm{deg}$ & 39.48609 & 296.4564 & 2.894119 \\
\hline Metal & 1925 & SS & 1 & $4.9 \mathrm{deg}$ & 63.69562 & 489.0324 & 4.797012 \\
\hline Metal & 1925 & ss & 1 & $5.4 \mathrm{deg}$ & 68.94101 & 533.0314 & 5.70328 \\
\hline Metal & 1925 & ss & 1 & dyn frict & 28.39758 & 151.7332 & 2.787226 \\
\hline Metal & 1925 & ss & 1 & $\begin{array}{l}\text { appar } \\
\text { stiff }\end{array}$ & 28.11302 & 5.261046 & 2.796001 \\
\hline Metal & 1925 & ss & 2 & static & 0.032067 & 2.360914 & -0.01997 \\
\hline Metal & 1925 & SS & 2 & kinetic/0 & 0.072141 & 21.8922 & 0.018519 \\
\hline Metal & 1925 & SS & 2 & $2.7 \mathrm{deg}$ & 15.85108 & 9.443704 & 2.906095 \\
\hline Metal & 1925 & SS & 2 & $4.9 \mathrm{deg}$ & 19.27409 & 102.7537 & 4.691356 \\
\hline Metal & 1925 & ss & 2 & $5.4 \mathrm{deg}$ & 32.46371 & 177.2837 & 5.632469 \\
\hline Metal & 1925 & Ss & 2 & dyn frict & 9.8191 & 31.02621 & 2.851449 \\
\hline Metal & 1925 & ss & 2 & $\begin{array}{l}\text { appar } \\
\text { stiff }\end{array}$ & 10.10289 & -0.15298 & 2.885059 \\
\hline Metal & 1925 & ss & 3 & static & -0.09175 & 7.780286 & 0.002178 \\
\hline Metal & 1925 & ss & 3 & kinetic/0 & $-6.6 E-06$ & 40.02833 & 0.015244 \\
\hline Metal & 1925 & ss & 3 & $2.7 \mathrm{deg}$ & 15.22046 & 31.38952 & 2.95619 \\
\hline Metal & 1925 & Ss & 3 & $4.9 \mathrm{deg}$ & 21.31291 & 118.0997 & 4.742545 \\
\hline Metal & 1925 & ss & 3 & $5.4 \mathrm{deg}$ & 26.76139 & 140.3674 & 5.709801 \\
\hline Metal & 1925 & ss & 3 & dyn frict & 9.075541 & 42.81022 & 2.899723 \\
\hline Metal & 1925 & ss & 3 & $\begin{array}{l}\text { appar } \\
\text { stiff }\end{array}$ & 8.994615 & 27.11816 & 2.998802 \\
\hline Metal & 1925 & SS & 4 & static & 0.034736 & 18.35081 & 0.050117 \\
\hline Metal & 1925 & ss & 4 & kinetic/0 & 0.018708 & 55.15971 & 0.033773 \\
\hline Metal & 1925 & ss & 4 & $2.7 \mathrm{deg}$ & 28.53304 & 228.7946 & 3.155518 \\
\hline Metal & 1925 & ss & 4 & $4.9 \mathrm{deg}$ & 56.04264 & 398.5663 & 4.983273 \\
\hline Metal & 1925 & Ss & 4 & $5.4 \mathrm{deg}$ & 69.63846 & 486.135 & 5.902596 \\
\hline Metal & 1925 & ss & 4 & dyn frict & 23.4478 & 136.7529 & 3.210276 \\
\hline Metal & 1925 & ss & 4 & $\begin{array}{l}\text { appar } \\
\text { stiff }\end{array}$ & 21.77884 & 53.40069 & 3.211744 \\
\hline Metal & 1925 & SS & 5 & static & -0.09263 & 5.312057 & -0.02868 \\
\hline Metal & 1925 & Ss & 5 & kinetic/0 & -0.05612 & 5.204743 & -0.0109 \\
\hline
\end{tabular}




\begin{tabular}{|c|c|c|c|c|c|c|c|}
\hline Metal & 1925 & ss & 5 & $2.7 \mathrm{deg}$ & 15.21512 & 69.59351 & 2.728545 \\
\hline Metal & 1925 & Ss & 5 & $4.9 \mathrm{deg}$ & 27.01526 & 188.6054 & 4.740366 \\
\hline Metal & 1925 & SS & 5 & $5.4 \mathrm{deg}$ & 39.34714 & 250.2039 & 5.482157 \\
\hline Metal & 1925 & SS & 5 & dyn frict & 10.92182 & 53.41142 & 2.851465 \\
\hline Metal & 1925 & ss & 5 & $\begin{array}{l}\text { appar } \\
\text { stiff }\end{array}$ & 10.58125 & 11.88695 & 2.759977 \\
\hline Metal & 2125 & alastic & 1 & static & 0.065908 & 5.2584 & -0.02868 \\
\hline Metal & 2125 & alastic & 1 & kinetic/0 & -1.5498 & 194.132 & -0.0109 \\
\hline Metal & 2125 & alastic & 1 & $2.7 \mathrm{deg}$ & 9.413936 & 119.4411 & 2.728545 \\
\hline Metal & 2125 & alastic & 1 & $4.9 \mathrm{deg}$ & 22.53411 & 118.7436 & 4.740366 \\
\hline Metal & 2125 & alastic & 1 & $5.4 \mathrm{deg}$ & 33.50857 & 192.1467 & 5.482157 \\
\hline Metal & 2125 & alastic & 1 & dyn frict & 11.73435 & 105.0281 & 2.851465 \\
\hline Metal & 2125 & alastic & 1 & $\begin{array}{l}\text { appar } \\
\text { stiff }\end{array}$ & 12.42385 & 13.91207 & 2.759977 \\
\hline Metal & 2125 & alastic & 2 & static & 0.026712 & 3.326743 & -0.02868 \\
\hline Metal & 2125 & alastic & 2 & kinetic/0 & -4.34221 & 348.2894 & -0.0109 \\
\hline Metal & 2125 & alastic & 2 & $2.7 \mathrm{deg}$ & 15.6694 & 200.1954 & 2.728545 \\
\hline Metal & 2125 & alastic & 2 & $4.9 \mathrm{deg}$ & 28.48495 & 274.2961 & 4.740366 \\
\hline Metal & 2125 & alastic & 2 & $5.4 \mathrm{deg}$ & 37.63166 & 315.6122 & 5.482157 \\
\hline Metal & 2125 & alastic & 2 & dyn frict & 12.71205 & 172.9863 & 2.851465 \\
\hline Metal & 2125 & alastic & 2 & $\begin{array}{l}\text { appar } \\
\text { stiff }\end{array}$ & 14.4226 & 102.2884 & 2.759977 \\
\hline Metal & 2125 & alastic & 3 & static & -0.17902 & 0.536571 & -0.02868 \\
\hline Metal & 2125 & alastic & 3 & kinetic/0 & -3.65545 & 289.6957 & -0.0109 \\
\hline Metal & 2125 & alastic & 3 & $2.7 \mathrm{deg}$ & 14.78762 & 153.2989 & 2.728545 \\
\hline Metal & 2125 & alastic & 3 & $4.9 \mathrm{deg}$ & 38.67914 & 335.0361 & 4.740366 \\
\hline Metal & 2125 & alastic & 3 & $5.4 \mathrm{deg}$ & 48.9909 & 372.5425 & 5.482157 \\
\hline Metal & 2125 & alastic & 3 & dyn frict & 18.24667 & 125.4978 & 2.851465 \\
\hline Metal & 2125 & alastic & 3 & $\begin{array}{l}\text { appar } \\
\text { stiff }\end{array}$ & 19.36182 & 39.45408 & 2.759977 \\
\hline Metal & 2125 & alastic & 4 & static & 0.032066 & 4.1316 & 0.036309 \\
\hline Metal & 2125 & alastic & 4 & kinetic/0 & -0.75889 & 186.1907 & 0.027226 \\
\hline Metal & 2125 & alastic & 4 & $2.7 \mathrm{deg}$ & 11.66384 & 79.89568 & 2.576059 \\
\hline Metal & 2125 & alastic & 4 & $4.9 \mathrm{deg}$ & 23.34107 & 81.66637 & 4.876522 \\
\hline Metal & 2125 & alastic & 4 & $5.4 \mathrm{deg}$ & 37.96031 & 114.3437 & 5.745754 \\
\hline Metal & 2125 & alastic & 4 & dyn frict & 11.72053 & 57.67247 & 2.902362 \\
\hline Metal & 2125 & alastic & 4 & $\begin{array}{l}\text { appar } \\
\text { stiff }\end{array}$ & 11.17049 & -26.3739 & 2.850025 \\
\hline Metal & 2125 & alastic & 5 & static & 0.014252 & 4.185255 & 0.011623 \\
\hline Metal & 2125 & alastic & 5 & kinetic/0 & -2.68285 & 329.5094 & 0.02723 \\
\hline Metal & 2125 & alastic & 5 & $2.7 \mathrm{deg}$ & 10.41059 & 223.3216 & 2.916987 \\
\hline Metal & 2125 & alastic & 5 & $4.9 \mathrm{deg}$ & 18.53924 & 186.1908 & 4.961478 \\
\hline Metal & 2125 & alastic & 5 & $5.4 \mathrm{deg}$ & 29.82899 & 234.7506 & 5.766447 \\
\hline Metal & 2125 & alastic & 5 & dyn frict & 8.563167 & 207.7087 & 2.956786 \\
\hline Metal & 2125 & alastic & 5 & $\begin{array}{l}\text { appar } \\
\text { stiff }\end{array}$ & 9.04615 & 130.9934 & 2.925613 \\
\hline Metal & 2125 & Ss & 1 & static & -0.2102 & 18.88739 & 0.029414 \\
\hline Metal & 2125 & SS & 1 & kinetic/0 & -0.42218 & 125.3971 & 0.030496 \\
\hline Metal & 2125 & SS & 1 & $2.7 \mathrm{deg}$ & 28.19635 & 184.903 & 2.605466 \\
\hline Metal & 2125 & Ss & 1 & $4.9 \mathrm{deg}$ & 53.00442 & 353.8161 & 4.541045 \\
\hline
\end{tabular}




\begin{tabular}{|c|c|c|c|c|c|c|c|}
\hline Metal & 2125 & ss & 1 & $5.4 \mathrm{deg}$ & 61.53654 & 395.7761 & 5.396108 \\
\hline Metal & 2125 & Ss & 1 & dyn frict & 24.08684 & 99.49022 & 2.755698 \\
\hline Metal & 2125 & ss & 1 & $\begin{array}{l}\text { appar } \\
\text { stiff }\end{array}$ & 23.78439 & 16.66352 & 2.800733 \\
\hline Metal & 2125 & Ss & 2 & static & -0.11223 & 6.116908 & 0.039203 \\
\hline Metal & 2125 & Ss & 2 & kinetic/0 & -0.68673 & 115.8997 & -0.00327 \\
\hline Metal & 2125 & ss & 2 & $2.7 \mathrm{deg}$ & 18.79579 & 84.2956 & 2.419195 \\
\hline Metal & 2125 & SS & 2 & $4.9 \mathrm{deg}$ & 29.60191 & 156.7329 & 4.319918 \\
\hline Metal & 2125 & SS & 2 & $5.4 \mathrm{deg}$ & 40.11941 & 204.1123 & 5.202221 \\
\hline Metal & 2125 & SS & 2 & dyn frict & 12.21553 & 56.8156 & 2.537663 \\
\hline Metal & 2125 & ss & 2 & $\begin{array}{l}\text { appar } \\
\text { stiff }\end{array}$ & 11.95038 & 1.669246 & 2.494521 \\
\hline Metal & 2125 & SS & 3 & static & -4.08571 & 7.941357 & 0.012712 \\
\hline Metal & 2125 & SS & 3 & kinetic/0 & -3.94675 & 232.819 & -0.0207 \\
\hline Metal & 2125 & SS & 3 & $2.7 \mathrm{deg}$ & 49.56538 & 415.0927 & 2.621795 \\
\hline Metal & 2125 & Ss & 3 & $4.9 \mathrm{deg}$ & 66.78728 & 535.9826 & 4.295978 \\
\hline Metal & 2125 & SS & 3 & $5.4 \mathrm{deg}$ & 77.90335 & 605.6298 & 5.292635 \\
\hline Metal & 2125 & SS & 3 & dyn frict & 28.77274 & 250.0657 & 2.59436 \\
\hline Metal & 2125 & ss & 3 & $\begin{array}{l}\text { appar } \\
\text { stiff }\end{array}$ & 27.54661 & 124.307 & 2.623174 \\
\hline Metal & 2125 & SS & 4 & static & 0.105096 & 4.775486 & 0.001818 \\
\hline Metal & 2125 & SS & 4 & kinetic/0 & -0.24852 & -0.3756 & 0.023967 \\
\hline Metal & 2125 & SS & 4 & $2.7 \mathrm{deg}$ & 51.77255 & 44.26725 & 2.728551 \\
\hline Metal & 2125 & SS & 4 & $4.9 \mathrm{deg}$ & 75.68547 & 565.3331 & 4.724032 \\
\hline Metal & 2125 & Ss & 4 & $5.4 \mathrm{deg}$ & 76.91198 & 631.3852 & 5.6292 \\
\hline Metal & 2125 & SS & 4 & dyn frict & 29.71909 & 260.9166 & 2.735295 \\
\hline Metal & 2125 & ss & 4 & $\begin{array}{l}\text { appar } \\
\text { stiff }\end{array}$ & 25.45997 & -155.632 & 2.788658 \\
\hline Metal & 2125 & SS & 5 & static & 0.011584 & 5.258409 & 0.033033 \\
\hline Metal & 2125 & SS & 5 & kinetic/0 & 0.227122 & 106.5633 & -0.02396 \\
\hline Metal & 2125 & SS & 5 & $2.7 \mathrm{deg}$ & 39.98845 & 434.5166 & 2.504171 \\
\hline Metal & 2125 & SS & 5 & $4.9 \mathrm{deg}$ & 71.32187 & 789.6742 & 4.655413 \\
\hline Metal & 2125 & SS & 5 & $5.4 \mathrm{deg}$ & 81.8955 & 873.0576 & 5.436419 \\
\hline Metal & 2125 & Ss & 5 & dyn frict & 28.25592 & 204.3362 & 2.79336 \\
\hline Metal & 2125 & ss & 5 & $\begin{array}{l}\text { appar } \\
\text { stiff }\end{array}$ & 27.71312 & -28.8246 & 2.820393 \\
\hline Mystique & 18 & alastic & 1 & static & 0.048981 & 9.604631 & -0.03086 \\
\hline Mystique & 18 & alastic & 1 & kinetic/0 & -0.38213 & 38.20396 & -0.01525 \\
\hline Mystique & 18 & alastic & 1 & $2.7 \mathrm{deg}$ & 18.14111 & 111.8753 & 2.712231 \\
\hline Mystique & 18 & alastic & 1 & $4.9 \mathrm{deg}$ & 32.61873 & 195.5271 & 4.582456 \\
\hline Mystique & 18 & alastic & 1 & $5.4 \mathrm{deg}$ & 39.83081 & 221.2826 & 5.574765 \\
\hline Mystique & 18 & alastic & 1 & dyn frict & 16.05478 & 96.79075 & 2.665712 \\
\hline Mystique & 18 & alastic & 1 & $\begin{array}{l}\text { appar } \\
\text { stiff }\end{array}$ & 14.80542 & 18.88678 & 2.54625 \\
\hline Mystique & 18 & alastic & 2 & static & 0.041855 & 2.307257 & 0.0639 \\
\hline Mystique & 18 & alastic & 2 & kinetic/0 & -1.85714 & 184.2055 & 0.016336 \\
\hline Mystique & 18 & alastic & 2 & $2.7 \mathrm{deg}$ & 2.420946 & 129.6361 & 2.569542 \\
\hline Mystique & 18 & alastic & 2 & $4.9 \mathrm{deg}$ & 10.46675 & 105.061 & 4.539984 \\
\hline Mystique & 18 & alastic & 2 & $5.4 \mathrm{deg}$ & 15.78429 & 95.24173 & 5.433146 \\
\hline Mystique & 18 & alastic & 2 & dyn frict & 1.767686 & 99.89068 & 2.805624 \\
\hline
\end{tabular}




\begin{tabular}{|c|c|c|c|c|c|c|c|}
\hline Mystique & 18 & alastic & 2 & $\begin{array}{l}\text { appar } \\
\text { stiff }\end{array}$ & 1.979496 & 49.92681 & 2.705923 \\
\hline Mystique & 18 & alastic & 3 & static & 0.055225 & 4.560951 & -0.0127 \\
\hline Mystique & 18 & alastic & 3 & kinetic/0 & -2.98211 & 45.71608 & -0.04031 \\
\hline Mystique & 18 & alastic & 3 & $2.7 \mathrm{deg}$ & 3.254649 & 29.13592 & 1.972625 \\
\hline Mystique & 18 & alastic & 3 & $4.9 \mathrm{deg}$ & 10.45337 & 23.71655 & 4.070508 \\
\hline Mystique & 18 & alastic & 3 & $5.4 \mathrm{deg}$ & 16.68747 & 33.69678 & 5.111818 \\
\hline Mystique & 18 & alastic & 3 & dyn frict & 4.915904 & 4.901002 & 2.456304 \\
\hline Mystique & 18 & alastic & 3 & $\begin{array}{l}\text { appar } \\
\text { stiff }\end{array}$ & 5.26129 & -16.324 & 2.377748 \\
\hline Mystique & 18 & alastic & 4 & static & -0.05343 & 23.6629 & 0.014156 \\
\hline Mystique & 18 & alastic & 4 & kinetic/0 & 0.8631 & 82.5249 & -0.03813 \\
\hline Mystique & 18 & alastic & 4 & $2.7 \mathrm{deg}$ & 3.219922 & 66.21311 & 2.278719 \\
\hline Mystique & 18 & alastic & 4 & $4.9 \mathrm{deg}$ & 6.79524 & 59.93523 & 4.426708 \\
\hline Mystique & 18 & alastic & 4 & $5.4 \mathrm{deg}$ & 6.218049 & 56.5548 & 5.228386 \\
\hline Mystique & 18 & alastic & 4 & dyn frict & -1.10819 & 26.72374 & 2.628241 \\
\hline Mystique & 18 & alastic & 4 & $\begin{array}{l}\text { appar } \\
\text { stiff }\end{array}$ & -0.63779 & -3.8936 & 2.693112 \\
\hline Mystique & 18 & alastic & 5 & static & -0.09798 & 6.063282 & 0.053005 \\
\hline Mystique & 18 & alastic & 5 & kinetic/0 & -1.94532 & 84.13463 & 0.031581 \\
\hline Mystique & 18 & alastic & 5 & $2.7 \mathrm{deg}$ & 9.119986 & 75.92508 & 2.399616 \\
\hline Mystique & 18 & alastic & 5 & $4.9 \mathrm{deg}$ & 15.70677 & 100.9293 & 4.394019 \\
\hline Mystique & 18 & alastic & 5 & $5.4 \mathrm{deg}$ & 26.06396 & 134.948 & 5.245799 \\
\hline Mystique & 18 & alastic & 5 & dyn frict & 3.880945 & 52.19492 & 2.636648 \\
\hline Mystique & 18 & alastic & 5 & $\begin{array}{l}\text { appar } \\
\text { stiff }\end{array}$ & 3.831958 & 10.7527 & 2.572217 \\
\hline Mystique & 18 & SS & 1 & static & -0.2592 & 3.863314 & 0.052636 \\
\hline Mystique & 18 & SS & 1 & kinetic/0 & -2.05755 & 124.2703 & 0.034852 \\
\hline Mystique & 18 & SS & 1 & $2.7 \mathrm{deg}$ & 1.905227 & 105.1683 & 2.290693 \\
\hline Mystique & 18 & SS & 1 & $4.9 \mathrm{deg}$ & 4.702943 & 69.75449 & 4.341735 \\
\hline Mystique & 18 & SS & 1 & $5.4 \mathrm{deg}$ & 7.933541 & 84.1347 & 5.220747 \\
\hline Mystique & 18 & ss & 1 & dyn frict & -3.87643 & 67.33993 & 2.591974 \\
\hline Mystique & 18 & ss & 1 & $\begin{array}{l}\text { appar } \\
\text { stiff }\end{array}$ & -3.32885 & 13.48395 & 2.699392 \\
\hline Mystique & 18 & SS & 2 & static & 0.187056 & 21.24833 & 0.00945 \\
\hline Mystique & 18 & ss & 2 & kinetic/0 & -2.31139 & 17.49233 & -0.02287 \\
\hline Mystique & 18 & ss & 2 & $2.7 \mathrm{deg}$ & 11.14014 & 3.541371 & 2.354956 \\
\hline Mystique & 18 & ss & 2 & $4.9 \mathrm{deg}$ & 21.92217 & 40.61856 & 4.240437 \\
\hline Mystique & 18 & SS & 2 & $5.4 \mathrm{deg}$ & 31.85717 & 66.32043 & 5.233815 \\
\hline Mystique & 18 & ss & 2 & dyn frict & 9.273652 & 1.49842 & 2.655501 \\
\hline Mystique & 18 & ss & 2 & $\begin{array}{l}\text { appar } \\
\text { stiff }\end{array}$ & 9.463408 & -53.4442 & 2.71722 \\
\hline Mystique & 18 & SS & 3 & static & -0.13183 & -0.48291 & 0.010525 \\
\hline Mystique & 18 & SS & 3 & kinetic/0 & -1.88653 & 28.9213 & -0.00762 \\
\hline Mystique & 18 & Ss & 3 & $2.7 \mathrm{deg}$ & 13.53969 & 54.03294 & 2.375648 \\
\hline Mystique & 18 & Ss & 3 & $4.9 \mathrm{deg}$ & 21.00029 & 127.1141 & 4.367875 \\
\hline Mystique & 18 & ss & 3 & $5.4 \mathrm{deg}$ & 28.82162 & 139.5626 & 5.224012 \\
\hline Mystique & 18 & SS & 3 & dyn frict & 8.115873 & -0.50717 & 2.670251 \\
\hline Mystique & 18 & ss & 3 & $\begin{array}{l}\text { appar } \\
\text { stiff }\end{array}$ & 8.443461 & -40.609 & 2.612738 \\
\hline
\end{tabular}




\begin{tabular}{|c|c|c|c|c|c|c|c|}
\hline Mystique & 18 & ss & 4 & static & -0.0472 & 1.234114 & 0.067895 \\
\hline Mystique & 18 & Ss & 4 & kinetic/0 & 0.077491 & 59.23767 & -0.01416 \\
\hline Mystique & 18 & SS & 4 & $2.7 \mathrm{deg}$ & 8.302319 & 106.2414 & 2.44971 \\
\hline Mystique & 18 & SS & 4 & $4.9 \mathrm{deg}$ & 24.71991 & 133.9286 & 4.482241 \\
\hline Mystique & 18 & SS & 4 & $5.4 \mathrm{deg}$ & 30.77763 & 166.4449 & 5.28501 \\
\hline Mystique & 18 & Ss & 4 & dyn frict & 9.370866 & 57.17997 & 2.721348 \\
\hline Mystique & 18 & ss & 4 & $\begin{array}{l}\text { appar } \\
\text { stiff }\end{array}$ & 9.713864 & 26.8568 & 2.753749 \\
\hline Mystique & 18 & SS & 5 & static & -0.26186 & -2.03902 & -0.05553 \\
\hline Mystique & 18 & SS & 5 & kinetic/0 & -1.10091 & 47.6477 & -0.0294 \\
\hline Mystique & 18 & SS & 5 & $2.7 \mathrm{deg}$ & 9.967068 & 117.0802 & 2.178512 \\
\hline Mystique & 18 & SS & 5 & $4.9 \mathrm{deg}$ & 26.56101 & 173.6886 & 4.316689 \\
\hline Mystique & 18 & SS & 5 & $5.4 \mathrm{deg}$ & 29.94125 & 200.41 & 5.084595 \\
\hline Mystique & 18 & SS & 5 & dyn frict & 8.476321 & 77.05774 & 2.531056 \\
\hline Mystique & 18 & ss & 5 & $\begin{array}{l}\text { appar } \\
\text { stiff }\end{array}$ & 7.803482 & 15.80022 & 2.505211 \\
\hline Mystique & 1925 & alastic & 1 & static & 0.043629 & 5.526715 & 0.001816 \\
\hline Mystique & 1925 & alastic & 1 & kinetic/0 & -0.61727 & 176.7471 & -0.03485 \\
\hline Mystique & 1925 & alastic & 1 & $2.7 \mathrm{deg}$ & 16.60463 & 293.8809 & 2.470404 \\
\hline Mystique & 1925 & alastic & 1 & $4.9 \mathrm{deg}$ & 49.91543 & 486.9935 & 4.575907 \\
\hline Mystique & 1925 & alastic & 1 & $5.4 \mathrm{deg}$ & 58.59987 & 524.5536 & 5.318782 \\
\hline Mystique & 1925 & alastic & 1 & dyn frict & 23.43301 & 214.6374 & 2.70838 \\
\hline Mystique & 1925 & alastic & 1 & $\begin{array}{l}\text { appar } \\
\text { stiff }\end{array}$ & 23.05939 & 65.61912 & 2.689393 \\
\hline Mystique & 1925 & alastic & 2 & static & 0.03295 & -0.96583 & 0.005087 \\
\hline Mystique & 1925 & alastic & 2 & kinetic/0 & -2.33012 & 281.5397 & -0.01199 \\
\hline Mystique & 1925 & alastic & 2 & $2.7 \mathrm{deg}$ & 10.27166 & 221.8728 & 2.358204 \\
\hline Mystique & 1925 & alastic & 2 & $4.9 \mathrm{deg}$ & 30.12828 & 364.0646 & 4.462626 \\
\hline Mystique & 1925 & alastic & 2 & $5.4 \mathrm{deg}$ & 41.08402 & 403.0735 & 5.278475 \\
\hline Mystique & 1925 & alastic & 2 & dyn frict & 12.15192 & 215.9185 & 2.686986 \\
\hline Mystique & 1925 & alastic & 2 & $\begin{array}{l}\text { appar } \\
\text { stiff }\end{array}$ & 12.30785 & 132.7072 & 2.730935 \\
\hline Mystique & 1925 & alastic & 3 & static & 0.08996 & -0.16098 & -0.05592 \\
\hline Mystique & 1925 & alastic & 3 & kinetic/0 & -1.27729 & 125.9874 & -0.01742 \\
\hline Mystique & 1925 & alastic & 3 & $2.7 \mathrm{deg}$ & 7.751855 & 191.2883 & 2.386533 \\
\hline Mystique & 1925 & alastic & 3 & $4.9 \mathrm{deg}$ & 32.1805 & 262.1695 & 4.238245 \\
\hline Mystique & 1925 & alastic & 3 & $5.4 \mathrm{deg}$ & 48.29078 & 346.1432 & 5.12163 \\
\hline Mystique & 1925 & alastic & 3 & dyn frict & 14.33571 & 133.7642 & 2.509397 \\
\hline Mystique & 1925 & alastic & 3 & $\begin{array}{l}\text { appar } \\
\text { stiff }\end{array}$ & 13.3263 & 35.56579 & 2.441414 \\
\hline Mystique & 1925 & alastic & 4 & static & 0.099759 & 2.682857 & 0.008706 \\
\hline Mystique & 1925 & alastic & 4 & kinetic/0 & -1.39754 & 182.6494 & $-5.5 E-06$ \\
\hline Mystique & 1925 & alastic & 4 & $2.7 \mathrm{deg}$ & 2.447668 & 160.9183 & 2.405041 \\
\hline Mystique & 1925 & alastic & 4 & $4.9 \mathrm{deg}$ & 14.63259 & 134.2506 & 4.459357 \\
\hline Mystique & 1925 & alastic & 4 & $5.4 \mathrm{deg}$ & 18.97215 & 136.7188 & 5.323134 \\
\hline Mystique & 1925 & alastic & 4 & dyn frict & 5.822495 & 117.1982 & 2.707802 \\
\hline Mystique & 1925 & alastic & 4 & $\begin{array}{l}\text { appar } \\
\text { stiff }\end{array}$ & 5.365555 & 40.5368 & 2.654136 \\
\hline Mystique & 1925 & alastic & 5 & static & -0.06235 & 14.38012 & 0.027238 \\
\hline Mystique & 1925 & alastic & 5 & kinetic/0 & -5.85999 & 60.90096 & 0.016332 \\
\hline
\end{tabular}




\begin{tabular}{|c|c|c|c|c|c|c|c|}
\hline Mystique & 1925 & alastic & 5 & $2.7 \mathrm{deg}$ & -0.49168 & 32.67721 & 2.368007 \\
\hline Mystique & 1925 & alastic & 5 & $4.9 \mathrm{deg}$ & 16.58859 & 63.63747 & 4.571553 \\
\hline Mystique & 1925 & alastic & 5 & $5.4 \mathrm{deg}$ & 27.83025 & 120.0313 & 5.415727 \\
\hline Mystique & 1925 & alastic & 5 & dyn frict & 4.522333 & 20.35609 & 2.809109 \\
\hline Mystique & 1925 & alastic & 5 & $\begin{array}{l}\text { appar } \\
\text { stiff }\end{array}$ & 5.350081 & -44.262 & 2.823513 \\
\hline Mystique & 1925 & Ss & 1 & static & -0.26454 & 52.10119 & 0.040673 \\
\hline Mystique & 1925 & SS & 1 & kinetic/0 & -3.24129 & 702.8567 & -0.0196 \\
\hline Mystique & 1925 & SS & 1 & $2.7 \mathrm{deg}$ & 17.91132 & 651.8823 & 2.433369 \\
\hline Mystique & 1925 & SS & 1 & $4.9 \mathrm{deg}$ & 25.65783 & 688.3693 & 4.328653 \\
\hline Mystique & 1925 & SS & 1 & $5.4 \mathrm{deg}$ & 38.78068 & 685.4718 & 5.121625 \\
\hline Mystique & 1925 & SS & 1 & dyn frict & 10.77377 & 496.753 & 2.556028 \\
\hline Mystique & 1925 & ss & 1 & $\begin{array}{l}\text { appar } \\
\text { stiff }\end{array}$ & 10.29402 & 319.544 & 2.488031 \\
\hline Mystique & 1925 & SS & 2 & static & -0.18527 & 1.341429 & 0.021416 \\
\hline Mystique & 1925 & SS & 2 & kinetic/0 & -0.38746 & 74.63726 & -0.01198 \\
\hline Mystique & 1925 & SS & 2 & $2.7 \mathrm{deg}$ & 17.31808 & 23.23359 & 2.855986 \\
\hline Mystique & 1925 & SS & 2 & $4.9 \mathrm{deg}$ & 24.62904 & 19.26291 & 4.698982 \\
\hline Mystique & 1925 & SS & 2 & $5.4 \mathrm{deg}$ & 29.07816 & 71.4715 & 5.530081 \\
\hline Mystique & 1925 & SS & 2 & dyn frict & 11.37099 & -60.3375 & 2.974618 \\
\hline Mystique & 1925 & ss & 2 & $\begin{array}{l}\text { appar } \\
\text { stiff }\end{array}$ & 10.84986 & -138.955 & 2.996825 \\
\hline Mystique & 1925 & SS & 3 & static & -0.08016 & 3.273086 & 0.023606 \\
\hline Mystique & 1925 & SS & 3 & kinetic/0 & -1.34406 & 278.9642 & 0.002178 \\
\hline Mystique & 1925 & Ss & 3 & $2.7 \mathrm{deg}$ & 33.80784 & 573.2744 & 2.497627 \\
\hline Mystique & 1925 & SS & 3 & $4.9 \mathrm{deg}$ & 55.30782 & 779.4793 & 4.482232 \\
\hline Mystique & 1925 & SS & 3 & $5.4 \mathrm{deg}$ & 76.5566 & 854.8678 & 5.266491 \\
\hline Mystique & 1925 & SS & 3 & dyn frict & 25.80585 & 274.4514 & 2.723112 \\
\hline Mystique & 1925 & SS & 3 & $\begin{array}{l}\text { appar } \\
\text { stiff }\end{array}$ & 25.58174 & 66.94302 & 2.744958 \\
\hline Mystique & 1925 & SS & 4 & static & 0.187934 & 121.8557 & -0.03884 \\
\hline Mystique & 1925 & SS & 4 & kinetic/0 & -1.8598 & 301.2856 & 0.010895 \\
\hline Mystique & 1925 & ss & 4 & $2.7 \mathrm{deg}$ & 26.51824 & 242.2626 & 2.490005 \\
\hline Mystique & 1925 & Ss & 4 & $4.9 \mathrm{deg}$ & 29.95728 & 266.1938 & 4.361327 \\
\hline Mystique & 1925 & SS & 4 & $5.4 \mathrm{deg}$ & 38.87152 & 273.8668 & 5.165197 \\
\hline Mystique & 1925 & SS & 4 & dyn frict & 17.43651 & 76.40425 & 2.577748 \\
\hline Mystique & 1925 & SS & 4 & $\begin{array}{l}\text { appar } \\
\text { stiff }\end{array}$ & 17.72167 & -65.8183 & 2.573956 \\
\hline Mystique & 1925 & SS & 5 & static & 0.007126 & 0.053663 & 0.015982 \\
\hline Mystique & 1925 & SS & 5 & kinetic/0 & -0.68674 & 51.02805 & 0.005438 \\
\hline Mystique & 1925 & SS & 5 & $2.7 \mathrm{deg}$ & 15.27391 & 115.8997 & 2.384351 \\
\hline Mystique & 1925 & ss & 5 & $4.9 \mathrm{deg}$ & 44.91588 & 330.6361 & 4.361322 \\
\hline Mystique & 1925 & ss & 5 & $5.4 \mathrm{deg}$ & 61.36552 & 430.2777 & 5.155382 \\
\hline Mystique & 1925 & SS & 5 & dyn frict & 16.68607 & 56.94688 & 2.591356 \\
\hline Mystique & 1925 & ss & 5 & $\begin{array}{l}\text { appar } \\
\text { stiff }\end{array}$ & 16.02076 & -109.302 & 2.560262 \\
\hline Mystique & 2125 & alastic & 1 & static & 0.130935 & 5.687657 & -0.03377 \\
\hline Mystique & 2125 & alastic & 1 & kinetic/0 & -0.06681 & 259.5403 & -0.01199 \\
\hline Mystique & 2125 & alastic & 1 & $2.7 \mathrm{deg}$ & 50.63423 & 538.7191 & 2.578237 \\
\hline Mystique & 2125 & alastic & 1 & $4.9 \mathrm{deg}$ & 59.50838 & 688.6912 & 4.360235 \\
\hline
\end{tabular}




\begin{tabular}{|c|c|c|c|c|c|c|c|}
\hline Mystique & 2125 & alastic & 1 & $5.4 \mathrm{deg}$ & 69.7667 & 719.1685 & 5.288278 \\
\hline Mystique & 2125 & alastic & 1 & dyn frict & 41.90624 & 407.876 & 2.691891 \\
\hline Mystique & 2125 & alastic & 1 & $\begin{array}{l}\text { appar } \\
\text { stiff }\end{array}$ & 39.56959 & 218.791 & 2.65947 \\
\hline Mystique & 2125 & alastic & 2 & static & 0.048981 & 1.395086 & 0.009428 \\
\hline Mystique & 2125 & alastic & 2 & kinetic/0 & 1.918576 & 277.891 & -0.03268 \\
\hline Mystique & 2125 & alastic & 2 & $2.7 \mathrm{deg}$ & 61.40559 & 573.8109 & 2.516151 \\
\hline Mystique & 2125 & alastic & 2 & $4.9 \mathrm{deg}$ & 72.97594 & 731.5633 & 4.2829 \\
\hline Mystique & 2125 & alastic & 2 & $5.4 \mathrm{deg}$ & 59.56717 & 711.0663 & 5.184799 \\
\hline Mystique & 2125 & alastic & 2 & dyn frict & 43.23748 & 431.5441 & 2.605256 \\
\hline Mystique & 2125 & alastic & 2 & $\begin{array}{l}\text { appar } \\
\text { stiff }\end{array}$ & 40.34864 & 166.057 & 2.583033 \\
\hline Mystique & 2125 & alastic & 3 & static & 0.111333 & -2.36091 & 0.037407 \\
\hline Mystique & 2125 & alastic & 3 & kinetic/0 & 0.489003 & 144.6064 & 0.026147 \\
\hline Mystique & 2125 & alastic & 3 & $2.7 \mathrm{deg}$ & 37.5408 & 344.1578 & 1.824487 \\
\hline Mystique & 2125 & alastic & 3 & $4.9 \mathrm{deg}$ & 84.41534 & 675.7598 & 4.421237 \\
\hline Mystique & 2125 & alastic & 3 & $5.4 \mathrm{deg}$ & 98.0753 & 787.6889 & 5.243618 \\
\hline Mystique & 2125 & alastic & 3 & dyn frict & 47.48133 & 308.3415 & 2.707258 \\
\hline Mystique & 2125 & alastic & 3 & $\begin{array}{l}\text { appar } \\
\text { stiff }\end{array}$ & 47.53785 & 98.9212 & 2.685533 \\
\hline Mystique & 2125 & alastic & 4 & static & 0.228911 & 6.385201 & -0.00363 \\
\hline Mystique & 2125 & alastic & 4 & kinetic/0 & -0.32332 & 117.6704 & -0.00872 \\
\hline Mystique & 2125 & alastic & 4 & $2.7 \mathrm{deg}$ & 29.58853 & 260.3987 & 2.507438 \\
\hline Mystique & 2125 & alastic & 4 & $4.9 \mathrm{deg}$ & 67.18277 & 480.2326 & 4.485509 \\
\hline Mystique & 2125 & alastic & 4 & $5.4 \mathrm{deg}$ & 78.50994 & 516.022 & 5.208762 \\
\hline Mystique & 2125 & alastic & 4 & dyn frict & 30.95227 & 217.0506 & 2.690742 \\
\hline Mystique & 2125 & alastic & 4 & $\begin{array}{l}\text { appar } \\
\text { stiff }\end{array}$ & 31.33626 & 69.52333 & 2.695302 \\
\hline Mystique & 2125 & alastic & 5 & static & 0.10064 & -1.66336 & -0.00036 \\
\hline Mystique & 2125 & alastic & 5 & kinetic/0 & 0.029387 & 71.84705 & -0.01089 \\
\hline Mystique & 2125 & alastic & 5 & $2.7 \mathrm{deg}$ & 19.19659 & 42.38925 & 2.103331 \\
\hline Mystique & 2125 & alastic & 5 & $4.9 \mathrm{deg}$ & 38.83676 & 232.5506 & 4.367863 \\
\hline Mystique & 2125 & alastic & 5 & $5.4 \mathrm{deg}$ & 51.83402 & 264.3694 & 5.280655 \\
\hline Mystique & 2125 & alastic & 5 & dyn frict & 19.86122 & 50.51709 & 2.710851 \\
\hline Mystique & 2125 & alastic & 5 & $\begin{array}{l}\text { appar } \\
\text { stiff }\end{array}$ & 19.70051 & -70.0711 & 2.721423 \\
\hline Mystique & 2125 & ss & 1 & static & 0.142526 & 3.595031 & 0.03594 \\
\hline Mystique & 2125 & Ss & 1 & kinetic/0 & -0.61993 & 385.1519 & 0.047924 \\
\hline Mystique & 2125 & SS & 1 & $2.7 \mathrm{deg}$ & 43.32596 & 608.8491 & 2.635969 \\
\hline Mystique & 2125 & SS & 1 & $4.9 \mathrm{deg}$ & 76.44705 & 774.3282 & 4.367859 \\
\hline Mystique & 2125 & SS & 1 & $5.4 \mathrm{deg}$ & 94.37972 & 869.0333 & 5.230547 \\
\hline Mystique & 2125 & SS & 1 & dyn frict & 33.24204 & 415.1359 & 2.751313 \\
\hline Mystique & 2125 & SS & 1 & $\begin{array}{l}\text { appar } \\
\text { stiff }\end{array}$ & 32.66058 & 131.4667 & 2.726516 \\
\hline Mystique & 2125 & SS & 2 & static & -0.01783 & 6.653486 & -0.01997 \\
\hline Mystique & 2125 & SS & 2 & kinetic/0 & -0.46763 & 416.3805 & 0.014156 \\
\hline Mystique & 2125 & Ss & 2 & $2.7 \mathrm{deg}$ & 61.3201 & 695.1838 & 2.547741 \\
\hline Mystique & 2125 & SS & 2 & $4.9 \mathrm{deg}$ & 93.55939 & 874.0771 & 4.338444 \\
\hline Mystique & 2125 & SS & 2 & $5.4 \mathrm{deg}$ & 111.7192 & 1012.191 & 5.203311 \\
\hline Mystique & 2125 & SS & 2 & dyn frict & 48.81598 & 530.4749 & 2.686378 \\
\hline
\end{tabular}




\begin{tabular}{|c|c|c|c|c|c|c|c|}
\hline Mystique & 2125 & ss & 2 & $\begin{array}{l}\text { appar } \\
\text { stiff }\end{array}$ & 46.00669 & 199.1137 & 2.659893 \\
\hline Mystique & 2125 & ss & 3 & static & 0.273452 & 4.936457 & 0.011256 \\
\hline Mystique & 2125 & ss & 3 & kinetic/0 & -0.49434 & 99.85621 & 0.005449 \\
\hline Mystique & 2125 & Ss & 3 & $2.7 \mathrm{deg}$ & 16.85047 & 70.55934 & 2.540123 \\
\hline Mystique & 2125 & ss & 3 & $4.9 \mathrm{deg}$ & 26.27241 & 105.0073 & 4.390738 \\
\hline Mystique & 2125 & ss & 3 & $5.4 \mathrm{deg}$ & 44.49635 & 172.1326 & 5.282835 \\
\hline Mystique & 2125 & ss & 3 & dyn frict & 13.765 & 41.32679 & 2.694219 \\
\hline Mystique & 2125 & ss & 3 & $\begin{array}{l}\text { appar } \\
\text { stiff }\end{array}$ & 13.01819 & -32.6757 & 2.687013 \\
\hline Mystique & 2125 & ss & 4 & static & 0.145185 & 0.7512 & -0.03522 \\
\hline Mystique & 2125 & ss & 4 & kinetic/0 & -1.70216 & 235.4481 & 0.003265 \\
\hline Mystique & 2125 & ss & 4 & $2.7 \mathrm{deg}$ & 18.80914 & 201.8587 & 1.925775 \\
\hline Mystique & 2125 & Ss & 4 & $4.9 \mathrm{deg}$ & 45.31936 & 351.0796 & 4.30141 \\
\hline Mystique & 2125 & ss & 4 & $5.4 \mathrm{deg}$ & 60.95668 & 417.9902 & 5.152115 \\
\hline Mystique & 2125 & ss & 4 & dyn frict & 19.0368 & 163.876 & 2.564042 \\
\hline Mystique & 2125 & ss & 4 & $\begin{array}{l}\text { appar } \\
\text { stiff }\end{array}$ & 18.97727 & 42.23094 & 2.562903 \\
\hline Mystique & 2125 & ss & 5 & static & -0.14251 & 0.912191 & -0.02434 \\
\hline Mystique & 2125 & ss & 5 & kinetic/0 & -0.14696 & 35.68207 & -0.01634 \\
\hline Mystique & 2125 & ss & 5 & $2.7 \mathrm{deg}$ & 47.58533 & 292.6468 & 2.481293 \\
\hline Mystique & 2125 & ss & 5 & $4.9 \mathrm{deg}$ & 86.60113 & 533.6753 & 4.368947 \\
\hline Mystique & 2125 & Ss & 5 & $5.4 \mathrm{deg}$ & 100.229 & 637.8777 & 5.174999 \\
\hline Mystique & 2125 & ss & 5 & dyn frict & 37.01475 & 188.1109 & 2.630736 \\
\hline Mystique & 2125 & ss & 5 & $\begin{array}{l}\text { appar } \\
\text { stiff }\end{array}$ & 37.56534 & -4.88922 & 2.664371 \\
\hline SmartClip & 18 & selfligation & 1 & static & 0.061468 & 4.99012 & 0.020701 \\
\hline SmartClip & 18 & selfligation & 1 & kinetic/0 & 1.237195 & 56.93033 & 0.013079 \\
\hline SmartClip & 18 & selfligation & 1 & $2.7 \mathrm{deg}$ & 14.21041 & 39.49176 & 2.497635 \\
\hline SmartClip & 18 & selfligation & 1 & $4.9 \mathrm{deg}$ & 15.88583 & 45.34039 & 4.328656 \\
\hline SmartClip & 18 & selfligation & 1 & $5.4 \mathrm{deg}$ & 15.5812 & 52.53045 & 5.169558 \\
\hline SmartClip & 18 & selfligation & 1 & dyn frict & 6.40429 & 23.16096 & 2.533524 \\
\hline SmartClip & 18 & selfligation & 1 & $\begin{array}{l}\text { appar } \\
\text { stiff }\end{array}$ & 5.923877 & 4.699998 & 2.527319 \\
\hline SmartClip & 18 & selfligation & 2 & static & 0.073041 & 3.219492 & -0.00944 \\
\hline SmartClip & 18 & selfligation & 2 & kinetic/0 & 0.03741 & 11.64366 & 0.037041 \\
\hline SmartClip & 18 & selfligation & 2 & $2.7 \mathrm{deg}$ & 15.44761 & 91.86129 & 2.655584 \\
\hline SmartClip & 18 & selfligation & 2 & $4.9 \mathrm{deg}$ & 23.79266 & 166.123 & 4.436496 \\
\hline SmartClip & 18 & selfligation & 2 & $5.4 \mathrm{deg}$ & 29.10755 & 213.2341 & 5.219664 \\
\hline SmartClip & 18 & selfligation & 2 & dyn frict & 6.818381 & 46.53315 & 2.67621 \\
\hline SmartClip & 18 & selfligation & 2 & $\begin{array}{l}\text { appar } \\
\text { stiff }\end{array}$ & 7.112193 & 19.94671 & 2.680903 \\
\hline SmartClip & 18 & selfligation & 3 & static & -0.03206 & 4.077943 & 0.024325 \\
\hline SmartClip & 18 & selfligation & 3 & kinetic/0 & -2.17245 & 2.736514 & -0.00545 \\
\hline SmartClip & 18 & selfligation & 3 & $2.7 \mathrm{deg}$ & 6.912802 & 2.6292 & 2.356024 \\
\hline SmartClip & 18 & selfligation & 3 & $4.9 \mathrm{deg}$ & 9.729241 & 8.316857 & 4.546481 \\
\hline SmartClip & 18 & selfligation & 3 & $5.4 \mathrm{deg}$ & 16.07288 & 20.33606 & 5.484342 \\
\hline SmartClip & 18 & selfligation & 3 & dyn frict & 3.554037 & 5.316863 & 2.712006 \\
\hline SmartClip & 18 & selfligation & 3 & $\begin{array}{l}\text { appar } \\
\text { stiff }\end{array}$ & 3.426574 & 7.945508 & 2.792469 \\
\hline
\end{tabular}




\begin{tabular}{|c|c|c|c|c|c|c|c|}
\hline SmartClip & 18 & selfligation & 4 & static & 0.126484 & 0.965829 & -0.03594 \\
\hline SmartClip & 18 & selfligation & 4 & kinetic/0 & -1.31202 & 1.609714 & -0.00871 \\
\hline SmartClip & 18 & selfligation & 4 & $2.7 \mathrm{deg}$ & 5.851964 & 28.38472 & 2.532476 \\
\hline SmartClip & 18 & selfligation & 4 & $4.9 \mathrm{deg}$ & 13.16292 & 65.40826 & 4.782859 \\
\hline SmartClip & 18 & selfligation & 4 & $5.4 \mathrm{deg}$ & 19.71232 & 69.70083 & 5.587807 \\
\hline SmartClip & 18 & selfligation & 4 & dyn frict & -0.01265 & 10.99868 & 2.835316 \\
\hline SmartClip & 18 & selfligation & 4 & $\begin{array}{l}\text { appar } \\
\text { stiff }\end{array}$ & 0.016528 & -0.82291 & 2.789349 \\
\hline SmartClip & 18 & selfligation & 5 & static & -0.11223 & 3.541371 & -0.01089 \\
\hline SmartClip & 18 & selfligation & 5 & kinetic/0 & -2.26329 & 11.69736 & 0.005445 \\
\hline SmartClip & 18 & selfligation & 5 & $2.7 \mathrm{deg}$ & -1.68344 & -9.44366 & 2.549889 \\
\hline SmartClip & 18 & selfligation & 5 & $4.9 \mathrm{deg}$ & 8.740548 & -11.3753 & 4.717498 \\
\hline SmartClip & 18 & selfligation & 5 & $5.4 \mathrm{deg}$ & 13.02132 & -13.5753 & 5.579091 \\
\hline SmartClip & 18 & selfligation & 5 & dyn frict & -1.19549 & -9.16361 & 2.816541 \\
\hline SmartClip & 18 & selfligation & 5 & $\begin{array}{l}\text { appar } \\
\text { stiff }\end{array}$ & -1.06046 & -17.6819 & 2.908893 \\
\hline SmartClip & 1925 & selfligation & 1 & static & -0.08105 & 6.599829 & 0.050094 \\
\hline SmartClip & 1925 & selfligation & 1 & kinetic/0 & -6.72043 & 410.4246 & 0.025046 \\
\hline SmartClip & 1925 & selfligation & 1 & $2.7 \mathrm{deg}$ & 10.45335 & 313.6805 & 2.364738 \\
\hline SmartClip & 1925 & selfligation & 1 & $4.9 \mathrm{deg}$ & 23.29562 & 249.9893 & 4.444075 \\
\hline SmartClip & 1925 & selfligation & 1 & $5.4 \mathrm{deg}$ & 27.81421 & 242.6382 & 5.240334 \\
\hline SmartClip & 1925 & selfligation & 1 & dyn frict & 9.615065 & 211.3136 & 2.494512 \\
\hline SmartClip & 1925 & selfligation & 1 & $\begin{array}{l}\text { appar } \\
\text { stiff }\end{array}$ & 10.48906 & 194.1772 & 2.572976 \\
\hline SmartClip & 1925 & selfligation & 2 & static & -0.01514 & 4.8828 & -0.02469 \\
\hline SmartClip & 1925 & selfligation & 2 & kinetic/0 & -3.59935 & 315.6122 & -0.0098 \\
\hline SmartClip & 1925 & selfligation & 2 & $2.7 \mathrm{deg}$ & 15.37546 & 218.7608 & 2.676241 \\
\hline SmartClip & 1925 & selfligation & 2 & $4.9 \mathrm{deg}$ & 23.19946 & 145.4649 & 4.87978 \\
\hline SmartClip & 1925 & selfligation & 2 & $5.4 \mathrm{deg}$ & 32.24197 & 128.5629 & 5.693462 \\
\hline SmartClip & 1925 & selfligation & 2 & dyn frict & 13.00719 & 147.0674 & 2.958219 \\
\hline SmartClip & 1925 & selfligation & 2 & $\begin{array}{l}\text { appar } \\
\text { stiff }\end{array}$ & 13.06975 & 129.4187 & 2.945045 \\
\hline SmartClip & 1925 & selfligation & 3 & static & -0.45427 & 6.277886 & -0.00762 \\
\hline SmartClip & 1925 & selfligation & 3 & kinetic/0 & -0.60123 & 132.4262 & -0.04684 \\
\hline SmartClip & 1925 & selfligation & 3 & $2.7 \mathrm{deg}$ & 11.27104 & 51.08173 & 2.580381 \\
\hline SmartClip & 1925 & selfligation & 3 & $4.9 \mathrm{deg}$ & 18.24532 & -20.7653 & 4.794825 \\
\hline SmartClip & 1925 & selfligation & 3 & $5.4 \mathrm{deg}$ & 28.76551 & -40.6722 & 5.768607 \\
\hline SmartClip & 1925 & selfligation & 3 & dyn frict & 10.29939 & 7.492548 & 2.987542 \\
\hline SmartClip & 1925 & selfligation & 3 & $\begin{array}{l}\text { appar } \\
\text { stiff }\end{array}$ & 11.69912 & -53.8145 & 2.969349 \\
\hline SmartClip & 1925 & selfligation & 4 & static & -0.13359 & 3.970629 & -0.0069 \\
\hline SmartClip & 1925 & selfligation & 4 & kinetic/0 & -0.14964 & 32.51628 & 0.002175 \\
\hline SmartClip & 1925 & selfligation & 4 & $2.7 \mathrm{deg}$ & 13.37671 & -65.8375 & 2.713282 \\
\hline SmartClip & 1925 & selfligation & 4 & $4.9 \mathrm{deg}$ & 14.89985 & -70.452 & 4.851462 \\
\hline SmartClip & 1925 & selfligation & 4 & $5.4 \mathrm{deg}$ & 21.93022 & -69.3252 & 5.740293 \\
\hline SmartClip & 1925 & selfligation & 4 & dyn frict & 8.066758 & -58.1941 & 2.985243 \\
\hline SmartClip & 1925 & selfligation & 4 & $\begin{array}{l}\text { appar } \\
\text { stiff }\end{array}$ & 7.996411 & -73.5259 & 3.020503 \\
\hline SmartClip & 1925 & selfligation & 5 & static & -0.05256 & 4.829143 & 0.014527 \\
\hline SmartClip & 1925 & selfligation & 5 & kinetic/0 & -2.30872 & 203.1465 & 0.020693 \\
\hline
\end{tabular}




\begin{tabular}{|c|c|c|c|c|c|c|c|}
\hline SmartClip & 1925 & selfligation & 5 & $2.7 \mathrm{deg}$ & 17.26733 & 136.8261 & 2.707857 \\
\hline SmartClip & 1925 & selfligation & 5 & $4.9 \mathrm{deg}$ & 27.30919 & 55.05243 & 4.824234 \\
\hline SmartClip & 1925 & selfligation & 5 & $5.4 \mathrm{deg}$ & 33.41768 & 40.51124 & 5.617225 \\
\hline SmartClip & 1925 & selfligation & 5 & dyn frict & 13.60507 & 54.96911 & 2.85211 \\
\hline SmartClip & 1925 & selfligation & 5 & $\begin{array}{l}\text { appar } \\
\text { stiff }\end{array}$ & 13.60361 & 38.86383 & 2.875899 \\
\hline SmartClip & 2125 & selfligation & 1 & static & 0.144297 & 5.043771 & -0.04611 \\
\hline SmartClip & 2125 & selfligation & 1 & kinetic/0 & -5.05299 & 920.4906 & -0.03376 \\
\hline SmartClip & 2125 & selfligation & 1 & $2.7 \mathrm{deg}$ & 26.44611 & 600.0494 & 2.793919 \\
\hline SmartClip & 2125 & selfligation & 1 & $4.9 \mathrm{deg}$ & 49.73908 & 741.3826 & 4.507296 \\
\hline SmartClip & 2125 & selfligation & 1 & $5.4 \mathrm{deg}$ & 64.05369 & 767.9967 & 5.289374 \\
\hline SmartClip & 2125 & selfligation & 1 & dyn frict & 20.06458 & 357.7723 & 2.745135 \\
\hline SmartClip & 2125 & selfligation & 1 & $\begin{array}{l}\text { appar } \\
\text { stiff }\end{array}$ & 20.02426 & 143.2129 & 2.73316 \\
\hline SmartClip & 2125 & selfligation & 2 & static & -0.02405 & 7.8876 & 0.039933 \\
\hline SmartClip & 2125 & selfligation & 2 & kinetic/0 & -0.1336 & 18.45807 & 0.032677 \\
\hline SmartClip & 2125 & selfligation & 2 & $2.7 \mathrm{deg}$ & 8.307647 & 12.0192 & 2.560821 \\
\hline SmartClip & 2125 & selfligation & 2 & $4.9 \mathrm{deg}$ & 25.89563 & 170.7911 & 4.604242 \\
\hline SmartClip & 2125 & selfligation & 2 & $5.4 \mathrm{deg}$ & 41.60777 & 279.769 & 5.490876 \\
\hline SmartClip & 2125 & selfligation & 2 & dyn frict & 10.95704 & 51.22561 & 2.807655 \\
\hline SmartClip & 2125 & selfligation & 2 & $\begin{array}{l}\text { appar } \\
\text { stiff }\end{array}$ & 11.23612 & -4.68202 & 2.849215 \\
\hline SmartClip & 2125 & selfligation & 3 & static & 0.105103 & 5.043771 & 0.019963 \\
\hline SmartClip & 2125 & selfligation & 3 & kinetic/0 & -0.66803 & 79.03719 & 0.040315 \\
\hline SmartClip & 2125 & selfligation & 3 & $2.7 \mathrm{deg}$ & 15.53578 & 27.95547 & 2.909397 \\
\hline SmartClip & 2125 & selfligation & 3 & $4.9 \mathrm{deg}$ & 19.62681 & 71.14957 & 4.897265 \\
\hline SmartClip & 2125 & selfligation & 3 & $5.4 \mathrm{deg}$ & 34.3182 & 154.4257 & 5.710911 \\
\hline SmartClip & 2125 & selfligation & 3 & dyn frict & 11.0385 & 48.91625 & 3.042017 \\
\hline SmartClip & 2125 & selfligation & 3 & $\begin{array}{l}\text { appar } \\
\text { stiff }\end{array}$ & 11.97314 & 28.92608 & 3.04526 \\
\hline SmartClip & 2125 & selfligation & 4 & static & -0.06768 & 1.878 & 0.042845 \\
\hline SmartClip & 2125 & selfligation & 4 & kinetic/0 & -0.13895 & 2.790171 & 0.011982 \\
\hline SmartClip & 2125 & selfligation & 4 & $2.7 \mathrm{deg}$ & 22.3043 & 127.0068 & 2.787379 \\
\hline SmartClip & 2125 & selfligation & 4 & $4.9 \mathrm{deg}$ & 29.98133 & 246.7162 & 4.637999 \\
\hline SmartClip & 2125 & selfligation & 4 & $5.4 \mathrm{deg}$ & 43.49165 & 261.5256 & 5.546407 \\
\hline SmartClip & 2125 & selfligation & 4 & dyn frict & 10.86968 & 26.31638 & 2.892974 \\
\hline SmartClip & 2125 & selfligation & 4 & $\begin{array}{l}\text { appar } \\
\text { stiff }\end{array}$ & 11.41731 & -13.5923 & 2.952167 \\
\hline SmartClip & 2125 & selfligation & 5 & static & -0.0294 & 4.453633 & 0.005089 \\
\hline SmartClip & 2125 & selfligation & 5 & kinetic/0 & -1.47234 & 279.6082 & -0.02723 \\
\hline SmartClip & 2125 & selfligation & 5 & $2.7 \mathrm{deg}$ & 42.29184 & 700.8714 & 2.559704 \\
\hline SmartClip & 2125 & selfligation & 5 & $4.9 \mathrm{deg}$ & 47.91935 & 725.9294 & 4.730588 \\
\hline SmartClip & 2125 & selfligation & 5 & $5.4 \mathrm{deg}$ & 61.64342 & 748.3581 & 5.474508 \\
\hline SmartClip & 2125 & selfligation & 5 & dyn frict & 12.25359 & 148.6059 & 2.842323 \\
\hline SmartClip & 2125 & selfligation & 5 & $\begin{array}{l}\text { appar } \\
\text { stiff }\end{array}$ & 12.24987 & 46.07836 & 2.872252 \\
\hline InvR & 18 & selfligation & 1 & static & 0.132722 & 0.268286 & 0.049751 \\
\hline InvR & 18 & selfligation & 1 & kinetic/0 & -0.07482 & -0.3756 & -0.00108 \\
\hline InvR & 18 & selfligation & 1 & $2.7 \mathrm{deg}$ & 4.096355 & -3.91697 & 3.055354 \\
\hline InvR & 18 & selfligation & 1 & $4.9 \mathrm{deg}$ & 9.015774 & -2.30726 & 5.245813 \\
\hline
\end{tabular}




\begin{tabular}{|c|c|c|c|c|c|c|c|}
\hline InvR & 18 & selfligation & 1 & $5.4 \mathrm{deg}$ & 15.02807 & -4.18526 & 6.317644 \\
\hline InvR & 18 & selfligation & 1 & dyn frict & 4.930315 & -5.82914 & 3.128506 \\
\hline InvR & 18 & selfligation & 1 & $\begin{array}{l}\text { appar } \\
\text { stiff }\end{array}$ & 4.656749 & -4.90458 & 3.053773 \\
\hline InvR & 18 & selfligation & 2 & static & 0.220901 & -0.05366 & -0.00544 \\
\hline InvR & 18 & selfligation & 2 & kinetic/0 & 0.128279 & 19.85316 & 0.025048 \\
\hline InvR & 18 & selfligation & 2 & $2.7 \mathrm{deg}$ & 1.138332 & 21.7312 & 2.603276 \\
\hline InvR & 18 & selfligation & 2 & $4.9 \mathrm{deg}$ & 9.445997 & 25.75552 & 4.835131 \\
\hline InvR & 18 & selfligation & 2 & $5.4 \mathrm{deg}$ & 16.65807 & 59.29127 & 5.776247 \\
\hline InvR & 18 & selfligation & 2 & dyn frict & 2.044546 & 12.04405 & 2.991288 \\
\hline InvR & 18 & selfligation & 2 & $\begin{array}{l}\text { appar } \\
\text { stiff }\end{array}$ & 2.044691 & -8.22392 & 2.907056 \\
\hline InvR & 18 & selfligation & 3 & static & -0.00356 & 2.843829 & 0.008715 \\
\hline InvR & 18 & selfligation & 3 & kinetic/0 & -0.5478 & 39.11616 & 0.031582 \\
\hline InvR & 18 & selfligation & 3 & $2.7 \mathrm{deg}$ & 7.965609 & 37.34547 & 2.398516 \\
\hline InvR & 18 & selfligation & 3 & $4.9 \mathrm{deg}$ & 6.185978 & 39.59907 & 4.714243 \\
\hline InvR & 18 & selfligation & 3 & $5.4 \mathrm{deg}$ & 13.90843 & 59.7206 & 5.683669 \\
\hline InvR & 18 & selfligation & 3 & dyn frict & 2.203908 & 14.45569 & 2.89929 \\
\hline InvR & 18 & selfligation & 3 & $\begin{array}{l}\text { appar } \\
\text { stiff }\end{array}$ & 2.221242 & -14.9954 & 2.905933 \\
\hline InvR & 18 & selfligation & 4 & static & -0.1532 & 4.829143 & 0.024695 \\
\hline InvR & 18 & selfligation & 4 & kinetic/0 & -0.06145 & 18.67269 & -0.00218 \\
\hline InvR & 18 & selfligation & 4 & $2.7 \mathrm{deg}$ & 1.068862 & 23.60922 & 2.456237 \\
\hline InvR & 18 & selfligation & 4 & $4.9 \mathrm{deg}$ & 12.65523 & 64.12048 & 4.734936 \\
\hline InvR & 18 & selfligation & 4 & $5.4 \mathrm{deg}$ & 18.44841 & 93.73923 & 5.650999 \\
\hline InvR & 18 & selfligation & 4 & dyn frict & 3.00621 & 30.555 & 2.890042 \\
\hline InvR & 18 & selfligation & 4 & $\begin{array}{l}\text { appar } \\
\text { stiff }\end{array}$ & 3.327688 & 10.2921 & 2.835922 \\
\hline InvR & 18 & selfligation & 5 & static & 0.029394 & -0.21464 & 0.005816 \\
\hline InvR & 18 & selfligation & 5 & kinetic/0 & -0.30195 & 88.58824 & -0.00436 \\
\hline InvR & 18 & selfligation & 5 & $2.7 \mathrm{deg}$ & 16.99476 & 197.6735 & 2.497621 \\
\hline InvR & 18 & selfligation & 5 & $4.9 \mathrm{deg}$ & 30.05614 & 303.271 & 4.852574 \\
\hline InvR & 18 & selfligation & 5 & $5.4 \mathrm{deg}$ & 36.69906 & 321.3535 & 5.732697 \\
\hline InvR & 18 & selfligation & 5 & dyn frict & 11.90123 & 157.4444 & 2.961414 \\
\hline InvR & 18 & selfligation & 5 & $\begin{array}{l}\text { appar } \\
\text { stiff }\end{array}$ & 12.1649 & 61.66661 & 2.913875 \\
\hline InvR & 1925 & selfligation & 1 & static & -0.19863 & 4.614515 & 0.046114 \\
\hline InvR & 1925 & selfligation & 1 & kinetic/0 & -0.41953 & 243.765 & 0.00763 \\
\hline InvR & 1925 & selfligation & 1 & $2.7 \mathrm{deg}$ & 7.115888 & 197.9954 & 2.268903 \\
\hline InvR & 1925 & selfligation & 1 & $4.9 \mathrm{deg}$ & 14.8357 & 206.9561 & 4.602065 \\
\hline InvR & 1925 & selfligation & 1 & $5.4 \mathrm{deg}$ & 29.22512 & 245.9649 & 5.450599 \\
\hline InvR & 1925 & selfligation & 1 & dyn frict & 11.16131 & 144.2969 & 2.699567 \\
\hline InvR & 1925 & selfligation & 1 & $\begin{array}{l}\text { appar } \\
\text { stiff }\end{array}$ & 11.40332 & 89.74947 & 2.744735 \\
\hline InvR & 1925 & selfligation & 2 & static & -0.03474 & 13.36063 & 0.001445 \\
\hline InvR & 1925 & selfligation & 2 & kinetic/0 & -0.05611 & 8.960743 & 0.004351 \\
\hline InvR & 1925 & selfligation & 2 & $2.7 \mathrm{deg}$ & 9.002423 & -21.141 & 2.488907 \\
\hline InvR & 1925 & selfligation & 2 & $4.9 \mathrm{deg}$ & 12.09676 & -24.9507 & 4.852559 \\
\hline InvR & 1925 & selfligation & 2 & $5.4 \mathrm{deg}$ & 23.48539 & 9.0144 & 5.695647 \\
\hline InvR & 1925 & selfligation & 2 & dyn frict & 6.719257 & -43.9456 & 2.94682 \\
\hline
\end{tabular}




\begin{tabular}{|c|c|c|c|c|c|c|c|}
\hline InvR & 1925 & selfligation & 2 & $\begin{array}{l}\text { appar } \\
\text { stiff }\end{array}$ & 6.821338 & -70.0823 & 3.047456 \\
\hline InvR & 1925 & selfligation & 3 & static & -0.11135 & 0.804857 & 0.01415 \\
\hline InvR & 1925 & selfligation & 3 & kinetic/0 & -3.67153 & 428.8826 & 0.042476 \\
\hline InvR & 1925 & selfligation & 3 & $2.7 \mathrm{deg}$ & 13.51564 & 376.5131 & 2.713289 \\
\hline InvR & 1925 & selfligation & 3 & $4.9 \mathrm{deg}$ & 22.94293 & 471.0036 & 4.270912 \\
\hline InvR & 1925 & selfligation & 3 & $5.4 \mathrm{deg}$ & 38.46535 & 615.127 & 5.09548 \\
\hline InvR & 1925 & selfligation & 3 & dyn frict & 10.23203 & 238.0707 & 2.553823 \\
\hline InvR & 1925 & selfligation & 3 & $\begin{array}{l}\text { appar } \\
\text { stiff }\end{array}$ & 8.919538 & 79.60665 & 2.454887 \\
\hline InvR & 1925 & selfligation & 4 & static & -0.05521 & 4.292571 & -0.00617 \\
\hline InvR & 1925 & selfligation & 4 & kinetic/0 & -1.90254 & 508.6174 & 0.004357 \\
\hline InvR & 1925 & selfligation & 4 & $2.7 \mathrm{deg}$ & 17.09899 & 473.2572 & 2.593467 \\
\hline InvR & 1925 & selfligation & 4 & $4.9 \mathrm{deg}$ & 20.60483 & 531.9583 & 4.386366 \\
\hline InvR & 1925 & selfligation & 4 & $5.4 \mathrm{deg}$ & 25.37191 & 464.8867 & 5.238174 \\
\hline InvR & 1925 & selfligation & 4 & dyn frict & 9.137146 & 307.0027 & 2.684037 \\
\hline InvR & 1925 & selfligation & 4 & $\begin{array}{l}\text { appar } \\
\text { stiff }\end{array}$ & 8.304308 & 177.2699 & 2.616018 \\
\hline InvR & 1925 & selfligation & 5 & static & -0.04364 & 1.609714 & -0.0185 \\
\hline InvR & 1925 & selfligation & 5 & kinetic/0 & -0.68408 & 335.4653 & -0.04247 \\
\hline InvR & 1925 & selfligation & 5 & $2.7 \mathrm{deg}$ & 17.90328 & 307.2952 & 2.473666 \\
\hline InvR & 1925 & selfligation & 5 & $4.9 \mathrm{deg}$ & 20.78918 & 295.9199 & 4.24042 \\
\hline InvR & 1925 & selfligation & 5 & $5.4 \mathrm{deg}$ & 23.27695 & 296.4565 & 5.005088 \\
\hline InvR & 1925 & selfligation & 5 & dyn frict & 7.857195 & 144.2316 & 2.50087 \\
\hline InvR & 1925 & selfligation & 5 & $\begin{array}{l}\text { appar } \\
\text { stiff }\end{array}$ & 7.163116 & 31.92181 & 2.54658 \\
\hline InvR & 2125 & selfligation & 1 & static & -0.02494 & 4.721831 & -0.05118 \\
\hline InvR & 2125 & selfligation & 1 & kinetic/0 & -0.73215 & 110.7486 & -0.04901 \\
\hline InvR & 2125 & selfligation & 1 & $2.7 \mathrm{deg}$ & 48.5954 & 438.9702 & 2.445347 \\
\hline InvR & 2125 & selfligation & 1 & $4.9 \mathrm{deg}$ & 77.00285 & 773.3087 & 4.236059 \\
\hline InvR & 2125 & selfligation & 1 & $5.4 \mathrm{deg}$ & 96.91557 & 908.3641 & 5.088949 \\
\hline InvR & 2125 & selfligation & 1 & dyn frict & 41.44827 & 193.4267 & 2.643526 \\
\hline InvR & 2125 & selfligation & 1 & $\begin{array}{l}\text { appar } \\
\text { stiff }\end{array}$ & 42.49357 & -134.608 & 2.675962 \\
\hline InvR & 2125 & selfligation & 2 & static & -0.0374 & 1.878 & -0.02905 \\
\hline InvR & 2125 & selfligation & 2 & kinetic/0 & -1.0475 & 402.2687 & 0.023959 \\
\hline InvR & 2125 & selfligation & 2 & $2.7 \mathrm{deg}$ & 18.64613 & 451.5797 & 2.559696 \\
\hline InvR & 2125 & selfligation & 2 & $4.9 \mathrm{deg}$ & 46.69284 & 670.8233 & 4.367846 \\
\hline InvR & 2125 & selfligation & 2 & $5.4 \mathrm{deg}$ & 55.35322 & 709.9395 & 5.20549 \\
\hline InvR & 2125 & selfligation & 2 & dyn frict & 17.94705 & 360.3882 & 2.657498 \\
\hline InvR & 2125 & selfligation & 2 & $\begin{array}{l}\text { appar } \\
\text { stiff }\end{array}$ & 16.61571 & 223.0549 & 2.642353 \\
\hline InvR & 2125 & selfligation & 3 & static & 0.100651 & 7.941257 & -0.04138 \\
\hline InvR & 2125 & selfligation & 3 & kinetic/0 & -0.56648 & 233.0872 & -0.02179 \\
\hline InvR & 2125 & selfligation & 3 & $2.7 \mathrm{deg}$ & 28.09748 & 411.6586 & 2.446425 \\
\hline InvR & 2125 & selfligation & 3 & $4.9 \mathrm{deg}$ & 57.80624 & 725.0172 & 4.4931 \\
\hline InvR & 2125 & selfligation & 3 & $5.4 \mathrm{deg}$ & 79.194 & 800.8349 & 5.141229 \\
\hline InvR & 2125 & selfligation & 3 & dyn frict & 26.63924 & 371.0185 & 2.639022 \\
\hline InvR & 2125 & selfligation & 3 & $\begin{array}{l}\text { appar } \\
\text { stiff }\end{array}$ & 24.79837 & 188.6053 & 2.702433 \\
\hline
\end{tabular}




\begin{tabular}{|c|c|c|c|c|c|c|c|}
\hline InvR & 2125 & selfligation & 4 & static & -0.05613 & 4.829143 & -0.00544 \\
\hline InvR & 2125 & selfligation & 4 & kinetic/0 & 0.472965 & 185.5469 & 0.0305 \\
\hline InvR & 2125 & selfligation & 4 & $2.7 \mathrm{deg}$ & 24.08392 & 300.1588 & 2.370184 \\
\hline InvR & 2125 & selfligation & 4 & $4.9 \mathrm{deg}$ & 47.20322 & 521.0122 & 4.227347 \\
\hline InvR & 2125 & selfligation & 4 & $5.4 \mathrm{deg}$ & 59.21179 & 671.3599 & 5.075881 \\
\hline InvR & 2125 & selfligation & 4 & dyn frict & 20.10887 & 176.3835 & 2.535493 \\
\hline InvR & 2125 & selfligation & 4 & $\begin{array}{l}\text { appar } \\
\text { stiff }\end{array}$ & 20.00578 & 32.96575 & 2.617973 \\
\hline InvR & 2125 & selfligation & 5 & static & 0.130931 & 1.663371 & 0.010525 \\
\hline InvR & 2125 & selfligation & 5 & kinetic/0 & -0.72415 & 80.91516 & 0.006533 \\
\hline InvR & 2125 & selfligation & 5 & $2.7 \mathrm{deg}$ & 11.86962 & 6.599829 & 2.493257 \\
\hline InvR & 2125 & selfligation & 5 & $4.9 \mathrm{deg}$ & 18.85725 & -25.7019 & 4.352601 \\
\hline InvR & 2125 & selfligation & 5 & $5.4 \mathrm{deg}$ & 24.11599 & -38.6869 & 5.155387 \\
\hline InvR & 2125 & selfligation & 5 & dyn frict & 9.114011 & -84.794 & 2.643603 \\
\hline InvR & 2125 & selfligation & 5 & $\begin{array}{l}\text { appar } \\
\text { stiff }\end{array}$ & 9.553804 & -208.201 & 2.683381 \\
\hline
\end{tabular}




\section{CURRICULUM VITAE}

Name:

Date of Birth:

Place of Birth:

Education:

August 1993-December 1997

August 1998-August 2002

May 2002-May 2003

July 2003-April 2006

Professional Memberships:
Todd S. Bovenizer

November 23, 1974

Bluefield, West Virginia

Virginia Tech

Blacksburg, Virginia

Bachelor of Science, Biology

WVU School of Dentistry

Morgantown, West Virginia

Doctorate of Dental Surgery

WVU School of Dentistry

Morgantown, West Virginia

Advanced Education in General Dentistry

WVU School of Dentistry

Department of Orthodontics

Morgantown, West Virginia

Master of Science

American Association of Orthodontists American Dental Association 